ENGINEERING CHANGE NOTICE $\quad$ Page 1 of 2

1. ECN 651404

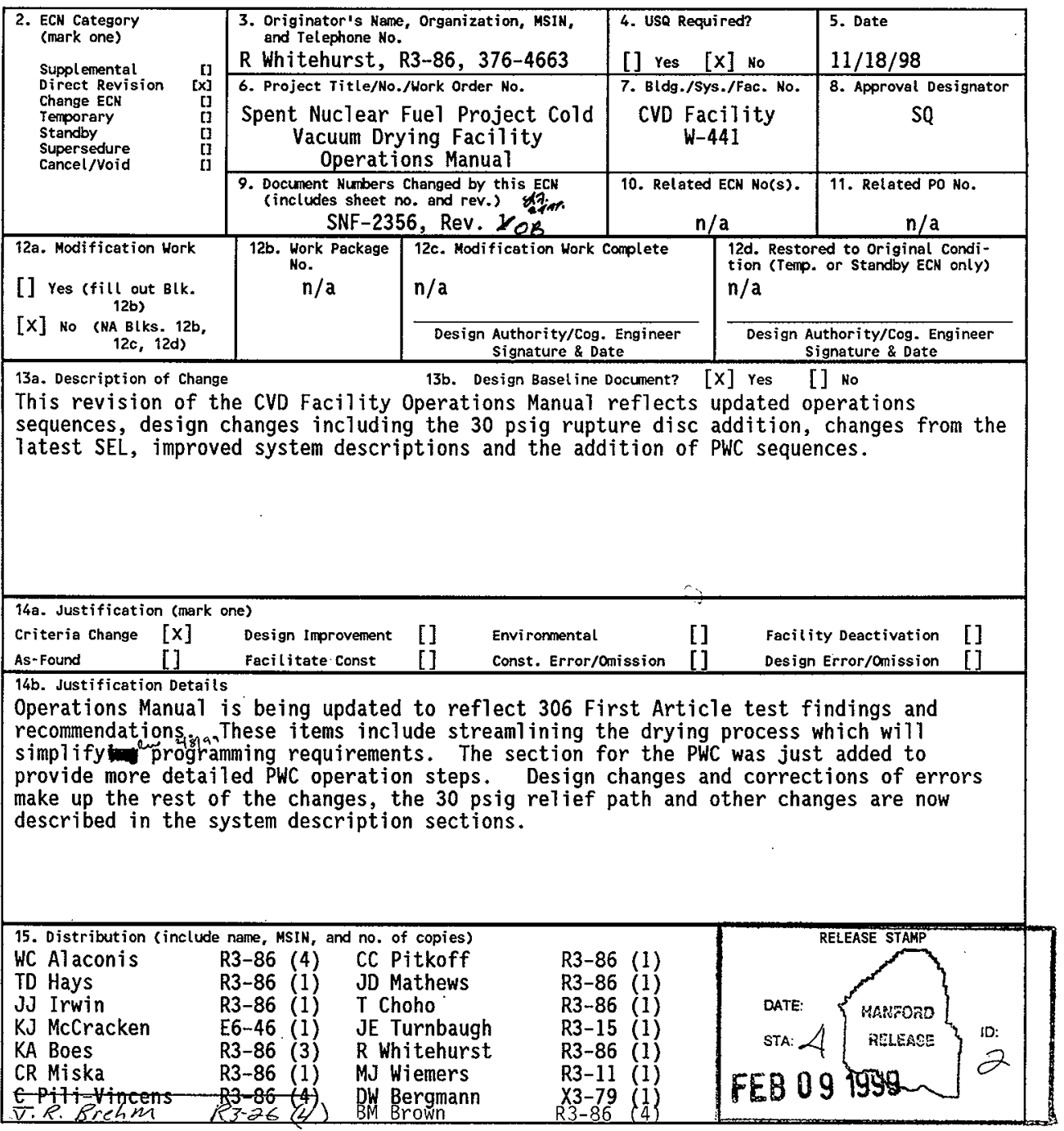

A-7900-013-2 (05/96) GEF095 


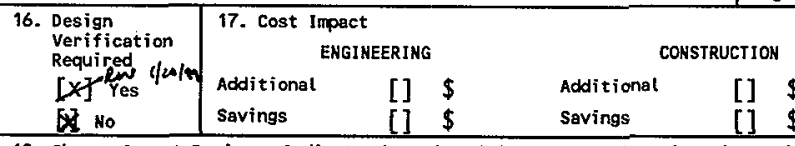

18. Schedule impact (days)

19. Change Impact Review: Indicate the related documents (other then the engineering documents identified on side 1 ) that will be affected by the change described in Block 13 . Enter the affected document number in Block 20. SDD/DD

Functional Design Criteria

Operating Specification

Criticality Specification

Conceptual Design Report

Equipmant Spec.

Const. Spec.

Procurement Spec.

Vendor information

OM Manual

FSAR/SAR

Safety Equipment List

Radiation Work Permit

Environmental Impact Statement

Environmental Report

Environmental Permit

\section{[] \\ Soismic/Stress Analysis}

[]

[]

[]

[]

[]

[]

[]

[]

[]

[x]

[]

[]

[]

[]

[]
Stress/Design Report

Interface Control Drawing

Calibration Procedure

Installation Procedure

Maintensence Proceduro

Engineering Procedure

Operating instruction

Operating Procedure

Operational Safety Requirement

IEFD Drawing

Cell Arrangement Drawing

Esential Material Specification

Fac. Proc. Samp. Schedule

Inspoction Pian

Inventory Adjustment Request
[]
[]
[]
[]
[]
[]
[]
[]
[]
[]
[]
[]
[]
[]
[]
[] Tank Calibration Manual

Health Physics Procedure

Spares Multiple Unit Listing

Test Procedures/Specification

Component Inctex

ASME Coded them

Human Factor Consideration

Computer Software

Electric Circuit Schedule

ICRS Procedure

Process Control Manual/Plan

Process Flow Chart

Purchase Requisition

Tickler File

20. Other Affected Documents: (NOTE: Documents (isted below will not be revised by this ECN.) Signatures below indicate that the signing organization has been notified of other affected documents listed below. Document Number/Revision

21. Approvals

Design Authority R. Whitehurst

Cog. Eng.

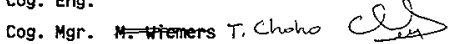

QA SL Mischke

Fuclar JR Brehm

Environ.

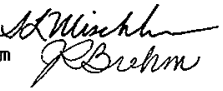

other mot

tolli $=2$

cc Pitkoff Qedslup

JJ Irwin

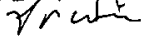

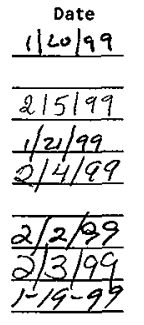

\section{DEPARTMENT OF ENERGY}

signature or a Control Number that

tracks the Approval signature

ADDITIONAL 


\title{
Spent Nuclear Fuel Project Cold Vacuum Drying Facility Operations Manual
}

\author{
J. J. Irwin, C. R. Niska
}

Numatec Hanford Corporation, Richland, WA 99352

C. C. Pitkoff, R. Whitehurst

DE\&S Hanford, Inc:, Richland, WA 99352

U.S. Department of Energy Contract DE-AC06-96RL13200

$\begin{array}{lll}\text { EDT/ECN: } & 651404 & \text { UC: } 105339 / \text { BA40 } \\ \text { Org Code: } & 8 C 453 & \text { Charge Code: } \\ \text { B\&R Code: } & 39 E W 70400 & \text { Total Pages: } 93\end{array}$

Key Words: Cold Vacuum Drying, Operations Sequence, System Design Descriptions

Abstract: This document provides the Operations Manual for the Cold Vacuum Drying Facility (CVDF). The Manual was develped in conjunction with HNF-SD-SNF-SAR-002, Safety Analysis Report for the Cold Vacuum Drying Facility, Phase 2, Supporting Installation of Processing Systems (Garvin 1998) and, the HNF-SD-SNF-DRD-002, 1997, Cold Vacuum Drying Facility Design Requirements, Rev. 3a. The Operations Manual contains general descriptions of all the process, safety and facility systems in the CVDF, a general CVD operations sequence, and has been developed for the SNFP Operations Organization and shall be updated, expanded, and revised in accordance with future design, construction and startup phases of the CVDF until the CVDF final ORR is approved.

TRADEMARK DISCLAIMER. Reference herein to any specific commercisl product, process, or service by trade name, trademark, manufacturer, or otherwise, does not necessarily constitute or imply its endorsenent, recommendation, or favoring by the United States Government or any agency thereof or $i$ ts contractors or subcontractors.

Printed in the United States of America. To obtain copies of this document, contact: Document Control Services, P.0. Box 950, Mailstop H6-08, Richland WA 99352, Phone (509) 372-2420; Fax (509) 376-4989.
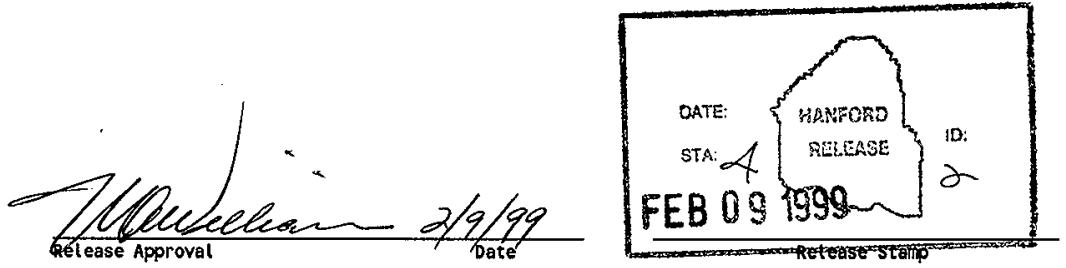


\section{RECORD OF REVISION}

(1) Document Number

SNF-2356

Page I

(2) Title

Spent Nuclear Fuel Project Cold Vacuum Drying Facility Operations Manual

CHANGE CONTROL RECORD

(3) Revision (4) Description of Change - Replace, Add, and Delete Pages

(7) Initial Release EDT 623998

Oa $\quad$ Revised per ECN 645101 - general revision

ob $\quad$ Revised per ECN 645110 - general revision with inclusion of Sdds

1 RS Revised per ECN 651404

Authorized for Release

\begin{tabular}{l|ll} 
(5) Cog. Engr. & (6) Cog. Mgr. Date
\end{tabular}

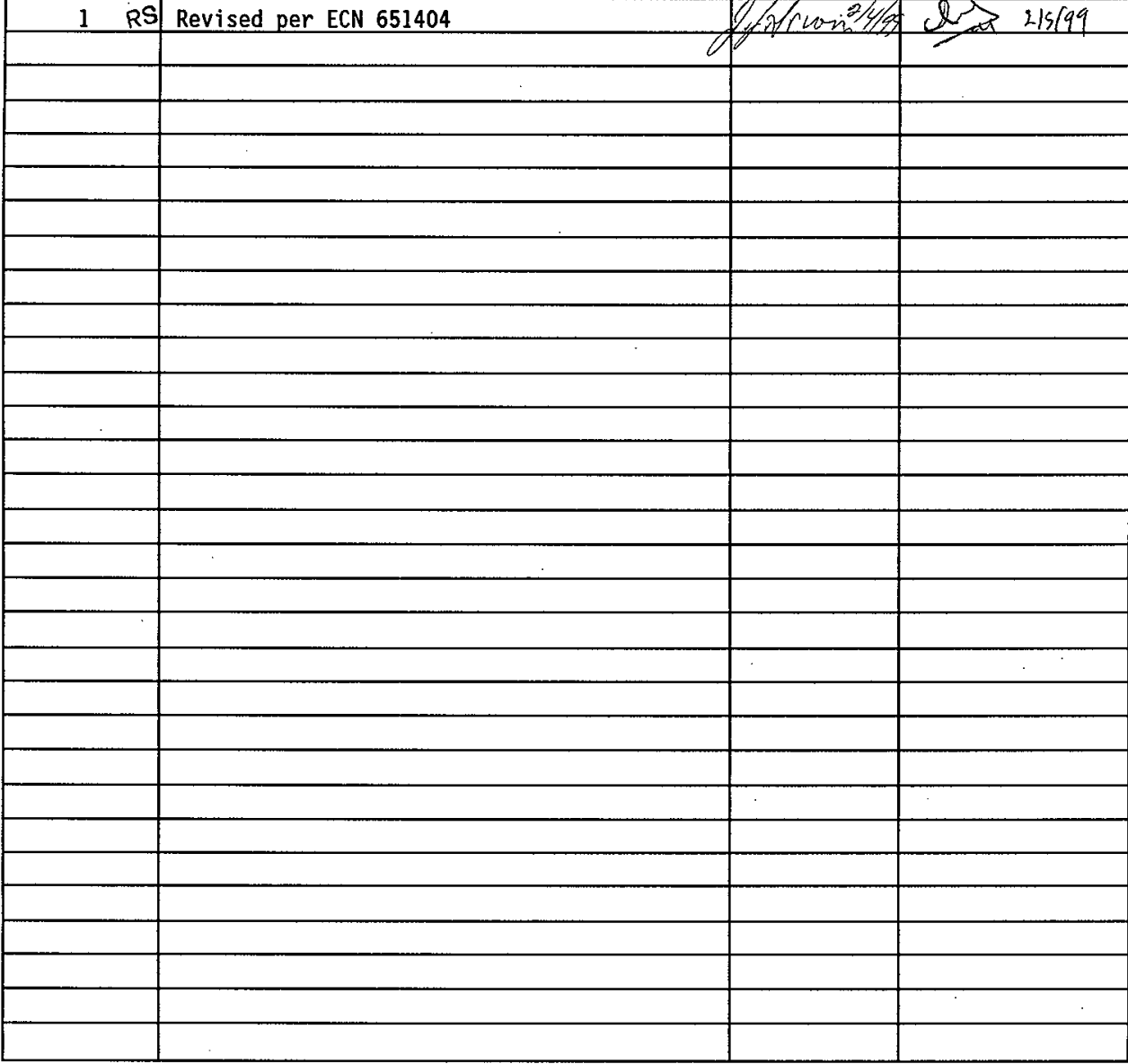


SNF-2356 Rev. 1

\section{SPENT NUCLEAR FUEL PROJECT \\ COLD VACUUM DRYING FACILITY OPERATIONS MANUAL}

Prepared for the U.S. Department of Energy

Numatec Hanford Corporation

Richland, Washington

DE\&S Hanford, Inc.

Richland, Washington 
SNF-2356 Rev. 1

This page intentionally left blank. 


\section{TABLE OF CONTENTS}

1.0 COLD VACUUM DRYING FACILITY OVERVIEW $\ldots \ldots \ldots \ldots \ldots \ldots \ldots \ldots \ldots \ldots \ldots$

2.0 COLD VACUUM DRYING PROCESS SYSTEMS OVERVIEW $\ldots \ldots \ldots \ldots \ldots \ldots \ldots \ldots .2-1$

3.0 COLD VACUUM DRYING FACILITY SYSTEM DESCRIPTIONS $\ldots \ldots \ldots \ldots \ldots \ldots \ldots .1$

3.1 COLD VACUUM DRYING FACILITY PROCESS SYSTEMS $\ldots \ldots \ldots \ldots \ldots \ldots \ldots$.

3.1.1 System 07, Vacuum Purge System (VPS) . . . . . . . . . . . . . . .

3.1.2 System 46-1, Process Water Conditioning System (PWC) . . . . . . . . . 3-5

3.1.3 System 46-2, Conditioned Water Shipping System (CWS) . . . . . . . . . 3-6

3.1.4 System 46-3, Contaminated Water Sampling and Analysis System (SMP). . . . . 3-6

3.1.5 System 47-1, Tempered Water (Annulus) System (TW) . . . . . . . . . 3-6

3.2 COLD VACUUM DRYING SAFETY CLASS SYSTEMS OVERVIEW $\ldots \ldots \ldots \ldots \ldots$. $\ldots$

3.2.1 System 13-2, Safety Class Helium System (SCHe) $\ldots \ldots \ldots \ldots \ldots \ldots \ldots \ldots .7$

3.2.2 System 93-2, Safety Class Instrumentation and Control System (SCIC). . . . . . 3-9

3.3 COLD VACUUM DRYING FACILITY AND UTILITY SYSTEMS $\ldots \ldots \ldots \ldots \ldots \ldots .12$

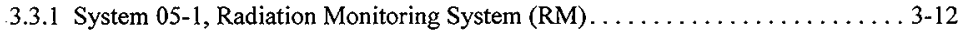

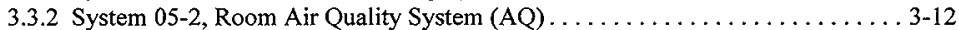

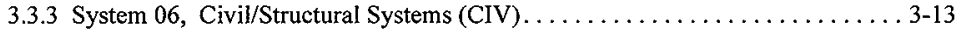

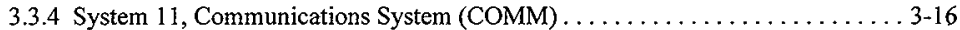

3.3.5 System 12, Instrument Air System (CA ) . . . . . . . . . . . . . . 3-18

3.3.6 System 13-1, General Service Helium System (He). . . . . . . . . . . . . 3-19

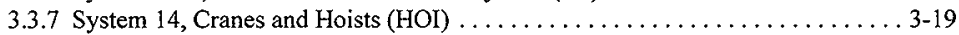

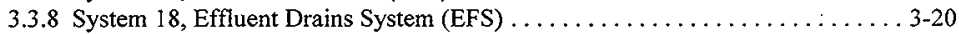

3.3.9 System 19, Condensate Collection System (CCS) . . . . . . . . . . . . 3-20

3.3.10 System 20-1, Electrical Power Distribution System (EPD) . . . . . . . . . 3-21

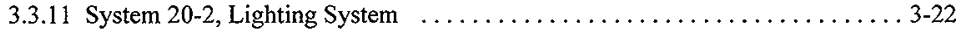

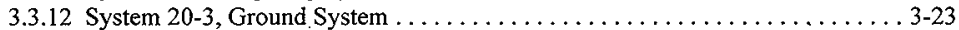

3.3.13 System 20-4, Facility Uninterruptible Power Supply System . . . . . . . . . 3-23

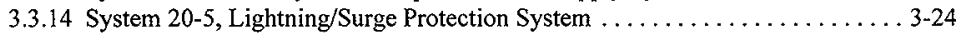

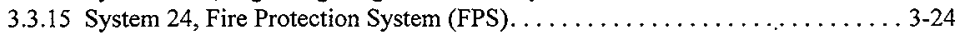

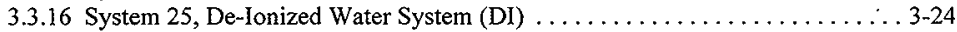

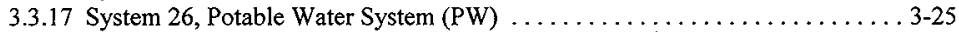

3.3.18 System 27, Sanitary Sewage Collection System (SANS)............. 3-25

3.3.19 System 30-1, Administration Building Heating, Ventilating, and Air Conditioning

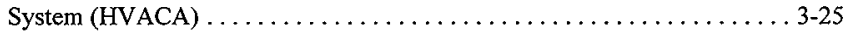

3.3.20 System 30-2, Process Bay Recirculation Heating, Ventilating, and Air Conditioning

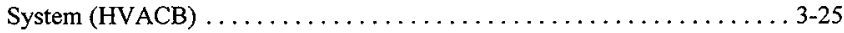

3.3.21 System 30-3, Process Bay Local Exhaust Heating, Ventilating, and Air Conditioning and

Process Vent System (HVACC/PV) . . . . . . . . . . . . . . 3-26

3.3.22 System 30-4, Process General Supply/Exhaust Heating, Ventilating, and Air

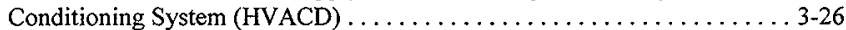

3.3.23 System 30-5, Reference Air System (RA) . . . . . . . . . . . . . . 3-27

3.3:24 System 47-2, Tempered Water Cooling System (TWC) . . . . . . . . . 3-27

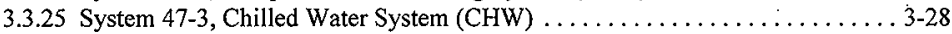

3.3.26 System 47-4, Vacuum Purge System Chilled Water System (VPSCHW) . . . . 3-28 
3.3.27 System 50, Stack Monitoring System (SM) $\ldots \ldots \ldots \ldots \ldots \ldots \ldots \ldots \ldots . . \ldots \ldots$

3.3 .28 System 54 , Security System (SEC) . . . . . . . . . . . . . . . . . . . . 3-29

3.3.29 System 93-1, Monitoring and Control System (MCS) . . . . . . . . . . . . 3-29

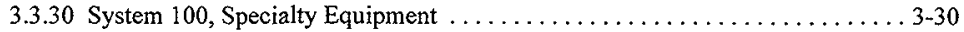

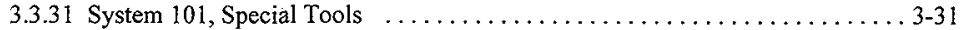

3.4 COLD VACUUM DRYING SYSTEMS OPERATIONS OVERVIEW . . . . . . . 3-32

3.4.1 Cold Vacuum Drying Facility Prerequisites for the Cask-Multi-Canister Overpack

Transporter Receipt Operation and Normal Cold Vacuum Drying Process

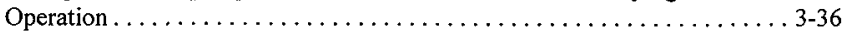

3.4.2 Cask-Multi-Canister Overpack Transporter Receipt Operation. . . . . . . . . . 3-37

3.5 PROCESS WATER CONDITIONING SYSTEM OPERATION $\ldots \ldots \ldots \ldots \ldots \ldots \ldots .62$

3.5.1 Process Water Conditioning Vacuum Pumping and Receiving - Prerequisites . 3-62

3.5.2 Process Water Conditioning Vacuum Pumping and Receiving - MCO Bulk Water

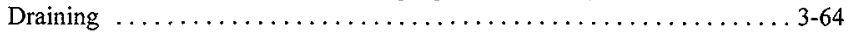

3.5.3 Process Water Conditioning Vacuum Pumping and Receiving - VPS Condenser Tank Draining

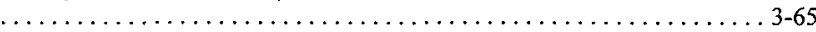

3.5.4 Process Water Conditioning Vacuum Pumping and Receiving - Tempered Water

System Draining . ......................... 3-67

3.5.5 Process Water Conditioning Vacuum Pumping and Receiving - Cask-MCO Annulus

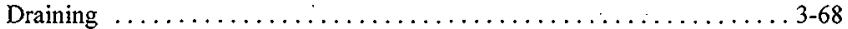

3.5.6 Process Water Conditioning Impurity Removal . . . . . . . . . . . . . 3-68

3.5.7 Process Water Conditioning IXM Water Sampling . . . . . . . . . . . . . 3-69

3.5.8 Process Water Conditioning Transfer to PWC Holding Tank, PWC-TK-4001 . 3-70

3.5.9 Process Water Conditioning Transfer from PWC-TK-4001 to KW Basin Tractor

Trailer .................................

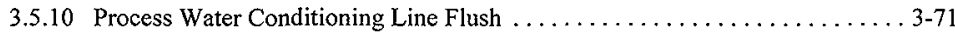

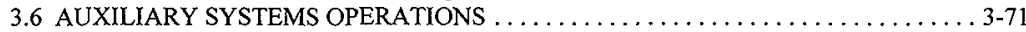

3.6.1 Operation of the Safety Class Instrument and Control System. . . . . . . 3-72

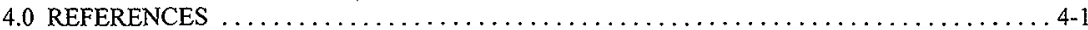

\section{LIST OF TABLES}

2-1. Cask-Multicanister Overpack Configuration upon Receipt at the CVD Facility. ..........2 2-3

2-2. Cask-Multicanister Overpack Configuration with Process Systems at the CVD Facility. . . . . . 2-3

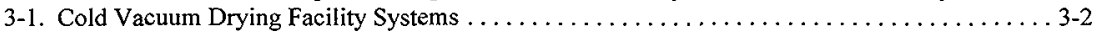

\section{LIST OF FIGURES}

3-1. Cold Vacuum Drying Facility Block Flow Diagram Estimated Average Cask/MCO Receiving Times. Estimated Average MCO CVD and Cask/MCO Process Times ............... 3-33

3-2. Cold Vacuum Drying Facility Block Flow Diagram Estimated Average Cask/MCO Preparation

Times . . . . . . . . . . . . . . . . . . . . . . . . . . .

3-3. Cold Vacuum Drying Facility Block Flow Diagram

Estimated Average MCO CVD and Cask/MCO Process Times . . . . . . . . . . . 3-35

3-4. Cold Vacuum Drying Facility Block Flow Diagram Estimated Average PWC System Operation

Times. . . . . . . . . . . . . . . . . . . . . . . . . . . . . . 63 


\section{LIST OF TERMS}

$\begin{array}{ll}\text { CSB } & \text { Canister Storage Building } \\ \text { CVDF } & \text { Cold Vacuum Drying Facility } \\ \text { HEPA } & \text { high-efficiency particulate air (filter) } \\ \text { HVAC } & \text { heating, ventilating, and air conditioning } \\ \text { I/O } & \text { input/output } \\ \text { IXM } & \text { ion exchange module } \\ \text { MCO } & \text { multi-canister overpack } \\ \text { MCS } & \text { monitoring and control system } \\ \text { MSLD } & \text { mass spectrometer leak detection } \\ \text { P\&ID } & \text { piping and instrumentation diagram } \\ \text { PWC } & \text { process water conditioning (system) } \\ \text { SCHe } & \text { safety class helium (system) } \\ \text { SCIC } & \text { safety class instrument and control (system) } \\ \text { SNF } & \text { spent nuclear fuel } \\ \text { STP } & \text { standard temperature and pressure } \\ \text { UPS } & \text { uninterruptible power supply } \\ \text { VPS } & \text { Vacuum Purge system }\end{array}$




\section{SPENT NUCLEAR FUEL PROJECT \\ COLD VACUUM DRYING FACILITY OPERATIONS MANUAL}

\subsection{COLD VACUUM DRYING FACILITY OVERVIEW}

The mission of the Spent Nuclear Fuel (SNF) Project Cold Vacuum Drying Facility (CVDF) is to achieve the earliest possible removal of free water from water-filled multi-canister overpacks (MCOs) containing metallic uranium SNF that have been removed from the $100 \mathrm{~K}$ Area fuel storage basins (i.e., the K East and K West Basins) at the U.S. Department of Energy Hanford Site in southeastern Washington State. Immediate removal of free water is necessary to halt water-induced corrosion of exposed uranium surfaces and to allow the MCOs and their SNF payloads to be safely transported to the Hanford Site 200 East Area and stored within the SNF Project Canister Storage Building (CSB).

The CVDF is located within a few hundred meters of the basins just southwest of the $165 \mathrm{KW}$ Power Control Building and the $105 \mathrm{KW}$ Reactor Building. This facility site is in close proximity to all of the required utilities. The site area required for the facility and vehicle circulation is approximately 2 acres. Access and egress is provided by the main entrance to the $100 \mathrm{~K}$ inner area using existing roadways.

The CVDF will remove free water from the MCOs to reduce the potential for continued fuel-water corrosion reactions. The cold vacuum drying process involves the draining of bulk water from the MCO and subsequent vacuum drying at no more than $50^{\circ} \mathrm{C}$. The $\mathrm{MCO}$ will be evacuated to a pressure of 3 torr or less and backfilled with an inert gas (helium). The $\mathrm{MCO}$ will be sealed and leak tested and then transported to the CSB within a sealed transportation cask. (The MCO remains within the same shipping cask from the time it enters the basin to receive its SNF payload until it is removed from the cask by the CSB MCO handling machine.)

The CVDF has a minimum of four drying stations (with capability to expand to a fifth station), and provides excess capacity to simplify transport operations as defined by WHC-SD-SNF-TI-016, Development of Design Basis Capacity for SNF Project Systems. The CVDF subproject acquires the required process systems, supporting equipment, and facilities. The cold vacuum drying operations result in an $\mathrm{MCO}$ containing dried fuel prepared for shipment to the CSB by the cask-transporter system. The CVDF subproject also provides equipment to dispose of solid wastes generated by the cold vacuum drying process and to transport process water removed from the MCO back to the K West Basin.

WHC-SD-SNF-FRD-020, K Basin Spent Nuclear Fuel Cold Vacuum Drying Facility Functions and Requirements, summarizes the requirements of the CVDF subproject and identifies federal, state, and local regulations and laws that may be applicable to the CVDF subproject. HNF-SD-SNF-DRD-002, Cold Vacuum Drying Facility Design Requirements, provides the detailed design requirements for the CVDF that establish the basis for the design, development, and testing of equipment to safely and efficiently vacuum dry the K Basins SNF. Finally, HNF-SD-SNF-SAR-002, Safety Analysis Report for the Cold Vacuum Drying Facility, provides the existing safety basis for the CVDF. The CVDF procurement and performance specifications are as follows: 
- W-441-P1, Procurement Specification For the Fabrication, Acceptance Testing, and Shipment of the Cold Vacuum Drying System Equipment Process Skid

- W-441-P2, Procurement Specification For the Fabrication, Acceptance Testing, and Shipment of the Cold Vacuum Drying System Equipment Process Water Conditioning Skid

- W-441-P3, Procurement Specification For the Fabrication, Acceptance Testing, and Shipment of the Monitoring and Control System of the Cold Vacuum Drying Facility Equipment

- W-441-P4, Procurement Specification For the Fabrication, Acceptance Testing, and Shipment of the Cold Vacuum Drying System Process Hood/Seal Ring

- W-441-P5, Procurement Specification For the Fabrication, Acceptance Testing, and Shipment of the Cold Vacuum Drying Facility Safety Class Helium Equipment

- HNF-3228, CVD Safety Class Instrument and Control System Performance Specification 


\subsection{COLD VACUUM DRYING PROCESS SYSTEMS OVERVIEW}

The cask-MCO handling operation starts with the receipt of the cask-MCO transporter at the CVDF process bay. Operators raise the door to allow the transporter to back into the process bay. The transporter is backed into a predetermined position, the landing legs are raised on the transporter, and the truck is disconnected. The truck is driven out of the bay and the bay door is closed. Bay confinement is then established. Radiation surveys are conducted on the cask/transporter, and the quality assurance package is delivered to the CVDF shift operations manager.

Next, the process bay instrument air service is connected to the transporter air supply control station, and the transporter is leveled and set onto the transporter suspension hard points (air shocks depressurized). Finally, a bridge is installed from the process bay mezzanine to the transporter work platform. Contamination control supplies are installed on the work platform. The top of the cask is prepared for venting, purging, and cask lid removal.

The MCO is vented to the cask headspace (the cask annulus was partially filled with water by operations at the K Basins), see Figure 2-1. The cask headspace was purged and filled with helium at approximately 3 psig before it left the basin. During transport to the CVDF, hydrogen is generated and vented to the cask. Pressure also increases due to temperature increases associated with radioactive decay heat, solar heating, and water-uranium corrosion reactions. This gas is vented to the cold vacuum drying process vent system by means of special venting hardware and flex lines connected to the cask lid port and the CVDF process vent system. After venting, the cask headspace is purged with helium. Following purging, the cask lid is removed by the CVDF process bay overhead crane using a dedicated lifting fixture. The cold vacuum drying process hood/seal ring is installed onto the cask and the MCO is prepped for the process operations described below. A depiction of the MCO-cask with the processing system connected is shown in Figure 2-2.

The process is performed per prescribed operating procedures which include bulk water removal, helium purging, evacuation with and without helium purge, an initial pressure rebound test, an extended operation under vacuum at the base pressure of the system, a final pressure rebound test, an integrated leak test of the MCO mechanical seals, and backfilling with helium at $\sim 11+/-0.5$ psig with the MCO at $\sim 25$ ${ }^{\circ} \mathrm{C}$. The majority of all process actions are automatically actuated by the Monitoring and Control System (MCS) with input (start/stop commands) from the operators. There are minimal manual operator actions in the process sequences. Field operator actions, such as connecting the MCO process connectors, the $\mathrm{DI} / \mathrm{He}$ rinse/blowdown after draining and tempered water connections are required. The control room operator actions include acknowledging alarms or instructing the MCS to proceed with the next step. Valve state changes, water temperature control and other process parameter changes are performed by the MCS.

Protection from off-site consequences is provided by maintaining water in the $\mathrm{MCO} / \mathrm{Cask}$ annulus space, pressure venting via a $30 \mathrm{psig}$ rupture disc and automatic actuation of the Safety Class Instrument and Control (SCIC) system. The 30 psig vent path is passive and maintaining annulus water is, for the most part, passive. The $\mathrm{SCIC}$ will prevent the $\mathrm{TW}$ temperatures from exceeding $50^{\circ} \mathrm{C}$ by stopping the TW heater and circulation pump on high temperature detection. 
There are two normal operator interfaces, the MCS computers and the SCIC Mode switch, both are located in the CVDF control room. The SCIC seven position switch defines the MCO process mode which directly feed this information into the Monitoring and ControlSystem (MCS). While most sequences are held for operator permissives, some occur based solely on SCIC mode switch position. This is related to keeping hydrogen concentration low in the $\mathrm{MCO}$ and $\mathrm{PWC}$ receiving tanks.

Following the cold vacuum drying process, the cask-MCO transporter is prepped for shipment to the CSB. This operation is the reverse of the receipt operation. The cask-MCO is brought to a $25^{\circ} \mathrm{C}$ temperature, the MCO pressurized with helium at $\sim 1 \mathrm{I}+/-0.5 \mathrm{psig}$, and is then closed. The cask annulus is drained and dried with an instrument air purge, a He leak test of the MCO is performed, and the cask lid is then reinstalled. Only $1 \mathrm{~atm}$ of air is left in the cask annulus. The transporter is connected to the truck and released for shipment to the CSB. 

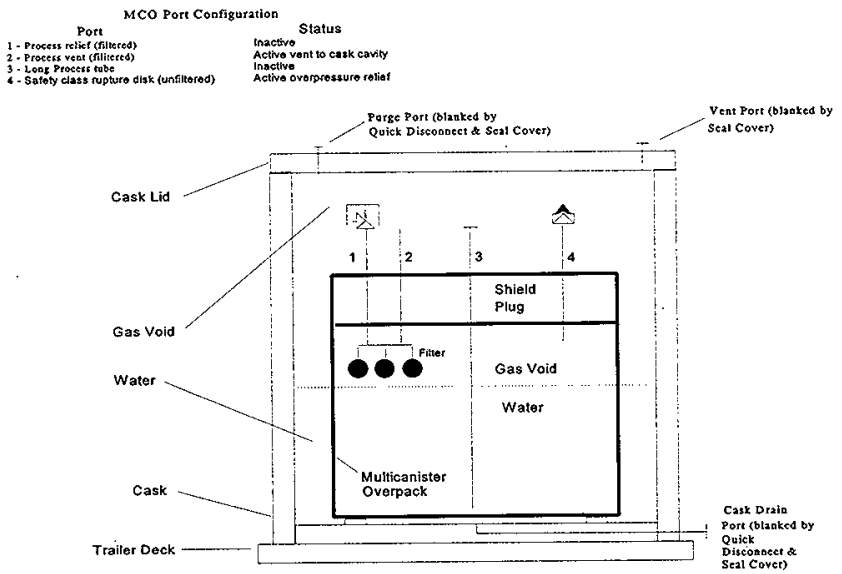

Figure 2-1. Cask-Multicanister Overpack Configuration upon Receipt at the CVD Facility.

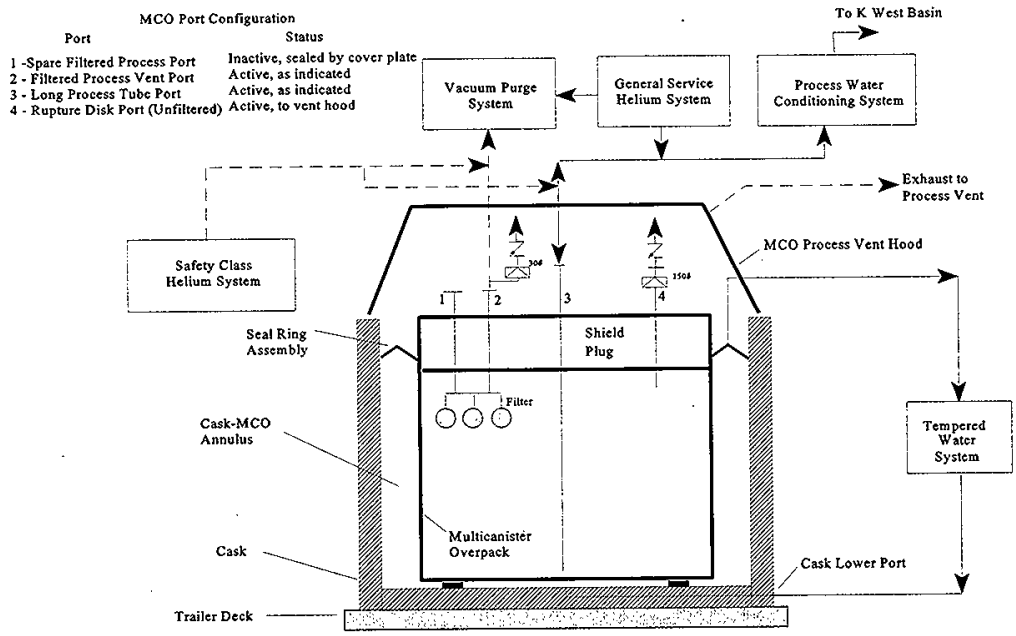

Figure 2-2. Cask-MulticanisterOverpack Configuration with Process Systems at the CVD Facility. 


\subsection{COLD VACUUM DRYING FACILITY SYSTEM DESCRIPTIONS}

\subsection{COLD VACUUM DRYING FACILITY PROCESS SYSTEMS}

The process equipment systems that will be operated in the CVDF were designed following the criteria in HNF-SD-SNF-DRD-002. Safety classification for the equipment is documented in HNF-SD-SNF-SEL-002, Safety Equipment list for the CVDF, and discussed in HNF-SD-SNF-SAR-002. Table 3-1 lists the various systems within the CVDF. These systems are briefly described in the sections below and in more detail in the system design descriptions, (see Table 3-1 and section 4.0 References for a listing of the SDDs).

\subsubsection{System 07, Vacuum Purge System (VPS)}

The CVDF Vacuum Purge System (VPS) (refer to piping and instrumentation diagrams [P\&IDs] $\mathrm{H}-1-82160$ through $\mathrm{H}-1-82163$ and $\mathrm{H}-1-83766)$ is designed to drain and dry SNF elements contained within an $\mathrm{MCO}$, which is in turn contained by a shielding cask vessel. The system consists of up to four process equipment skids each containing a gas purge and evacuation system, a gas stream analysis system and a tempered water system described below. There is one process equipment skid (PES) in each active process bay.

Components, piping, instruments, and electrical wiring are mounted on a platform and frame designated as a Process Equipment Skid (PES). The piping runs from the process equipment skid to a process hood/seal ring assembly (refer to H-1 82364 and H-1-83275) The process hood/seal ring assembly is swung over the top of the MCO by the CVDF crane fixed to the top of the cask (after removing the cask lid). This allows the MCO valve operators (refer to $\mathrm{H}-1-82366$ and $\mathrm{H}-1-82368$ ) to be attached to the $\mathrm{MCO}$, effectively providing process connection. The $\mathrm{MCO}$ tempered water system, described below, is also included on the process equipment skid.

The VPS consists of the following subsystems:

- System 07-1, Vacuum and purge system (VPS)

- System 07-2, Residual gas monitoring system (RGM)

- System 07-3, Helium mass spectrometer leak detection and auxiliary vacuum system (MSLD).

The VPS (System 07-1) consists of a single vacuum pump, piping and valves; pressure control valves and piping for helium purge gas supply and venting; a condensing assembly, piping, valves, and auxiliaries to dry process gases, and instrumentation and gas monitoring equipment that achieves, maintains, and monitors the required operating pressures and gas concentrations in the MCO (System 072). A separate subsystem (System 07-3) consists of a helium MSLD, auxiliary vacuum pump, piping, valves, and instrumentation to measure the pressure boundary leak rate of the MCO following the cold vacuum drying process. The tempered water system (System 47-2) is described elsewhere in this document. 
Table 3-1. Cold Vacuum Drying Facility Systems. (3 sheets)

\begin{tabular}{|c|c|c|c|c|}
\hline $\begin{array}{c}\text { System } \\
\text { Number }\end{array}$ & Cold Vacuum Drying System & Abbreviation & P\&ID or PFD & $\begin{array}{l}\text { SDD Doc. } \\
\text { No. }\end{array}$ \\
\hline 05 & Personnel monitoring system & (PMS) & & \\
\hline $05-1$ & Radiation monitoring system & (RM) & $\mathrm{H}-1-82243$ & SNF-3060 \\
\hline $05-2$ & Room air quality system & $(\mathrm{AQ})$ & $\mathrm{H}-1-82243$ & $\mathrm{SNF}-3060$ \\
\hline 06 & Civilistructural systems & $(\mathrm{CIV})$ & & \\
\hline $06-1$ & Administrative building (civil/structural/architectural) & $(\mathrm{CIV}-\mathrm{A})$ & $\mathrm{H}-1-82101$ to $\mathrm{H}-1-82103$ & SNF-3061 \\
\hline $06-2$ & Process bay (civil/structural/architectural) & $(\mathrm{CIV}-\mathrm{B})$ & $\mathrm{H}-1-82101$ to $\mathrm{H}-1-82103$ & $S N F-3061$ \\
\hline $06-3$ & $\begin{array}{l}\text { Transfer corridor/mechanical equipment room } \\
\text { (civil/structural/architectural) }\end{array}$ & $(\mathrm{CIV}-\mathrm{C})$ & $\mathrm{H}-\mathrm{J}-82101$ to $\mathrm{H}-1-82103$ & SNF-3061 \\
\hline 06- 4 & Process water tank room (civil/structural/architectural) & $(\mathrm{CIV}-\mathrm{D})$ & $\mathrm{H}-1-82101$ to $\mathrm{H}-1-82103$ & SNF-3061 \\
\hline 07 & Vacuum Purge system & (VPS) & & \\
\hline $07-1$ & Vacuum Purge system & (VPS) & $\mathrm{H}-1-83766$ & SNF-3062 \\
\hline $07-2$ & Residual gas monitoring system & (RGM) & H-1-83766 & $\mathrm{SNF}-3063$ \\
\hline $07-3$ & Helium MSLD and auxiliary vacuum system & (MSID) & TBD & SNF-3064 \\
\hline 11 & Communications system & $(\mathrm{COMM})$ & $\mathrm{H}-\mathrm{l}-82243$ & SNF-3065 \\
\hline 12 & Instrument air system & $(\mathrm{CA} / \mathrm{IA})$ & $\mathrm{H}+1-82222$ & SNF-3066 \\
\hline 13 & Helium systems & NA & & \\
\hline $13-1$ & General service helium system & $(\mathrm{He})$ & $\mathrm{H}-1-83766$ & SNF-3067 \\
\hline $13-2$ & Safety class helium system & $\overline{(\mathrm{SCHe})}$ & $\mathrm{H}-1.83766$ & SNF-3068 \\
\hline 14 & Cranes and hoists & (HOI) & $\mathrm{H}-1-82104, \mathrm{H}-1-82132$ & SNF-3072 \\
\hline 18 & Effluent drains system & (EFS) & $\mathrm{H}-1-82223$ & SNF-3073 \\
\hline 19 & Condensate collection system & $(\mathrm{CCS})$ & $\mathrm{H}-1-82223$ & SNF-3074 \\
\hline 20 & Electrical systems & (ES) & & \\
\hline $20-1$ & Electrical power distribution system & (EPD) & H-1-82241 to H-1-82248 & SNF-3075 \\
\hline $20-2$ & Lighting (external/internal/exit/entergency) system & NA & $\mathrm{H}-1-82241$ & SNF-3075 \\
\hline $20-3$ & Ground system (power/instrumentation and control) & NA & $\mathrm{H}-1-82246$ & SNF-3075 \\
\hline $20-4$ & Facility uninterruptible power supply system & NA & $\mathrm{H}-1-82241$ to $\mathrm{H}-1-82248$ & SNF-3075 \\
\hline 20.5 & Lightning/surge protection system & NA & $\mathrm{H}-1-82095$ & SNF-3075 \\
\hline 24 & Fire protection system & (FPS) & $\begin{array}{l}\mathrm{H}-1-82237 \text { to } \mathrm{H}-\mathrm{J}-82240 \\
\mathrm{H}-1-82244\end{array}$ & SNF-3077 \\
\hline 25 & Deionized water system & (DI) & $\mathrm{H}-1-82222$ & SNF-3078 \\
\hline 26 & Potable water system & $(P W)$ & $\mathrm{H}-1-82222$ & SNF-3079 \\
\hline 27 & Sanitary collection system & (SANS) & $\mathrm{H}-1-82222$ & SNF-3080 \\
\hline
\end{tabular}


Table 3-1. Cold Vacuum Drying Facility Systems. (3 sheets)

\begin{tabular}{|c|c|c|c|c|}
\hline $\begin{array}{l}\text { System } \\
\text { Number }\end{array}$ & Cold Vacuum Drying System & Abbreviation & P\&ID or PFD & $\begin{array}{l}\text { SDD Doc. } \\
\text { No. }\end{array}$ \\
\hline 30 & HVAC systems & (HVAC) & & \\
\hline $30-1$ & Administration Building HVAC system & (HVACA) & $\mathrm{H}-1-83769$ & $\mathrm{SNF}-3081$ \\
\hline $30-2$ & Process bay recirculation HVAC system & (HVACB) & $\mathrm{H}-1-83769$ & SNF-3081 \\
\hline $30-3$ & $\begin{array}{l}\text { Process bay local exhaust HVAC and process vent } \\
\text { system }\end{array}$ & (HVACC/PV) & $\mathrm{H}-1-83769$ & SNF-3081 \\
\hline $30-4$ & Process general supply/exhaust HVAC system & (HVACD) & H-1-83769 & SNF-3081 \\
\hline $30-5$ & Reference air system & (RA) & $\mathrm{H}-1-82207$ & SNF-3081 \\
\hline 46 & Process water systems & $\mathrm{NA}$ & $H-l-83766$ & \\
\hline $46-1$ & Process water conditioning system & (PWC) & $\mathrm{H}-1-83766$ & SNF-3082 \\
\hline $46-2$ & Conditioned water shipping system & (CWS) & $\mathrm{H}-1-83766$ & SNF-3083 \\
\hline $46-3$ & Contaminated water sampling and analysis system & (SMP) & $H-1-83766$ & SNF-3084 \\
\hline 47 & Tempered and Cooling water systems & $(\mathrm{CW})$ & & \\
\hline $47-1$ & Tempered water (annulus) system & $(T W)$ & H-1-83766 & SNF-3085 \\
\hline $47-2$ & Tempered water cooling system & (IWC) & $\mathrm{H}-1-83768$ & SNF-3085 \\
\hline $47-3$ & Chilled water system & $(\mathrm{CHW})$ & H.1-83768 & $S N F-3086$ \\
\hline $47-4$ & Vacuum Purge system chilled water system & (VPSCHW) & $\mathrm{H} \cdot 1-83767$ & SNF-3087 \\
\hline 50 & Stack monitoring system & $(\mathrm{SM})$ & H-1-82209 & SNF-3088 \\
\hline 54 & Security system & (SEC) & $\mathrm{H}-1-82245$ & SNF-3089 \\
\hline 93 & Instrumentation and control system & (IC) & & \\
\hline $93-1$ & Monitoring and control system & (MCS) & H-1-82291, H-1-82297 & SNF-3090 \\
\hline $93-2$ & Safety class instrumentation and control system & $(\mathrm{SCIC})$ & $\mathrm{H}-1-83766$ & SNF-3091 \\
\hline 100 & Specialty equipment & $(\mathrm{SE})$ & & SNF-3076 \\
\hline 101 & Special tools & (ST) & & SNF-3076 \\
\hline
\end{tabular}

HVAC $=$ heating, ventilating, and air conditioning.

MSLD $=$ mass spectrometer leak detector.

NA $=$ not applicable.

$P \& I D=$ piping and instrumentation diagram.

PFD $=$ process flow diagram.

The CVDF trace heat system consists of (1) self-regulating heat cable consisting of two bus wires, a semi-conductive polymer core whose resistance varies with temperature, and an insulating jacket; (2) connection accessories; and (3) local on-off thermostatic control. The trace cable is ChromaloxType SRM, $120 \mathrm{~V}$ service, with a fluorpolymer jacket over braid. The trace heat cable is controlled from a

Chromalox/Wieg and Industrial Company, Pittsburgh, Pennsylvania. 
Chromalox $\mathrm{DL}$ series local controller with resistance temperature detector input. The trace heat cable is installed on selected VPS piping in each of the four process equipment skids. The CVDF trace heat system maintains selected portions of the VPS piping at greater than $50^{\circ} \mathrm{C}$ to prevent condensation of water within the piping until the water vapor reaches the VPS condenser.

The process consists of first venting and purging the cask and $\mathrm{MCO}$, heating the $\mathrm{MCO}$ to $46^{\circ} \mathrm{C}$ using the tempered water system (refer to P\&ID H-1-82160 and H-1-83766). The SNF immersion water is drawn from the $\mathrm{MCO}$ and transferred to a receiving and treatment system (the Process Water Conditioning [PWC] system, see H-1-82164). Once the immersion water is removed from the MCO, the system is backfilled and purged with helium (see description of the helium supply system below) at a rate of approximately $1.9 \mathrm{scfm}$ as measured by FI- ${ }^{*} 20$ or FI- $1 * 21$. In the VPS, VPS-COND- $2 * 13$ (refer to P\&ID, H-1-83766) continuously dries the purge gas prior to exhausting to the facility vent system. A small purge maintains a slight pressurization in all piping and equipment to prevent hydrogen buildup and intrusion of air (via a small leak or line break).

The majority of the remaining water will be removed during the evacuation step. The vacuum pump (VPS-P-2*11) withdraws water vapor, trace hydrogen and helium until the pressure drops to an equilibrium value, expected to be about 60 to 100 torr, as measured by PI- $1 * 08$ or PI- $1 * 10$. The condenser is maintained at about $3{ }^{\circ} \mathrm{C}\left(38^{\circ} \mathrm{F}\right)$ as measured by $\mathrm{Tl}-2 * 36$. There will be a continuous purge of helium at a rate of approximately $1.9 \mathrm{scfm}$ through the $\mathrm{MCO}$ during the initial vacuum mode. In this mode the atmosphere in the MCO will be a low pressure mixture of water vapor, helium, and hydrogen. The condensed water is collected in a collection tank, VPS-TK- $2 * 16$, that is located on the process equipment skid. The condensed water in the tank is transferred to the PWC system at the end of the drying operation. The non-condensed gases (helium and hydrogen) are transferred through the vacuum pump to the facility HEPA filtered vent system and out the exhaust stack.

A helium purge of $\sim 1.9 \mathrm{scfm}$ is maintained to assure that hydrogen does not accumulate. This mode of operation is continued until the $\mathrm{MCO}$ is dried to a point that allows a pressure reduction to below 12 torr for a maximum time period of 8 hours. If pressure can not be reduced to less than 12 torr within the 8 hour period, the vacuum pump is isolated and a backfill of the MCO with helium is initiated. The pressure is increased to $1 \mathrm{psig}$ and a helium purge of $\sim 1.9 \mathrm{scfm}$ is then maintained. The purge is maintained for 4 hours to reduce thermal gradiants within the fuel which is a safety requirement (Thermal Reset). Following the helium backfill and purge for 4 hours, a second evacuation of the MCO is performed. The maximum time for the second and any subsequent evacuation will be 4 hours. Each subsequent evacuation will be followed by a 4-hour minimum duration of helium backfill and purge. Once the condenser is no longer removing water the condenser is isolated by closing VPS-GOV-2*21 and VPS-GOV- $2 * 22$, the flow is routed through a condenser bypass line by opening VPS-GOV- $2 * 03$, and the vacuum pump operates until pressure equalizes based on the minimum helium flow injection.

Upon reaching a pressure of $<0.5$ torr, the MCO is isolated by closing PWC-GOV- $1 * 30$, PWCGOV- $1 * 03$, VPS-GOV- $1 * 11$, VPS-GOV $1 * 17$, He-GOV- $1 * 06$, VPS-GOV- $1 * 05$, He-GOV- $1 * 02$, and VPS-GOV-1*09. A dryness verification test is performed by means of a pressure rebound test. If the pressure rises above 3 torr within an hour (pressure rebound test), insufficient drying has taken place and more drying is required. More vacuum pumping is performed if the test fails. Once the MCO passes the pressure rebound test, an evacuation to less than 30 torr for up to 28 hours is then conducted with the expected system base pressure of 0.1 torr, this is called the 6 PROOF" mode of operation. The " 6 PROOF" mode requires the use of the vacuum pump only, while residual gas analyzer $\mathrm{AI}-2 * 13$ samples the build-up of impurities within the MCO atmosphere during this operation. Multiple faulted conditions 
could result in water addition to the $\mathrm{MCO}$, therefore a second and final rebound test is conducted at the end of the "6 PROOF" mode. This post drying operation (i.e., " 6 PROOF" mode) at $46^{\circ} \mathrm{C}$ is utilized to verify that $200 \mathrm{~g}(0.44 \mathrm{lb})$ of water or less is in the MCO prior to shipment to the CSB (see HNF-1851, Cold Vacuum Drying Residual Free Water Test Description) which is indicated by passing the final pressure rebound test.

At the completion of the $46^{\circ} \mathrm{C} " 6$ PROOF" mode operation, the cask-MCO temperature is reduced to $25^{\circ} \mathrm{C}$ by the tempered water system, the $\mathrm{MCO}$ is purged with helium and a pressure of $\sim 7$ psig is achieved, the MCO ports are closed, the process connectors removed, and the MCO ports helium leak tested, the space between the MCO and cask is drained and dried with an instrument air purge, and an integrated helium leak rate test of the $\mathrm{MCO}$ is conducted. All helium leak tests are conducted with the helium MSLD equipment (System 07-3). Finally, the process hood/seal ring is disconnected from the $\mathrm{MCO}$ and the cask lid is reinstalled while the cask annulus retains $1 \mathrm{~atm}$ of air.

The VPS performs safety class isolation functions between the $\mathrm{MCO}$ and isolation valves located on the process hood support stand. VPS piping between these valves and the $\mathrm{MCO}$ are considered to form an extension of the primary confinement barrier for release of contamination. These are considered safety class primary confinement and are designed to performance category 3 standards. The system design description for the VPS is contained in SNF-3062.

\subsubsection{System 46-1, Process Water Conditioning System (PWC)}

The PWC system (refer to P\&IDs H-1-82160, and H-1-83766) serves two purposes. First, the PWC system is a vacuum source and receiver for MCO waters. Second, the PWC system conditions the $\mathrm{MCO}$ waters by removing radioactive particulate and soluble species using filtration and ion exchange. The PWC system is designed to service one $\mathrm{MCO}$ at a time so priority determination and scheduling is important. The PWC vacuum source is a water jet ejector that requires a water circulation. The PWC system will continuously circulate water through the ejector thus having a continuous source of vacuum for draining MCOs, VPS condenser tanks, tempered water systems, or the MCO cask annulus.

Normal operations of the PWC system include draining water from the MCO, VPS condenser tank, the $\mathrm{MCO}$ cask annulus, and tempered water system; processing collected water through the ion exchange module (IXM); and transferring processed water to facility storage tank PWC-TK-4001.

The PWC system is powered by 2 ( 1 running and 1 spare) magnetically driven pumps, PWC-P-4035 and PWC-P-4036, capable of pumping $45 \mathrm{gal} / \mathrm{min}$ at a head of $140 \mathrm{ft}$ of water. The pump discharges into primary receiver tank PWC-TK-4032 through water jet-ejector PWC-EJR-4031. There is a second receiver tank, PWC-TK-4033, mounted in parallel to the primary receiver tank. The total capacity of the two tanks is approximately 236 gallons of water. The ejector is capable of pulling at least $5 \mathrm{gal} / \mathrm{min}$ of liquid at a head of $-17 \mathrm{ft}$ of water. Operation of the PWC vacuum pumping and receiving include control and monitoring of the pump operation; flow loop performance (FI-4037); receiver tank conditions (LI-4033, LAL-4034, LAH-4032); and the suction line performance (PI-4031).

The PWC impurity removal section consists of a flow branch for feeding approximately $40 \mathrm{gal} / \mathrm{min}$ of process water through IXMs, PWC-IXM-4037 or PWC-IXM-4038. Flow at $10 \mathrm{gpm}$ is eventually directed to a separate particulate filter PWC-F-4042 prior to water transfer to the PWC storage tank, TK4001. Automatic sampling is done before the IXM (PWC-SMP-4039), after the IXM (PWC-SMP-4040), 
and after the filter (PWC-SMP-4041). Process water can be directed to storage tank PWC-TK-4001 or returned to receiver tanks PWC-TK-4032 and PWC-TK-4033.

Control of process water to the IXMs is through PWC-GOV-4039 as measured by FI-4037 at a nominal rate of $40 \mathrm{gal} / \mathrm{min}$. A single IXM is connected to the PWC equipment skid by two stainless steel, teflon line flex lines with quick disconnects. Normally, flow is continuously fed through the IXMs. High differential pressure alarm PDAH-4040 alarms when the IXMs are beginning to plug. Operating experience will determine what differential pressure to set. IXM loading with transuranics will be administratively controlled as determined by sample analysis and will likely require IXM changeout prior to reaching the differential pressure limit. After the process water has passed through the IXMs, the treated water can be returned to the receiver tanks for recirculation through the PWC process.

Recirculation improves the impurity removal. Final transfer of processed water is to the facility storage tank, PWC-TK-4001. The system design description for the PWC system is contained in SNF 3082.

\subsubsection{System 46-2, Conditioned Water Shipping System (CWS)}

The conditioned water shipping system consists of a 8,000 gal tanker truck to transfer the CVDF process water back to the $\mathrm{K}$ Basins. The tanker is backed into process bay 1 (room 131) and a transfer line is connected to the tanker using a flex line and quick disconnect. The tanker has a HEPA filter vent. Water is pumped from PWC system holding tank PWC-TK-4001 to the tanker by opening valves PWC-V-008 and PWC-V-016, and starting pump PWC-P-4001 (refer to P\&ID H-1-83766). The level in tank PWC-TK-4001 is monitored from LI-4014. After the tanker is filled, it is released to ship the processed water to the $\mathrm{K}$ West Basin integrated water treatment system. The system design description for the system conditioned water shipping system is contained in SNF 3083. The tanker trailer is specified in HNF-2635.

\subsubsection{System 46-3, Contaminated Water Sampling and Analysis System (SMP)}

The contaminated water sampling and analysis system (refer to P\&ID H-1-83766) is used to take water samples before process water is fed into the PWC system IXMs, after water exits the IXMs and after PWC-F-4042. The sample bottles are periodically removed and sent to the $222 \mathrm{~S}$ Laboratory or K Basins for analysis. The results of the analysis will determine the quantity of radionuclides removed from the MCOs, the radionuclides contained in the IXMs and filter, and the water quality being transferred to the facility storage tank.

The PWC impurity removal operation consists of a flow branch for feeding approximately 45 $\mathrm{gal} / \mathrm{min}$ of process water through IXMs PWC-IXM-4037 or PWC-IXM-4038 and separate particulate filter PWC-F-4042 (flow is throttled to $10 \mathrm{gal} / \mathrm{min}$ at the filter). The three samplers must take samples whenever flow is registered through the IXMs. The MCS controls the sample, taking one $10 \mathrm{cc}$ sample every 100 gal fed. The MCS sends a momentary sample initiation signal to samplers PWC-SMP-4039, PWC-SMP-4040, and PWC-SMP-4041. The system design description for the contaminated water sampling and analysis system is contained in SNF 3084.

\subsubsection{System 47-1, Tempered Water (Annulus) System (TW)}

The MCO temperature, while at the CVDF, will normally be maintained over a temperature range of $15^{\circ} \mathrm{C}$ to $46^{\circ} \mathrm{C}$ using the tempered water system (refer to P\&IDs H-1-82160 and $\mathrm{H}-1-83766$ ). Water lines are connected to ports in the cask body and seal ring so that tempered water is circulated through the 
annulus between the shielding cask and the MCO. Water is transferred at a flow of $20 \mathrm{gal} / \mathrm{min}$ using pump TW-P-3*14, flow is measured with flowmeter FIT-3*16, and temperature is controlled through TIC- $3 * 05$. The water is heated or cooled by electric heater TW-HTR-3*11 and cooler TW-CLR- $3 * 10$. Chilled water to the cooler is supplied from the tempered water cooling system described below. The tempered water system supply pressure to the cask-MCO annulus is controlled at 25 psig utilizing pressure control valve SRV $-3 * 11$ and FCV $-3 * 18$. Pump discharge pressure is monitored at $\mathrm{PI}-3 * 08$. The tempered water system utilizes surge/holding tank TW-TK- $3 * 12$. The water level in this tank is monitored from LI-3*04 and has a high-level alarm (LAH-3*06).

The tempered water system has three safety functions, maintain water in the Cask/MCO annulus, maintain Cask/MCO inlet water temperature at less than $50^{\circ} \mathrm{C}$ and to provide local water level indication. All of these functions are required throughout the CVD drying process until the final pressure rebound test is completed. The design for maintaining water level is passive however level alarms are provided to the SCIC system for annunciation in the CVDF control room on low level. The two level switches are LSL$1 * 24$ and $1 * 25$ which are part of the level gauges, LG $-1 * 24$ and LG $1 * 25$. Two independent temperature switches (TSH $1 * 28$ and TSH $1 * 29$ ) provide input to the SCIC panels which will trip the TW heater and circulation pump if the temperature setpoint is exceeded. Both the level and temperature alarms are provided to the MCS which provided process parameter indication in the control room. The system design description for the tempered water (annulus) system is contained in SNF 3085.

\subsection{COLD VACUUM DRYING SAFETY CLASS SYSTEMS OVERVIEW}

\subsubsection{System 13-2, Safety Class Helium System (SCHe)}

3.2.1.1 General. The SCHe system (refer to P\&IDs H-1-82160 and H-1-83766) is designed to supply a helium purge to the MCO in the event the SCIC automatically actuates or is manually activated by the operator. Since the $\mathrm{SCHe}$ isolation valves are fail open, a loss of electrical power or Instrument Air will also result in an initiation of the SCHe system purge and vent.

The function of the SCHe system is to provide a minimum purge of helium through the MCO of $\sim 1.9 \mathrm{scfm}$ to maintain hydrogen below the Lower Flamability Limit $(<4 \%)$, or following a line break, remove oxygen that entered under $\mathrm{MCO}$ vacuum conditions. The SCHe system will maintain a positive pressure in the MCO under all events except a line break within the MCO process line isolation valves, in this case a steady flow of helium is provided to preclude air ingress until recovery action can be performed.

The elements of the SCHe system include four parallel purge systems, two on the MCO long process tube port connection and two on the MCO process vent port (HEPA filter) connection. Each of the four independent SCHe systems have two sources of helium: the $240 \mathrm{cu}$. ft at STP helium bottles, SCHe-TK $-5^{*} 01,-5^{*} 02,-5^{*} 03$ and $-5^{*} 04$, and the normal helium tube trailers. The safety class bottles take over should the non-safety tube trailer become unavailable. Safety to non-safety isolation is provided by a series of pressure control and check valves between these two sources assuring a safety class supply of helium to the MCO.

3.2.1.2 Pressure Control. Pressure controls (higher pressure control setpoints) are used to preferentially use normal (non-safety) helium gas supply from the tube trailers. Under non-faulted conditions (refer to HNF-SD-SNF-DRD-002, Section 2.2.10, for definition of faulted conditions) this would preserve the $\mathrm{SCHe}$ system purge bottle supply and reduce the need for $\mathrm{SCHe}$ bottle refill. Under any condition that 
does not allow normal helium supply, the SCHe system bottle supply would not be affected (safety class separation criteria) and would be utilized upon a SCIC purge initiation.

Regardless of the actual helium supply source, pressure control setting within the SCHe system will supply the helium purge gas through the long process tube port. The return gas flow will then backfeed into the $\mathrm{SCHe}$ system lower pressure supply headers, through pressure regulators, and into the process vent.

Under faulted conditions the pressure control arrangement will provide purge flow through any conceivable single line break. Under the condition of a pipe break within the safety class isolation valves to the $\mathrm{MCO}$, the flow of helium is as follows.

- Process line break on the MCO long process tube port side with little or no bulk water in the MCO. Purge will be through the MCO from the MCO HEPA filter supply side. MCO pressure will be maintained at slightly positive with flowing helium through the line break and/or out the process vent, depending on the size of the leak.

- Process line break on the MCO long process tube port side with bulk water in the MCO. If bulk water exists within the MCO, water will be pushed through the broken line until the pressure of the purge gas is overcome by the static head of the water column in the long process tube port. At this point the $\mathrm{MCO}$ is maintained at a positive pressure to preclude oxygen ingress. Prior to the line break, a positive pressure SCIC trip assures no oxygen in the $\mathrm{MCO}$.

- Process line break on the MCO HEPA filter side with little or no water in the MCO. Purge will be through the MCO from the MCO long process tube port side out the line break.

- Process line break on the MCO HEPA filter side with bulk water in the MCO. If bulk water exists in the MCO either the SCHe pressure will overcome the backpressure of the water and bubble through the water to maintain positive pressure or the $\mathrm{MCO}$ will be vented allowing $\mathrm{H} 2$ (at low initial concentrations) to disperse into the bay.

A minimum of one hour of purge volume has been provided to allow time to initiate and complete recovery operations (e.g., isolation of the $\mathrm{MCO}$ at the plug valves). A safety class alarm is provided in the control room to signal that an actuation of the SCHe system has commenced. Administrative procedure will require that the proper purge time has been provided prior to $\mathrm{MCO}$ isolation. Note that these faulted conditions are not considered to occur during a seismic event because all safety class lines are seismically qualified.

3.2.1.3 Instrumentation. Local safety class SCHe system bottle pressure gauges are provided at each SCHe system bottle, which provide supply capacity. Other instruments for local and remote monitoring are safety class for maintaining the pressure boundary but are non-safety for reading or electronic signals. The non-safety class systems are designed to require multiple failures to impact the safety class systems.

3.2.1.4 Alarms. Safety class alarms consist of safety class isolation and purge initiation (discussed in the SCIC section). The system design description for the SCHe system is contained in SNF 3068. 


\subsubsection{System 93-2, Safety Class Instrumentation and Control System (SCIC)}

3.2.2.1 General. The SCIC system provides active detection and response to process anomalies that, if unmitigated, would result in a safety class event. Specifically, actuation of the SCIC system includes two portions. The isolation of the MCO and initiation of the SCHe purge and the SCIC portion of the system which detects and stops excessive heat input to the MCO on high tempered water MCO inlet temperature. For the $\mathrm{MCO}$ isolation and purge, the $\mathrm{SCIC}$ receives signals from $\mathrm{MCO}$ pressure (both positive pressure and vacuum), helium flow rate, bay high temperature switches, seismic trips and time under vacuum trips. The MCO pressure and helium purge rates are used to prevent explosive accumulations of hydrogen and oxygen. The bay high temperature is used to protect against the effects of high bay temperature on the accuracies of the safety class instrumentations. Separate temperature switches are provided that, if exceeded, will initiate the safety class isolation and SCHe system purge.

The TW high temperature trips remove power from the water heater and recirculation pump through the heater and pump contactor. A safety-class alarm is provided to the CVDF control room on low water level in the cask-MCO annulus and an activation of the SCIC system.

In addition to the above trips, the SCIC provides safety significant alarms for the PWC pre and post purges. Should either of these two purges fail to be completed or are interrupted, the operator will be notified and corrective action is required. These alarms in conjunction with operator action prevent explosive gas ( $\mathrm{H} 2$ and $\mathrm{O} 2$ ) accumulations in the PWC receiving tanks.

3.2.2.2 Actuation of Safety Class Instrument and Control System. The SCIC system will isolate the $\mathrm{MCO}$ and start a SCHe system purge if any of the following occur.

a. Seismic event of sufficient magnitude (below the Uniform Building Code levels).

b. Manually initiated isolation and purge from one of the SCIC "ISO \& PURGE" buttons (administratively controlled).

c. Loss of Electrical Power to the SCIC (fail-safe condition)

d. MCO reaches an incorrect pressure state without adequate, verified purge volume. The MCO must be maintained above a positive pressure (approximately $0.5 \mathrm{psig}$ ) to prevent oxygen ingress unless a purge of adequate volume has been completed. During bulk water draining and the subsequence rinse, the MCO must remain above atmospheric pressure.

e. $\mathrm{MCO}$ is below atmospheric pressure and the helium flow is below the minimum required to keep hydrogen less than $4 \%$ by volume. When MCO pressure is below 12 torr there is insufficient hydrogen to exceed the $4 \%$ level and no purge is required. A five-minute time delay on low flow allows flow to be stopped in order to reach $<12$ torr.

f. Bay temperature exceeds the high temperature safety limit of $105^{\circ} \mathrm{F}$, which would impact safety class instrument calibration.

g. During the transition from above atmosphere $0.76 \mathrm{psig}[0.5 \mathrm{psig}$ ] to vacuum, time to reach less than -11.7 psig ( 155 torr $)$ shall not exceed 5 minutes. 
h. During the transition from below -11.1 psig ( $~ 185$ torr $)$ back to greater than $0.5 \mathrm{psig}$ pressure, the time shall not exceed 5 minutes.

i. Exceeding 8 hours at vacuum the first vacuum cycle or 4 hours at vacuum all subsequent vacuum cycles without re-pressurizing the MCO for a minimum of 4 hours. This is referred to as the $8 / 4 / 4$ requirement and provides thermal equilibrium within the $\mathrm{MCO}$.

3.2.2.3 Interlocks. The following safety class interlocks are provided by the SCIC system.

- During the 7 PRESSURE TEST mode, valves VPS-GOV $1 * 09$ and $-1 * 05$ are interlocked closed to preclude the potential of water addition which would invalidate the final pressure rebound test.

- During the 4 PURGEALUSH mode, valves VPS-GOV $1 * 09$ and $-1 * 05$ are interlocked closed to preclude the helium purge gas from being vented through any other path other than to the PWC receiving tanks. This is a limited timed interlock during this step.

- PWC-GOV $1 * 30$ and $-1 * 03$, isolation valves from the MCO to the PWC system are interlocked in 5 DRYING and PRESSURE TEST modes to isolate potential water and air sources from the MCO.

- VPS-GOV-1*17 and VPS-GOV-1*11 are interlocked closed in any mode except 3 DRAIN and 4 PURGE/FLUSH. This precludes water addition during heatup or after rinse is completed. Water addition after the Initial Pressure Rebound Test would invalidate this test and may lead to Safety Class consequences in the Canister Storage Facility.

- The tempered water heat temperature switches TSH $1 * 28$ and $1 * 29$ upon actuation will remove power from the TW Heater and Pump to preclude overheating the $\mathrm{MCO} / \mathrm{Cask}$. This failure would be equivalent to a loss of annulus water and would result in a thermal excursion under worst case conditions. The contacts of the TSHs are in series with the contactors of both the heater and pump. Removing this power will open the contactors which will de-energize the $480 \mathrm{VAC}$ power to these components.

3.2.2.4 System Description. The SCIC consists of two logic trains and redundant instruments and control functions. A total of four programmable logic controllers are utilized to perform the various setpoint comparisons and to provide all timing functions. The programmable logic controller in bay 2 serves as train "A" for both bay 2 and 3 . The bay 3 controller serves bays 2 and 3 as train "B." A similar arrangement is used for bays 4 and 5 . Two local control panels in each bay provide access to both train $A$ and B or access to that bay's safety class system. The following functions are provided by the SCIC:

- Local bay SCIC system, isolation and purge, activation switch

- Control switches for Train A and Train B for the seven different modes are provided in the CVDF control room. The modes are "2 BXPASS", "2 HEATUP" "3 DRAIN", "4 PURGEILUSH", "5 DRYING", "6 PROOF" and "7 PRESSURE TEST"

- Indication alarm lights for under pressure, low purge, tempered water high temperature, seismic trips, cask annulus water level low, bay high temperature 
- Logic test and reset switches

Sensors and transmitters providing inputs to the SCIC system consist of the following:

- MCO pressure PT-1*08 and PT-1*10 (vacuum levels)

- $\mathrm{MCO}$ higher vacuum pressure or above atmospheric pressure PT-1*36 and PT-1*37

- Normal helium purge rates FIT- $1 * 20$ and FIT- $1 * 21$

- Cask-MCO annulus water low-level switch LSL-1*24 and LSL-1*25

- Tempered water high temperature switch TSH- $1 * 28$ and TSH- $1 * 29$

- Process bay high temperature switch TSH- $1 * 38$, TSH- $1 * 39$, TSHH- $1 * 38$, and TSHH-1*39

- Seismic trip sensors and auctioneering circuitry (ATR-5335, ATR-5436, ATR-5537, ATR5538, ATR-5539)

NOTE: The seismic trips are independent of safety class logic. The seismic trip directly controls the final output relay which either is closed to allow power to the safety class valves or is opened on a trip or loss of power. Once a seismic trip is activated, all other logic is circumvented and no longer has a safety class function. These electrical circuits are seismically qualified.

3.2.2.5 Alarms. Safety class control room alarms consist of:

- BAY * ANNULUS LOW LEVEL

- $\mathrm{BAY} *$ PURGE

NOTE: The control room safety class annunciator is required for non-seismic events only. During a seismic event the SCIC system isolates and purges the MCO with no required operator action. Because all safety class lines are seismically qualified, no line breaks can occur within the safety class isolation boundary. A timed purge, based on bottle capacity, assures a pressure blanket will be maintained on the MCO for at least 96 hours, guaranteeing adequate operator response time.

3.2.2.6 Alarms. Safety Significant control room alarms consist of:

\section{- $\quad$ BAY * PWC LOW FLOW}

Note: This alarm serves to monitor and alarm the PWC Pre-Drain purge and Post Drain purge to preclude explosive levels of hydrogen and oxygen in the PWC receiving tanks. Manual operator action is required upon an alarm.

The system design description for the SCIC system is contained in SNF 3091. 


\subsection{COLD VACUUM DRYING FACILITY AND UTILITY SYSTEMS}

\subsubsection{System 05-1, Radiation Monitoring System (RM)}

Area radiation monitors are provided to monitor radiation levels in of the process bays and in routinely occupied or restricted access areas. The area radiation detector type is rated for medium- to high-energy gamma fields. Continuous air monitors are provided to monitor airborne radiation levels within of the process bays and within routinely occupied or restricted access areas. In accordance with HSRCM-1, Hanford Site Radiological Control Manual, they continuously monitor airborne beta and gamma radioactivity levels. Alpha monitoring is also provided by the continuous air monitors. Personnel contamination monitors are provided at entrances to the process area for personnel monitoring and contamination control. All area radiation monitors, continuous air monitors, and personnel contamination monitors provide local indication of contamination level (refer to P\&ID H-1-82243). The area radiation monitors and continuous air monitors are interfaced with the CVDF MCS. Remote indications and alarms will be displayed at the operations control stations and in the health physics technician room.

Eberline AMS- 4 continuous air monitors (alpha and beta) are located in each process bay ( 1 set at bay $1\{C A M-1311\}, 2$ sets at bays 2 through 5 \{CAM-1281, -1282, -1251, -1252, -1221, -1222, -1191, $1192\}$ ) and the tank room ( 1 set\{CAM-1321\}). A total of 10 continuous air monitors are provided. Eberline EC4-8 (with modifications) area radiation monitors (gamma) are located in each process bay ( 2 sets at bays 2 through $5,\{$ ARM-1281, $-1282,-1251,-1252,-1221,-1222,-1191,-1192\}$ ) and the tank room ( 2 sets, ARM-1171, -1172). A total of 10 area radiation monitors are provided. Five Eberline PCM-1B walk in portal monitors (one at each process bay access room, $\{$ PM-1181,-1211, $-1241,-1271$,$1301\}$; access to the tank room is controlled through the process bay 1 access room) and one Eberline PM-6A walkthrough monitor (located at the exit from the transfer corridor in room 115, PM-1151) are provided.

The radiation monitoring system requires an initial startup action and stays online during the life of the project. No maintenance activities are required during the CVDF two-year operating period. Periodic retest of the alarm circuits is required. The system design description for the radiation monitoring system is contained in SNF 3060 .

\subsubsection{System 05-2, Room Air Quality System (AQ)}

The process bay atmosphere is monitored for low oxygen with local and remote alarms via the MCS (refer to P\&IDs H-1-82243). Gas Tech oxygen monitors (eight per bay) are located in process bays 1 through 5 and in the PWC tank room (2 for the room).

The room air quality system requires an initial startup action and stays online during the life of the project. No maintenance activities are required during the CVDF two-year operating period. Periodic retest of the alarm circuits are required. The system design description for the room air quality system is contained in SNF 3060.

Eberline Instruments Company, Santa Fe, New Mexico.

Gas Tech, Incorporated, Newark, California. 


\subsubsection{System 06, Civil/Structural Systems (CIV)}

The CVDF main building consists of four process bays and a fifth skeleton bay within a single-story, steel-frame building containing a second-level mezzanine. Immediately adjacent to the process building on the west is a two-story structural steel metal building that encloses the transfer corridor, process bay support areas, and mechanical equipment room. Immediately adjacent to the process building on the south is a single-story, pre-engineered metal building that encloses administrative and change room functions. Immediately adjacent to the process building on the north is a single-story, concrete and structural steel building that encloses a process water tank room. The exterior composed of pre-stressed concrete panels for the process building and process water tank room, and composed of insulated metal panels for the transfer corridor and mechanical equipment building and administration building.

Construction material types utilized are durable, cleanable, and maintainable. The construction of the CVDF is in accordance with the Uniform Building Code and DOE Order 6430.1A, General Design Criteria, with egress requirements conforming to NFPA 101, Safety to Life from Fire in Buildings and Structures.

The recommended configuration of the CVDF requires a building footprint of approximately $12,800 \mathrm{ft}^{2}$ for the process bays and support areas and approximately $3,000 \mathrm{ft}$ for administrative and change room areas.

The occupancy of the CVDF has been identified as 20 persons. The system design description for the civil/structural systems is contained in SNF 3061.

3.3.3.1 Process Bays. Each process bay is designed to enclose an MCO cask transporter without the tractor attached. Process bay construction is designed to provide radiological separation and confinement within each bay.

The process bay building design utilizes a steel frame and prestressed concrete panel system that has a bay width of $30 \mathrm{ft}$ and a rigid steel frame system that has a nominal length of $60 \mathrm{ft}$. The height of the process bays is nominally $32 \mathrm{ft}$, which is dictated by the manned access working level of the shipping cask, the crane access to remove the cask lid, and the physical and functional requirements for all of the operations necessary in the CVDF.

Access to the process building is accomplished with a corridor that is contiguous with the main change room for radiological control of access and egress from the process area. Individual process bay access and egress control is through a change room.

3.3.3.2 Process Bay Space Requirements. Each process bay provides ground floor space for the following.

- Enclose a cask transporter without the tractor attached.

- Personnel circulation and functional space around the cask transporter.

- Vacuum drying module equipment and pump assemblies. 
- Access to the working level of the cask transporter.

- Radiological control between a process bay and the access corridor where operators change clothing and are monitored for radiological contamination prior to admittance to the access corridor.

- Bridge crane access to remove the cask lid and perform maintenance on equipment.

- A cabinet for supplies.

- Storage locker for special tools and equipment.

- Electrical panels.

- Health physics technician work table.

Access to the working level of the cask is accomplished using a mezzanine level with space for the following.

- Access to the working level of the cask transporter for connections from the vacuum drying module .

- Heating, ventilating, and air conditioning (HVAC) equipment.

- Process hood assembly.

3.3.3.3 Process Bay Support Areas. The process bay support areas serve as airlock between the controlled process bay and the uncontrolled access corridor. Functional requirements for each support areas are as follows:

- Seating space for two allowing for the dressing/undressing of special work permit clothes

- Storage of clean special work permit clothing

- Storage of dirty special work permit clothing

- Space for personnel contamination monitor equipment.

3.3.3.4 Decontamination Room. A single decontamination room serves all process bays. Access to the common change room area, is through this room. Requirements for this space are as follows:

- Clear standing space for the decontamination process

- Storage of decontamination materials and detection equipment

- One decontamination shower. 
3.3.3.5 Swipe and Count Room. A swipe and count room is provided to analyze and store samples taken from process bays or areas that have the potential for contamination. Requirements for this space are as follows:

- Desk space for preparing testing reports

- File storage of records

- Wall space for the mounting of gas bottle equipment.

3.3.3.6 Process Water Conditioning Tank Room. Water removed from an MCO has the potential for being contaminated, thus it will be stored in a tank located in an isolated room with controlled access. The process water conditioning tank room is located directly adjacent to a process bay to allow a tanker truck to enter the bay and receive the transfer of cask water liquid, after processing, from the storage tank to the tanker truck.

3.3.3.7 Deionized Water Equipment and Instrument Air Equipment Room. Approximately $120 \mathrm{ft}^{2}$ of enclosed floor space in the support area is required for the deionized water equipment and storage tank and the instrument air system equipment.

3.3.3.8 Security System Equipment Room. Approximately $120 \mathrm{ft}$ of enclosed floor space in the support area is provided for Security system equipment.

3.3.3.9 Mechanical Equipment Room. Approximately 3,000 $\mathrm{ff}^{2}$ of enclosed floor space in the support area is provided for HVAC and miscellaneous utility system equipment.

3.3.3.10 Administrative Area. Personnel access into the CVDF will be provided by the administrative area. Other functions listed below are also provided:

- Lunch/conference room

- Quality assurance and process engineer room

- Shift manager room

- Health physics technician and radiation monitoring room

- Control room

- Electrical and telecommunications room

- Fire riser room

- Men's and women's restrooms

- Men's and women's change rooms

- Access and egress control and personnel control monitoring of the process bays.

3.3.3.11 Lunch and Conference Room. A lunch and conference room is required with space for seating 12 people. Additional requirements are as follows:

- Space for refrigerator

- Casework with sink and storage.

3.3.3.12 Quality Assurance and Process Engineering Office. Provides office space for two persons performing quality assurance and process engineering duties. Work spaces contain desks and associated equipment. 
3.3.3.13 Shift Manager Office. Provides office space for one person performing shift management duties. Work space contains desk and associated equipment.

3.3.3.14 Health Physics Technician and Radiation Monitoring Room. Provides office space for onehealth physics technician performing radiation monitoring. This monitoring room provides:

- Work space with desk and associated instrumentation equipment

- Storage space for health physics technician equipment

- Wall space for the mounting of gas bottle equipment.

3.3.3.15 Control Room. Provides space for process bay control room functions:

- Computer monitoring stations

- MCS programmable logic controller cabinet space

- SCIC system annunciator and Mode control panels

- Security monitors (two) and egress alarm panel

- HVAC Control panels.

3.3.3.16 Electrical and Telecommunication Room. Provides space for electrical and telecommunication systems and equipment.

3.3.3.17 Fire Riser Room. Provides space for fire protection system alarm check valve riser and accessories.

3.3.3.18 Men's and Women's Restrooms. Restroom facilities are provided for both men and women employees. This function should be in close proximity to the respective change rooms. Restrooms provide:

- Men's toilet and urinal fixtures

- Women's toilet fixtures

- Men's and women's lavatory fixtures.

3.3.3.19 Men's and Women's Change Rooms. Change room facilities are provided for men and women employees. This function should be in close proximity to the respective restrooms. Change rooms provide:

- Men's shower facilities

- Women's shower facilities

- Men's and women's storage lockers and benches

- Space for change room supplies storage.

\subsubsection{System 11, Communications System (COMM)}

The communications system provides the operations personnel the ability to communicate within the facility for the efficient operation of the facility systems. The communications system interfaces with the $100 \mathrm{~K}$ Area communications, the Hanford Local Area Network system, and the local telephone network. The CVDF communications system consists of a voice paging system, a telephone system, and Hanford Local Area Network computer connections. 
The communications system is designed to send and receive routine CVDF operations messages between the CVDF administrative locations and the respective process and utility areas of the CVDF. In addition, the system is capable of transmitting and receiving emergency warning signals and messages to and from the $100 \mathrm{~K}$ Area alarm station. The CVDF communications system layout is shown on diagram $\mathrm{H}-1-82243$. The CVDF communication system is provided by Lockheed Martin Information Services, Incorporated in accordance with HNF-S-0403, Standard Specification for Hanford Site Telecommunications Systems and Facilities.

The voice paging system includes the following features.

a. The voice paging system is controlled from the operations control room. The system is capable of paging from the control room to the CVDF work locations. These areas include the process bays, process water tank room, transfer corridor, mechanical equipment room, administrative annex, and the external equipment pads.

b. The voice paging system is one-way. Talk-back speakers are provided only in the process bays. Wall-mounted speakers are located throughout the facility.

c. The voice paging system is able to send alarm initiation codes and public address messages to multiple remote alarm stations. Codes for evacuation and take-cover signals are included in the voice paging system code list. The voice paging system includes a voice handset or provisions for a microphone to be used for the public address function.

d. The voice paging system is able to receive and translate alarm initiation codes from the $100 \mathrm{~K}$ Area alarm station. The voice paging system will recognize the codes for evacuation and take-cover alarms and is capable of broadcasting the standard Hanford Site signals for these alarms over the speaker and/or horns. The CVDF is connected to the existing $100 \mathrm{~K}$ Area Valcom ${ }^{4}$ voice paging system.

e. The link between the $100 \mathrm{~K}$ Area emergency warning signal base station and the remote alarm station at the CVDF is a radio base station. This radio will carry modulated codes to differentiate among the different emergency signals that must be generated. Additionally, to send emergency messages, the radio is able to transmit voice signals to the speaker and/or horn at the remote alarm station at the CVDF. The remote alarm station is in the control room.

f. The sound level produced by the speakers and/or horns will be $10 \mathrm{~dB}$ above background noise in all CVDF areas covered by the system. In areas where intermittent high-noise conditions exist or normal background noise exposure requires workers to wear ear protection, flashing lights of a distinctive color will be triggered with any alarm signal or with any public address message. Provisions to reduce background noise interference are made at intercom stations in high-noise areas.

Valcom Incorporated, Roanoke, Virginia. 
The telephone system includes the following features.

a. The telephone system provides standard telephone service to the CVDF administrative annex. Outside line telephones are to be provided in the shift operations manager office (one), the process engineer and quality assurance office (two), the health physics technician office (two), the operations control room (one), the administrative annex entrance (one), and the conference room (one).

b. The intercom and voice paging systems are integrated with the standard telephone. The system is capable of paging from every station. Control of the intercom and voice paging is from the control room. Each intercom station can be individually addressed from the control room station. The intercom and voice paging systems consist of speaker phones located in each of the five process bays (two each), each of the five bay access rooms (one each), the tank room (one), transfer corridor (one), mechanical equipment room (two), at exit of the transfer corridor (one), men's change room (one), and women's change room (one).

c. A telephone with autodial features is located in each process bay, in room 126, and two are located in the control room. These telephones have outside line connections and have autodial feature to directly connect to the crash alarm system.

d. In addition to standard telephone service, a crash alarm phone is provided for the facility. A crash alarm phone system is available to operations personnel to use in relaying emergency messages. The crash alarm is located in the control room.

e. Each telephone outlet (for outside line service) includes a telephone jack and data communications jack (Hanford Local Area Network).

f. A fax machine is located in the CVDF conference room.

g. No backup up power will be required in the CVDF for the telephone system.

Hanford Local Area Network service is extended to the CVDF to support routine operations administrative activities. Hanford Local Area Network service is located in the shift operations manager's office (two), the process engineer and quality assurance office (two), the health physics technician office (one), the operations control room (one), and the conference room (one). NOTE: All telephone outlets (for outside line service) have Hanford Local Area Network service.

The communication system requires an initial startup action and stays online during the life of the project. No maintenance activities are required during the CVDF two-year operating period. The system design description for the communications is contained in SNF 3065.

\subsubsection{System 12, Instrument Air System (CA)}

The instrument air system (refer to P\&ID H-1-82222) supplies dry, filtered, oil-free instrument air at approximately 100 psig to the process equipment skid and valve and damper operators throughout the facility. This air is used to operate the spring return automatic valves, to inflate the MCO shield/seal ring bladder, and to purge the cask-MCO annulus following the cold vacuum drying operation. Instrument air at 25 psig is supplied to the HVAC system. 
The Instrument air system supplies air for pneumatic tools at 100 psig. Instrument air is required for pneumatic wrenches for removal installation of the cask lid, installation of the cask-MCO, and for the cask transporter air ride suspension operation.

The instrument air system consists of duplex two stage piston type compressors, CA-CMP-5019, a 250 gal receiver tank CA-TK-5019, pressure control valve PCV-5006, an air dryer with automatic regenerative desiccant beds CA-DRY-5020, pressure relief valve SRV-5007, low pressure alarm PAL-5008, and associated distribution piping and valves. The instrument air system has a specified rating of $(25.1 \mathrm{cfm}$ at $175 \mathrm{psig})$. Air with a $-40^{\circ} \mathrm{C}\left(-40^{\circ} \mathrm{F}\right)$ dewpoint and oil free has been specified for the air quality. The instrument air system is to be run in automatic mode continuously. Only local start and stop of the compressor is provided (no remote operation). Sufficient supply of instrument air to accommodate a four-hour compressor downtime has been specified.

The instrument air system requires an initial startup action and stays online during the life of the project. No maintenance activities are required during the CVDF two-year operating period. The system design description for the instrument air system is contained in SNF 3066.

\subsubsection{System 13-1, General Service Helium System (He)}

The general service helium system (refer to P\&IDs $\mathrm{H}-1-82160$, and $\mathrm{H}-1-83766$ ) is designed to allow control of flow or of pressure to multiple points within the process. Flowrate to the VPS is measured by $\mathrm{FE}-1 * 19, \mathrm{FE}-1 * 20$ and $\mathrm{FE}-1 * 21$. The required flowrate is sent to $\mathrm{FV}-1 * 20$ by remote setpoint from FIC $-1 * 20$ which is computed in the MCS from FE- $1 * 20$ or FE-1*21, whichever is lower. The actual injection point is He-GOV-1*12 for vacuum pump condenser input; He-GOV-1*06 and HeGOV-1*02 for MCO long dip tube inlet; He-V-*026/*063 for vacuum pump interstage purge; He-V${ }^{*} 016 / * 066$ for cask-MCO purge; He-V-*126, VPS-GOV-1*11/1*17 for PWC line purge and He-V-*026/HE-V-*071, He-V-*026/HE-V-*072, He-V-*026/HE-V-*073, and He-V-*026/HE-V-*074 for SCHe supply.

The general service helium system requires an initial startup action and stays online during the life of the project. No maintenance activities are required during the CVDF two-year operating period. Periodic changeout of depleted tube trailers is required (estimated on a biweekly basis). The system design description for the helium system is contained in SNF 3067.

\subsubsection{System 14, Cranes and Hoists (HOI)}

The CVDF has four overhead trolley cranes, one in each active process bay. The crane is utilized to remove and install the cask lid from the cask and to install and remove the process hood from the top of the cask-MCO. The cranes can also be used to assist in maintenance activities within the process bay when required. The bay 2 bridge crane is labeled HOI-520; bay 3 bridge crane, HOI-530; bay 4 bridge crane, HOI-540; and bay 5 bridge crane, HOI-550. .

The CVDF cranes have a service rating of $1,800 \mathrm{~kg}(4,000 \mathrm{lb})$. The cranes are designed in accordance with the criteria included in CMAA 74, Specifications for Top Running and Under Running Single Girder Electric Overhead Traveling Cranes Utilizing Under Running Trolley Hoist, with Class " $\mathrm{D}^{\text {" }}$ heavy service rating. The cranes are top running, single girder with capping channel. The bridge, trolley, and hoist are driven by electric motors and are capable of operation from the mezzanine level by the use of 
a pushbutton station. The pushbutton station is a three-motion, eight-button unit with a NEMA 12 rating. Controls allow hoist up or down, carrier forward or reverse, trolley forward or reverse, and crane power on or off. The pushbutton unit is permanently mounted to the mezzanine guardrail. The crane has brakes in accordance with CMAA 74. The crane has limit switches to prevent over travel of the hoist in the raise direction only. The crane has removable seismic stops which prevent the end trucks from lifting off the runway rail.

The crane is designed in accordance with performance category 3 criteria utilizing the criteria for seismic analysis and is qualified for seismic $3 / 1$ criteria in accordance with HNF-SD-SNF-DRD-002, Section 6.3.4. The crane support structure is anchored for the design basis seismic performance category 3 criteria in accordance with WHC-SD-GN-DGS-30006, Seismic Design Guide for Safety Class 3 and 4 Equipment at the Hanford Site. Lifts involving the cask-MCO equipment may be classified as critical lifts. Crane operating procedures and load testing are in accordance with DOE-RL-92-36, Hanford Site Hoisting and Rigging Manual.

The cranes require an initial startup action and stay online during the life of the project. No maintenance activities are required during the CVDF two-year operating period. The system design description for the cranes and hoists system is contained in SNF 3072.

\subsubsection{System 18, Effluent Drains System (EFS)}

Surface drains in the process areas will serve to provide spill confinement and to collect fire discharge water. All of the spill containment fire and discharge water will be routed in piping to an above ground retention basin located west of the facility (refer to P\&ID H-1-82223). The containment piping is routed from a monitoring sump, sized for $200 \mathrm{gal}$, where the spill discharge occurrence may be detected by a moisture sensor. The discharge may then be tested by plant personnel for contamination. The spill containment monitoring box has a low discharge opening to drain the sump If contamination is detected in the sump, then this water will be pumped to a storage drum by a specialty equipment pump (system 100). The drum will be transported to the $\mathrm{KW}$ basin for processing by operations personnel.

In case of fire detection, the monitoring sump has an isolation valve that will allow the high water flow of the fire sprinklers to pass through the monitoring sump into the 20,000 gal retention basin. The fire water requirement is 20 minutes of water flow at the largest area 7,200 gal. The 20,000 gal retention basin is a concrete structure with a sheet metal roof. The interior of the basin basin is coated with an enamel paint. Pump out of the basin will be performed by operations personnel.

The effluent drains system requires an initial leak test and stays online during the life of the project. No maintenance activities are required during the CVDF two-year operating period. Periodic retest of the floor sump circuits may be required. The system design description for the effiuent drains system is contained in SNF 3073.

\subsubsection{System 19, Condensate Collection System (CCS)}

Condensate from the process bay HVAC system is routed in piping to a collection tank located on the floor of the process bay. Water from the collection tanks will periodically be drained and sampled as required. If contamination is detected in the tank, then this water will be pumped to a storage drum by a specialty equipment pump (system 100). The drum will be transported to the $\mathrm{KW}$ basin for processing by operations personnel. 
The condensate collection system requires an initial leak test and stays online during the life of the project. No maintenance activities are anticipated during the CVDF two-year operating period. The system design description for the condensate collection system is contained in SNF 3074.

\subsubsection{System 20-1, Electrical Power Distribution System (EPD)}

The electrical power distribution system provides electrical power distribution for the CVDF, equipment, and instruments as required. Normal power is provided with a grounding system to ensure safety to personnel and equipment, to provide a connection to earth for transformer neutrals, to provide a discharge path to ground through lightning and surge arresters, and to provide a reference point for electronic systems.

The electrical design follows the guidelines and incorporates the following regulations and requirements. The applicable portions are included in the construction specifications:

- DOE Order 6430.1A, General Design Criteria, Division 16, "Electrical"

- NFPA 70, National Electric Code

- ANSI C2, National Electrical Safety Code

- Fire Resistance Directory.

All electrical equipment is energy efficient where applicable and available.

The design includes the extension of an overhead $13.8 \mathrm{kV}$ primary circuit from existing poles at a point adjacent to the site. The existing circuit is extended and routed overhead to a point near the south edge of the construction site. Using fused cutouts and lightning arresters, the extended overhead circuit is converted to an underground circuit to supply the new building pad-mounted transformer.

All underground primary conduit is concrete encased and buried a minimum of $2 \mathrm{ft}$ below finished grade. A conduit marking tape is provided above the underground conduit route at a depth of $1 \mathrm{ft}$ below finished grade.

A nonflammable, oil-filled, pad-mounted transformer is located on the southwest side of the facility. The transformer is sized to accommodate the electrical requirements. Secondary power at $277 / 480 \mathrm{~V}$ is routed into the building through underground conduits.

Power is distributed by a free-standing, metal-enclosed switchboard. Phase, neutral, and ground bussing is provided. The switchboard bussing has the capacity to accommodate a $20 \%$ increase in electrical demand. Switchboard main and feeder circuit breakers have adjustable solid-state trip units responsive to long-time, short-time, instantaneous, and ground-fault current characteristics.

A primary meter measuring kilowatt-hour is installed on the overhead power pole to measure power usage.

Motor loads that are not part of prepackaged equipment are powered from a $480 \mathrm{~V}$, 3-phase motor control center located in the electrical room. The motor control center is free-standing and metal enclosed with modular plug-in combination motor controllers. Assembly and wiring complies with the National Electrical Manufacturer's Association ICS Standards Type II-C. All wiring is extended to terminal 
compartments for ready access. Controllers are National Electrical Manufacturer's Association-rated and contain spare interlocks.

Panel boards for power distribution, lighting, receptacles, and small loads are constructed in accordance with Federal Specification W-P-115, Type 1, Class 1. Main circuit breakers are provided in panel boards. Panel board circuit breakers are the molded case bolt-on type.

Duplex receptacles are provided around the inside perimeter of the process bays for $120 \mathrm{VAC}$ loads. Ground fault circuit interrupting type receptacles are provided for the receptacles located within 5 $\mathrm{ft}, 0$ in. of wet surfaces and sinks as required by NFPA 70 and are located in process bays 1 through 5 and the tank room due to decontamination activities. Office areas are provided with $120 \mathrm{~V}$ duplex receptacles. Appropriate receptacles are provided for cord-connected equipment such as lunchroom equipment, computer equipment, and radiation monitoring equipment.

The design provides for installation of feeders (conduit and wire) adequately sized for equipment to be installed. Where equipment packages (e.g., the process equipment skid) have several motors or electrical loads, not all of which will operate simultaneously, the feed was sized for the loads expected to operate simultaneously.

Generally, all power and control conduits used within the facility are rigid galvanized steel, with the exception of those used in the alarm systems.

The electrical power distribution system requires an initial startup action and stays online during the life of the project. No maintenance activities are required during the CVDF two-year operating period. Periodic retest of the distribution circuits may be required. The system design description for the electrical power distribution system is contained in SNF 3075.

\subsubsection{System 20-2, Lighting System}

3.3.11.1 Interior Lighting. Interior facility lighting consists of energy-efficient fixtures typically operated at $120 \mathrm{~V}$. Lighting levels are as recommended in the Illuminating Engineering Society Lighting Handbook. High-bay area lighting consists of metal-halide fixtures when ceiling height permits good lighting design. Lighting for storage areas and mechanical areas are high-output industrial fluorescent fixtures. Other interior lighting consists of surface or flush-mounted commercial fluorescent fixtures. Multiple-level switching is generally provided for areas with fluorescent fixtures. The facility interior lighting is detailed on drawing $\mathrm{H}-1-82241$.

The interior lighting system requires an initial startup action and stays online during the life of the project. No maintenance activities are required during the CVDF two-year operating period. Periodic changeout of failed lights will be required.

3.3.11.2 Exterior Lighting System. Exterior building lighting is provided. Metal-halide, wall-mounted fixtures with photocells are installed at all exterior doors. The facility exterior lighting is detailed on drawing H-1-82241.

The exterior lighting system requires an initial startup action and stays online during the life of the project. No maintenance activities are required during the CVDF two-year operating period. Periodic changeout of failed lights will be required. 
3.3.11.3 Exit Lighting System. Exit signs are provided at the interior of each building exit. In areas where means of egress are not readily apparent, directional exit signs are provided. Exit signs include integral chargers, batteries, and relays to provide illumination automatically upon failure of the normal power source. The facility exit lighting is detailed on drawing $\mathrm{H}-1-82241$.

The exit lighting system requires an initial startup action and stays online during the life of the project. No maintenance activities are required during the CVDF two-year operating period. Periodic retest of the charging circuits are required.

3.3.11.4 Emergency Lighting System. Emergency lighting is provided inside the facility in accordance with NFPA 101. Emergency lighting in areas with fluorescent lighting is provided by use of fluorescent fixtures with integrally mounted backup battery packs with a 90-minute capacity. The facility emergency lighting is detailed on drawing $\mathrm{H}-1-82241$.

The emergency lighting system requires an initial startup action and stays online during the life of the project. No maintenance activities are required during the CVDF two-year operating period. Periodic retest of the charging circuits is required.

The system design description for the lighting system is contained in SNF 3075.

\subsubsection{System 20-3, Ground System}

A grounding electrode system is constructed in accordance with NFPA 70, Article 250. Interconnected elements include building reinforcing steel, water piping, and a concrete-encased grounding electrode. A separate equipment ground conductor is routed with all power conductors and lighting circuits. The facility grounding system is detailed on drawings $\mathrm{H}-1-82242$ and $\mathrm{H}-1-82246$.

The system design description for the ground system is contained in SNF 3075.

\subsubsection{System 20-4, Facility Uninterruptible Power Supply System}

One $30 \mathrm{kVA}, 208 / 120 \mathrm{~V}$ to $208 / 120 \mathrm{~V}$, facility UPS system is provided to assure facility systems critical to safety have continuous power supplied during and after a design basis accident. The facility UPS system is complete with battery packs, battery disconnect switch and circuit breaker, and a maintenance bypass cabinet. The facility UPS system is detailed on drawing $\mathrm{H}-1-82247$, sheet 3 . Backup power from facility UPS system UPS- 1 is provided $t$ in the case where site power is lost. All MCS programmable logic controllers, process bay remote $1 / O$ panels, operator control stations, continuous air monitors, area radiation monitors, and oxygen monitors are provided with a UPS system with a minimum of one hour run time at full load. The facility UPS is located in Room 129.

One $3.1 \mathrm{kVA}, 208 / 120 \mathrm{~V}$ to $208 / 120 \mathrm{~V}$, UPS system complete with battery packs, battery disconnect switch and circuit breaker, and maintenance bypass cabinet is provided to the security system for continuous power during but not after a design basis accident. All security sensors, cameras, and sensor and video transmission equipment is provided with a UPS system with a minimum of eight hours run time at full load. The security UPS is located in Room 126. 
The SCIC system local control panels (one each in bays 2 through 5) and annunciator panel (in the control room) do not require a UPS directly; a power conditioning device is required which is derived from a UPS device. The SCIC system UPS is provided as part of the CVDF design (H-1-82301 sheets 1 and 13). Seismic trip equipment is provided with a self-contained UPS. Design requirements are specified in HNF-SD-SNF-DRD-002.

Other backup power is provided for specific systems only by use of direct current battery systems and battery chargers. The battery backup systems are provided for:

- Fire alarm control panel (integrally mounted)

- Emergency egress and exit illumination (integrally mounted)

- Communications system (as required).

The various UPS systems require an initial startup action and stay online during the life of the project. No maintenance activities are required during the CVDF two-year operating period. Periodic retest of the UPS systems is required. The system design description for the facility UPS system is contained in SNF 3075.

\subsubsection{System 20-5, Lightning/Surge Protection System}

Lightning and surge protection is provided for the building using pole-lined mounted lightning arresters as detailed on diagram $\mathrm{H}-1-82095$. The lightning/surge protection system complies with all requirements of the latest edition of NFPA 780, Lightning Protection Systems, and NFPA 70. The lighting/surge protection system is passive and thus requires no startup activities. The system design description for the lightning/surge protection system is contained in SNF 3075.

\subsubsection{System 24, Fire Protection System (FPS)}

The CVDF fire protection water system (refer to drawings H-1-82092, H-1-82094, H-1-82237 to $\mathrm{H}-1-82240$, and $\mathrm{H}-1-82244$ ) includes the required isolation valves, two fire hydrants, a post indicator valve, and supervisory functions. The transfer line to the CVDF FPS supply water is an 8 in. diameter polyvinyl chloride main service line which originates in the $165-\mathrm{KW}$ cross tie tunnel. A 6 in. diameter building service line is connected to the new main service to supply the building sprinkler system ( $\mathrm{H}-1-82237$ to $\mathrm{H}-1-82240$ ). The CVDF fire protection alarm system is detailed on drawing H-1-82244. The fire alarm control panel and radio fire alarm reporter are located near the main building entrance as depicted on drawing $\mathrm{H}-1-82244$.

The fire protection system requires an initial startup action and stays online during the life of the project. No maintenance activities are required during the CVDF two-year operating period. The system design description for the fire protection system is contained in SNF-3077.

\subsubsection{System 25, De-Ionized Water System (DI)}

Deionized water is supplied to the process via a package deionized water unit (refer to P\&ID $\mathrm{H}-1-82222$ ). The deionization unit is sized for a minimum flow of $5 \mathrm{gal} / \mathrm{min}$. The unit is located in the process access area storage room. The system shall contain two deionization tanks, a holding tank, and a pump. Water received from deionized tanks will be recirculated through the holding tank on a continuous basis. 
The deionized water system requires an initial startup action and stays online during the life of the project. Maintenance of the system will be contracted to the supplying vendor. The system design description for the deionized water system is contained in SNF-3078.

\subsubsection{System 26, Potable Water System (PW)}

Potable water is supplied to the CVDF from the existing $100 \mathrm{~K}$ Area sanitary water loop on the west side of $165-\mathrm{KW}$. The sanitary water service main is a 2 -inch diameter copper or polyvinyl chloride pipe. Backflow preventers and pressure-reducing valves are inside the CVDF (refer to P\&ID H-1-82222). Potable water feeds the administrative building plumbing fixtures in standard copper piping. The potable water also feeds two residential-type 52-gal hot water heaters to provide adequate hot water for the four showers (hot potable water). The potable water supplies the process deionized water unit via a reduced pressure backflow preventer and the chilled water makeup connection (non-potable water). All potable water lines are insulated.

The potable water system requires an initial startup action and stays online during the life of the project. No maintenance activities are required during the CVDF two-year operating period. The system design description for the potable water system is contained in SNF-3079.

\subsubsection{System 27, Sanitary Sewage Collection System (SANS)}

Sanitary sewage from the CVDF is gravity drained to a 5,000-gal underground holding tank located west of the building (refer to P\&ID H-1-82222) and has a fluid level sensor. The pipe material is polyvinyl chioride or acrylonitrile-butudiene-styrene, except where exposed, which is galvanized. The holding tank is to have the capacity to store three days of sanitary water with maximum occupancy of the facility. The tank is expected to be pumped by using a pumper truck designed for such purposes.The sanitary sewage collection system requires an initial startup action and stays online during the life of the project. The system design description for the sanitary sewage collection system is contained in SNF3080 .

\subsubsection{System 30-1, Administration Building Heating, Ventilating, and Air Conditioning System (HVACA)}

The Administration Building is conditioned with air from a dedicated air handling unit for this area (refer to P\&ID H-1-82195). Air is recirculated in this system with a minimum of make-up air to maintain air quality and provide air for the change room and shower area exhaust system. Air from the change room and shower areas is exhausted directly to the outside and is not recirculated. To prevent possible contamination, air in the room connecting the administration area to the transfer corridor is not recirculated but is directed toward the transfer corridor and the HEPA filtered general exhaust system. The HVAC control system is located in the CVDF control room which provides alarm and monitoring of all HVAC functions according to the detailed HVAC operational control description included in SNF-3081. The system design description for the Administration Building HVAC system is contained in SNF-3081.

\subsubsection{System 30-2, Process Bay Recirculation Heating, Ventilating, and Air Conditioning System (HVACB)}

Each process bay is served by an independent supply air system which filters and conditions the supply air (refer to P\&ID H-1-83769). A majority of the bay air is recirculated to conserve energy. The 
supply and return air passes through a prefilter and two HEPA filter stages to control contamination. Make-up air is supplied, as required, to maintain air quality in the bay and to provide air for the local exhaust system. Each process bay air intake system is provided with a confinement isolation damper and backdraft damper to prevent backflow of air to the outside. The HVAC control system is located in the CVDF control room which provides alarm and monitoring of all HVAC functions according to the detailed HVAC operational control description The system design description for the process bay recirculation HVAC system is contained in SNF-3081.

\subsubsection{System 30-3, Process Bay Local Exhaust Heating, Ventilating, and Air Conditioning and Process Vent System (HVACC/PV)}

A local exhaust system is provided to serve all of the process bays (refer to P\&ID H-1-83769). This system serves the MCO process hoods and the process system exhaust and vent streams that may be normally contaminated. Confinement isolation dampers are provided on all duct branches connecting to the hood system to prevent back flow in the event of system shutdown. The process vents are opened to the HEPA filters during operation and in the event the system shuts down. Fully redundant exhaust fans are provided for the process bay local HVAC and process vent exhaust system. The air in this exhaust system passes through an air handling unit (located in the mechanical equipment room) containing a prefilter and two HEPA filter stages before exhausting through the stack.

The process vent system is part of an integrated, multi-zone HVAC venting system (refer to P\&IDs H-1-83766 and H-1-83769). The process vent system removes offgas from the process equipment skid and PWC system skid equipment, and provides a sweep function for the process vent hood located on the top of the MCO.

The process bay local exhaust HVAC and process vent system require an initial startup action and stays online during the life of the project. No maintenance activities are required during the CVDF two-year operating period. The HVAC control system is located in the CVDF control room which provides alarm and monitoring of all HVAC functions according to the detailed HVAC operational control description. The system design description for the process bay local exhaust HVAC and process vent system is contained in SNF-3081.

\subsubsection{System 30-4, Process General Supply/Exhaust Heating, Ventilating, and Air Conditioning System (HVACD)}

The transfer corridor, associated support rooms, the tank room, and the mechanical room are supplied with conditioned air from the process general supply/exhaust HVAC system (refer to P\&ID H-183769). The air in this system is not recirculated. Confinement isolation dampers are provided on the outside air intake and tank room supply duct to prevent backflow of air in the event of system shutdown.

Each process bay is served by the process general supply/exhaust HVAC system (refer to P\&ID H1-83769) with sufficient capacity to ensure adequate controlled ventilation flow as required to contain contamination in the event of a credible breach in the secondary confinement barrier (process bay local exhaust system). The system controls exhaust air flow and maintains a negative pressure differential in the process bays with respect to all other areas external to the secondary confinement barrier. Air from the transfer corridor, associated support rooms, the tank room, and the mechanical room is also exhausted into the process general supply/exhaust HVAC system. Confinement isolation dampers are provided on all duct branches connecting to the general exhaust system to prevent backflow in the event of exhaust system 
shutdown. Fully redundant exhaust fans are provided for the system. The air in the system passes through a prefilter and two HEPA filter stages before exhausting through the stack. The HVAC control system is located in the CVDF control room which provides alarm and monitoring of all HVAC functions according to the detailed HVAC operational control description located in SNF-3081. The system design description for the process general supply/exhaust HVAC system is contained in SNF-3081.

\subsubsection{System 30-5, Reference Air System (RA)}

The pressure in the process bays and the PWC system tank room are maintained at a negative pressure with respect to the remainder of the CVDF by the general and local exhaust systems. The reference air system consists of a series of static differential pressures sensors, located throughout the CVDF (refer to P\&ID H-1-82207), that are interconnected by copper tubing. The reference pressure is measured from shieided static pressure sensor RA-BAF-001 located above the administration building roof. Each process bay pressure differential is monitored on PDI-8*20; in the tank room on PDI-8080; in the transfer corridor and access rooms on PDI-8073 through PDI-8078; in the mechanical equipment room on PDI-8070; and in the administration access corridor on PDI-8079. The HVAC control system monitors all reference air pressures. The nominal setpoints are that the process bays are $-0.20 \mathrm{in}$. water gauge, tank room is -0.25 in. water gauge), transfer corridor access rooms are $-0.15 \mathrm{in}$. water gauge, the transfer corridor and mechanical equipment rooms are -0.10 in. water gauge, and the administration access corridor is 0.01 in. water gauge.

The reference air system requires an initial startup action and stays online during the life of the project. No maintenance activities are required during the CVDF two-year operating period. The system design description for the reference air system is contained in SNF-3081.

\subsubsection{System 47-2, Tempered Water Cooling System (TWC)}

The tempered water cooling system (refer to P\&ID $\mathrm{H}-1-83768$ ) is used to supply cooling water at $10^{\circ} \mathrm{C}\left(50^{\circ} \mathrm{F}\right)$ and $20 \mathrm{gal} / \mathrm{min}$ to tempered water system cooler TW-CLR-3*10. The system cools the tempered water recirculation loop during the cask-MCO cooling operational phase. The cooling water source is a closed water loop supplied by heat exchanger TWC-HX-7051 and pumps TWC-P-7058 and TWC-P-9 (refer to P\&ID H-1-83768). The facility chilled water system removes the heat from the closed loop. The chilled water supply for the tempered water cooler is supplied by an intermediate cooling loop interfaced with the facility chilled water system through a process heat exchanger. The intermediate loop consists of a circulation loop with spare pumps. The system is designed to remove $73 \mathrm{~kW}$ $(250,000 \mathrm{Btu} / \mathrm{h})$. The cooling circuit provides cooling to the MCOs in each of the four process bays at any given time. The system design description for the tempered water cooling system is contained in SNF3085 . 


\subsubsection{System 47-3, Chilled Water System (CHW)}

The chilled water system (refer to P\&ID H-1-83766) serves the cooling coils in the process bay recirculation HVAC system and the process general supply/exhaust HVAC system and serves the process heat exchanger for tempered water cooling. The chilled water distribution system has two fully redundant pumps. Two-way control valves are used on each cooling coil distribution loop.

The chilled water refrigeration sub-system is comprised of two partially redundant, split system, air-cooled water chillers with remote condensing units. Each chiller has a dedicated primary pump, piped in parallel to provide standby protection. The refrigerant system incorporates a chiller sequencing controller, staged compressors, bypass flow line, and back pressure valves to accommodate varying chilled water demand. This system interfaces directly with the chilled water system.

The chilled water system requires an initial startup action and stays online during the life of the project. No maintenance activities are required during the CVDF two-year operating period. The system design description for the chilled water system is contained in SNF-3086.

\subsubsection{System 47-4, Vacuum Purge System Chilled Water System (VPSCHW)}

The VPS chilled water system (refer to P\&ID H-1-83767) is used to supply chilled water at $2{ }^{\circ} \mathrm{C}$ $\left(35^{\circ} \mathrm{F}\right)$ and $4 \mathrm{gal} / \mathrm{min}$ to VPS condenser VPS-COND- ${ }^{*} 13$ and VPS condenser rundown tank cooling jacket VPS-CLR-2*17 (refer to P\&ID H-1-83766). The system condenses water during the vacuum pumping operational phase and dries the gas stream during the gas purge or recirculation operational phase. FCV-2*01 controls the flow at $4 \mathrm{gal} / \mathrm{min}$ without MCS intervention. The chilled source is a closed loop water/propylene glycol loop supplied by VPSCHW-CHR-7075. The chilled water supply for the VPS condensers is a dedicated, low-temperature chiller (one chiller package for the four process bays, no redundancy). This chiller is capable of supplying $13.2 \mathrm{~kW}(45,000 \mathrm{Btu} / \mathrm{h})$ of $1.5^{\circ} \mathrm{C}\left(35^{\circ} \mathrm{F}\right)$ water to all condensers. A total of $4 \mathrm{gal} / \mathrm{min}$ is available to each process bay.

The VPS chilled water system requires an initial startup action and stays online during the life of the project. No maintenance activities are required during the CVDF two-year operating period. The system design description for the VPS chilled water system is contained in SNF-3087.

\subsubsection{System 50, Stack Monitoring System (SM)}

The stack monitoring system is a Gaseous Effluent Monitoring System (GEMS), microprocessorbased particulate and iodine monitor, and particulate and iodine collector mounted in a two-component, open-frame skid and cabinet assembly. The primary purpose of the system is to collect particulate and iodine effluent on fixed media for later laboratory analysis and documentation of emissions. The stack monitoring system is also designed to monitor real time alpha and beta particulate and iodine-129 gamma radiation effluent in the CVDF HVAC ventilation exhaust stack. The system provides early warning of out-of-ordinary emissions to plant personnel. Visual digital and alarm indications and contact output for remote alarms are provided for high radiation and failure conditions. Analog and digital outputs are provided to the MCS. A computer data logging system is provided to record monitored functions for later download as appropriate. 
The stack monitoring system consists of an open frame skid and cabinet with a sample probe subassembly. The stack monitoring system is comprised of the following subassemblies:

a. Stack sample probe assembly and piping

b. Sampler skid assembly with record sampler and alpha, beta, and gamma monitors

c. Redundant sample pumps

d. Auxiliary instrumentation including stack flow rate and temperature and sample flow rates

e. Control console with electrical power interface, microprocessor, and MCS interface

f. Local alarm indication.

The stack monitor skid is located in the CVDF mechanical equipment room near the exhaust stack. Piping to and from the stack to the skid is routed in a structural steel support assembly. The system design description for the stack monitor system is contained in SNF-3088.

\subsubsection{System 54, Security System (SEC)}

The security system for the CVDF shall contain security sensor, closed circuit television, and access control sub-systems. The system's main purpose is to protect the special nuclear materials during processing. In addition, the system will be utilized by operations to support reduced personnel radiation and possible contamination goals (as low as reasonably achievable) and provide controlled access throughout the facility. Security access system, components, installation, and testing shall meet the applicable requirements of NFPA 70.

The system has been designed by and will be installed by B\&W Protec, Incorporated, Security Engineering and Maintenance. The security access system shall be tested before acceptance of the installed system with an acceptance test procedure provided by B\&W Protec, Incorporated and performed by the contractor. The system design description for the security system is contained in SNF-3089.

\subsubsection{System 93-1, Monitoring and Control System (MCS)}

The MCS consists of a total of three control room computers, two operator workstations, and one engineering workstation. A fourth computer station is provided as a supervisor station in the manager's office. The main programmable logic controller control panel is also located in the control room and includes a local alarm and silence button. The remotely controlled $1 / O$ modules with termination panels are located in the bays (four), mechanical room (one), and the PWC tank room (one).

The operator interfaces are object-oriented color graphic displays on computer screens. All central processing units are connected on a local area network, which allows simultaneous access to the control system from multiple graphic displays. The field-mounted remote $1 / O$ modules are individually controllable from the central control room. 
5):

The MCS interfaces with the following processes in each of the four process bays (bays 2 through
- General service Helium system (He)
- Tempered Water system (TW)
- Vacuum and Purge system (VPS)
- Deionized water system (DI)
- Process Water Conditioning system (PWC).

In addition, the MCS receives signals from the SCIC system and, under normal circumstances, is allowed to control MCO isolation valves used by the SCIC system. The SCHe system isolation valves are not controlled by the MCS but are directly controlled by the SCIC system. The SCIC system does not require the support or operability of the MCS to perform its required functions. The MCS will also interface with the CVDF utility systems excluding HVAC and Chilled Water. This includes radiation monitoring, stack monitoring, tempered water cooling, VPS chilled water, PWC, and instrument air. The system design description for the MCS is contained in SNF-3090.

\subsubsection{System 100, Specialty Equipment}

Several items of specialty equipment are required to operate the CVDF. The following is a list of known specialty equipment that are required to operate the process. This list is not intended to be all-inclusive, nor does it identify all necessary components for maintenance of the process skids or facility.

a. PWC Transporter and Water Tank. A truck and tanker shall be used to transport conditioned water from CVDF to the K Basins IWTS. The truck and tanker will be a part of the IWTS project.

b. PWC Sample Bottle Cask. A shielded cask is required to store and transport samples from the PWC system.

c. Swipe Count Pigs. Swipe count pigs are supplied in each process bay for measuring contamination levels on the MCO and cask.

d. DI Cask Annulus Refill Jumper. A jumper is required for each bay to allow refilling of the Cask annulus with deionized water for emergency recovery purposes.

e. Cask Trailer Bumper. Cask. Trailer Bumper is supplied in each process bay for locating the cask trailer within proper tolerances.

f. Cask Trailer Wheel chocks. Cask Trailer wheel chocks are supplied in each process bay for chocking the trailer wheels.

g. Cask Lid Lift Fixture. A lifting fixture is provided for each bay to remove the cask lid before the installation of the process hood seal ring.

h. Cask Lid Storage Fixture. A storage fixture is provided for each bay to storing the cask lid after removal from the cask. Features will be included to allow the decontamination of the lid and for lid seal replacement, if necessary. 
i. Cask Truck Exhaust Elephant Trunk. A flexible trunk is supplied for each bay to prevent the exhaust fumes from the cask truck from entering the process bay during delivery or removal of the cask transport trailer.

j. Cask Transporter Air Supply Glad Hand. A pneumatic hose with quick-connect on one end and glad hand and control valve compatible with the cask transport trailer is supplied in each bay. The hose shall be connected to the building's instrument air system.

k. Cask Venting/Purging Equipment.

1. Process Hood Lift Fixture. A lift fixture is supplied in each bay to install and remove the process hood-seal ring to the cask.

m. PWC Tank Room Hatch Lifting Fixture. A lifting fixture is supplied for the PWC tank room hatch.

n. PWC IXM Lifting Fixture. A lifting fixture is supplied for the removal and installation of the IXMs.

o. PWC IXM Lifting Crane. A portable crane is supplied for the removal and installation of the IXMs.

p. Floor Drain Radiation Monitor. A portable radiation. monitor is supplied to monitor the process bay floor drains for radiation.

q. RGM Calibration Equipment. A portable calibration cart is supplied for the periodic calibration of the RGAs .

r. Storage Lockers for Special Equipment and Tools. Storage lockers are required in each process bay for storage of various tools and equipment.

\subsubsection{System 101, Special Tools}

Several items of special tools are required to operate the CVDF. The following is a list of known special tools that are required to operate the process. This list is not intended to be all-inclusive, nor does it identify all necessary components for maintenance of the process skids or facility.

a. Cask Lid Bolting Torque Wrench and Sockets. A torque wrench with extension and sockets for the cask lid bolts is provided for each bay. Various socket sizes, wrenches, and pneumatic tools will be available for use in each bay.

b. Cask Lid Bolting Torque Wrench Calibration Standard. A torque wrench calibration standard is to be provided at the CVDF for periodic calibration of the cask bolting torque wrenches.

c. Cask Drain Port Tools. Tools are provided for each bay to remove and install the cask drain port cover and to install the tempered water lower cask port connection. 
SNF-2356 Rev. 1

d. Cask Vent Port Tool. A tool is supplied for each bay to remove and replace the cask vent port.

e. MCO Process Port Cover Removal and Installation Tool. A tool is supplied for each bay to remove and install the MCO process port covers (torque wrench and sockets).

f. MCO Process Port Connector Installation Tool. A tool (torque wrench and sockets) is supplied for each bay to remove and install the MCO process port connector and to open and close the $\mathrm{MCO}$ port plugs.

g. PWC and Vacuum Pumping System Process Skid Tools. Tools, other than standard, required for the maintenance of the PWC system and VPS and TWS are supplied with the equipment.

h. HEPA Filter Changeout Tools. Tools, other than standard, required for the removal of the HEPA filters from the filter housings is supplied with the equipment.

i. Instrumentation and Controls Calibration Tools. Calibration tools are supplied to verify and recalibrate instrumentation.

\subsection{COLD VACUUM DRYING SYSTEMS OPERATIONS OVERVIEW}

NOTE: In the following descriptions an asterisk (*) will appear in the second digit of a component or instrument tag number. The asterisk denotes the CVDF bay number in which the component or instrument will reside (e.g., DI-GOV-1*01 represents valves DI-GOV-1201, DI-GOV-1301, DIGOV-1401, and DI-GOV-1501 in bays 2 through 5, respectively). All components or instrument tag numbers with a zero in the second digit will reside in a common area within the CVDF. An asterisk in the first numerical digit of a piping line number has the same connotation.

The normal operations process system is shown in the block flow diagrams, Figures 3-1 through 34, process flow diagram (H-1-82166), and P\&IDs ( H-1-83766). The following describes the operating sequences that will activate the functions embodied in the P\&IDs. Note, indicated process step duration times are estimates based on a nominal $\mathrm{MCO}$. Times are shown in both critical path time and time to complete step, ex. $(25 / 100 \mathrm{~min})$, since all or portions of the step can be performed in parallel or "offline". Definitive estimates will be provided during Pre-operational testing and the Process Validation operation. 
SNF-2356 Rev. 1

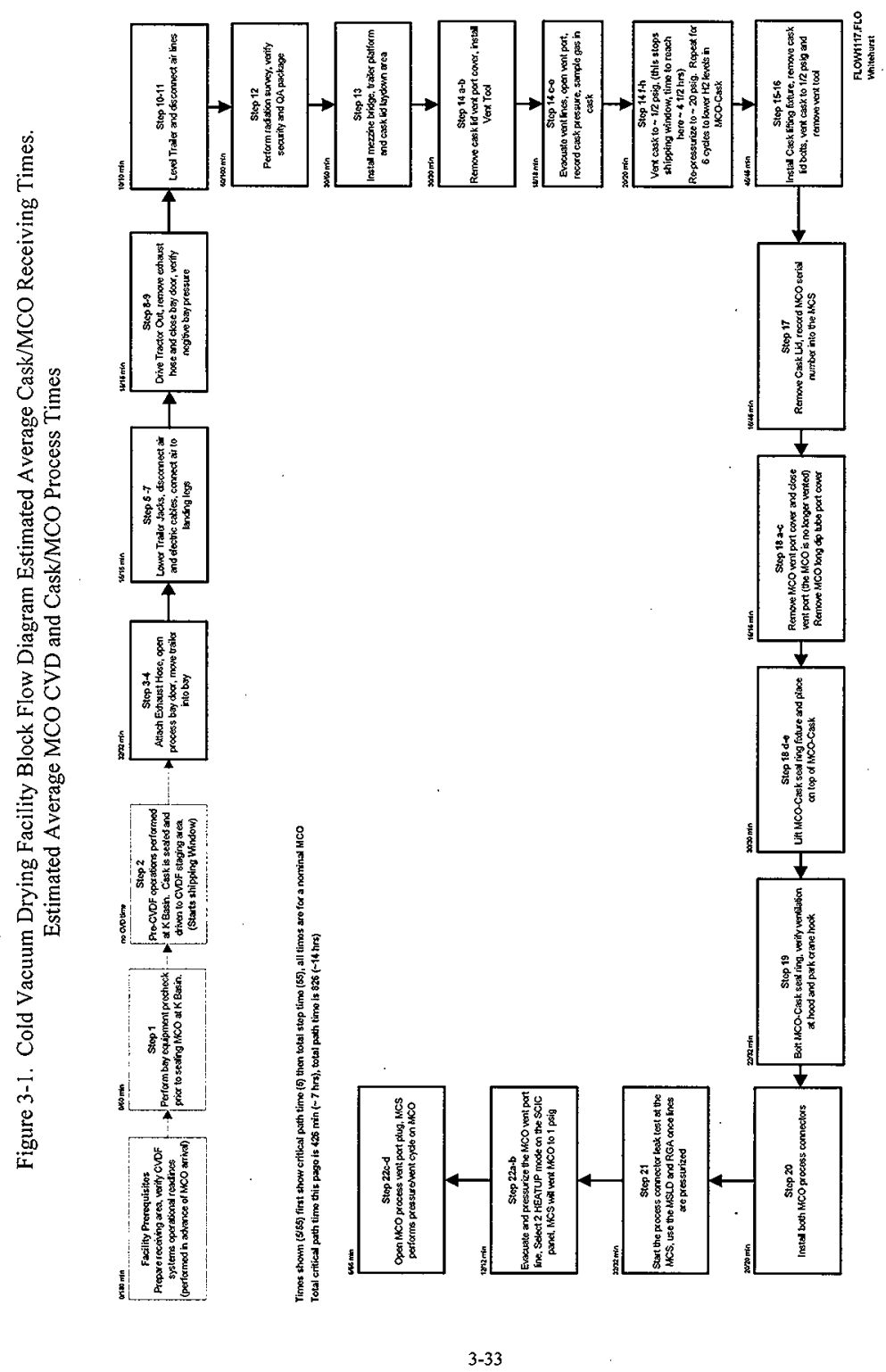


SNF-2356 REV.1

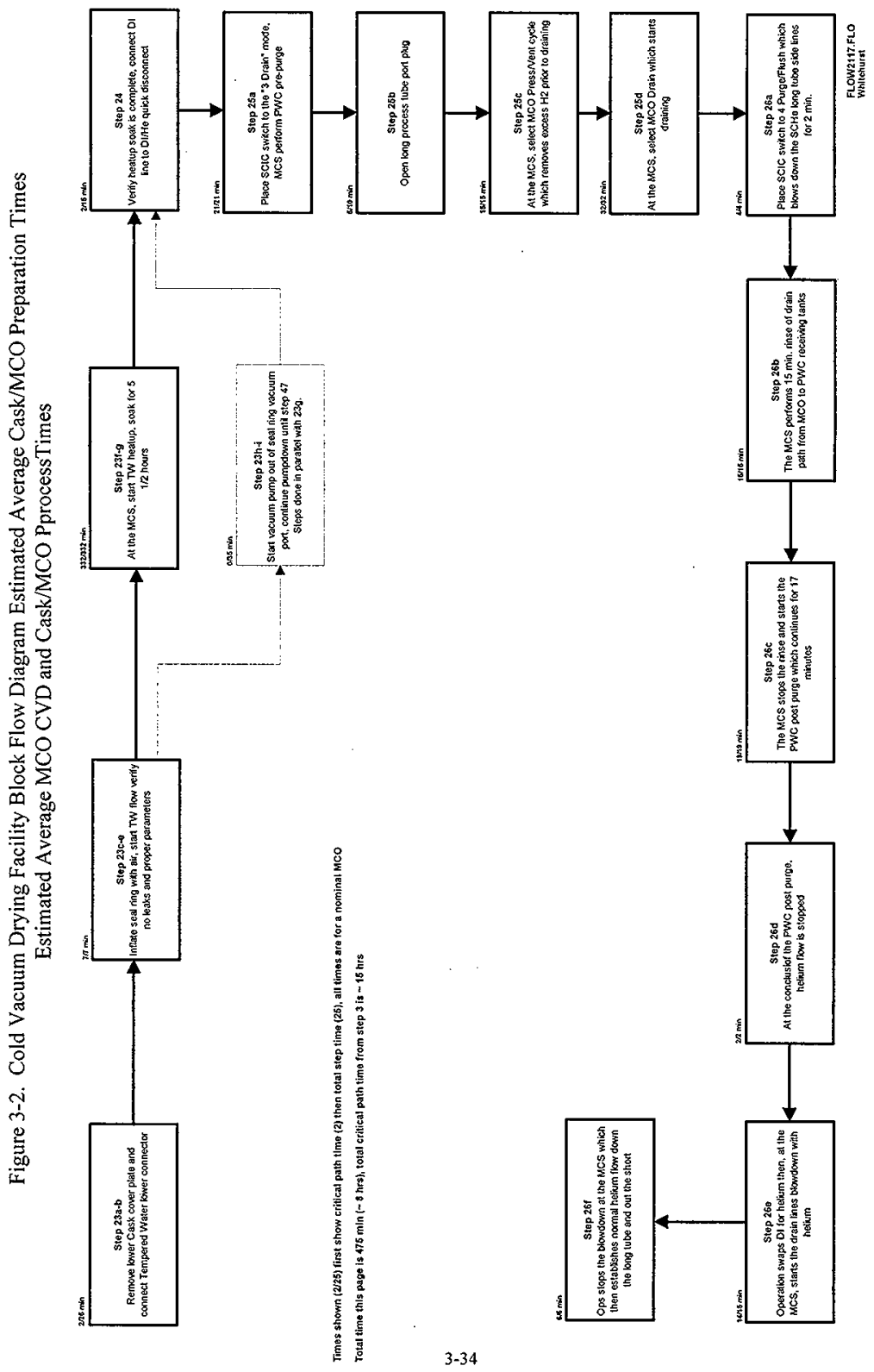


SNF-2356 REV. 1

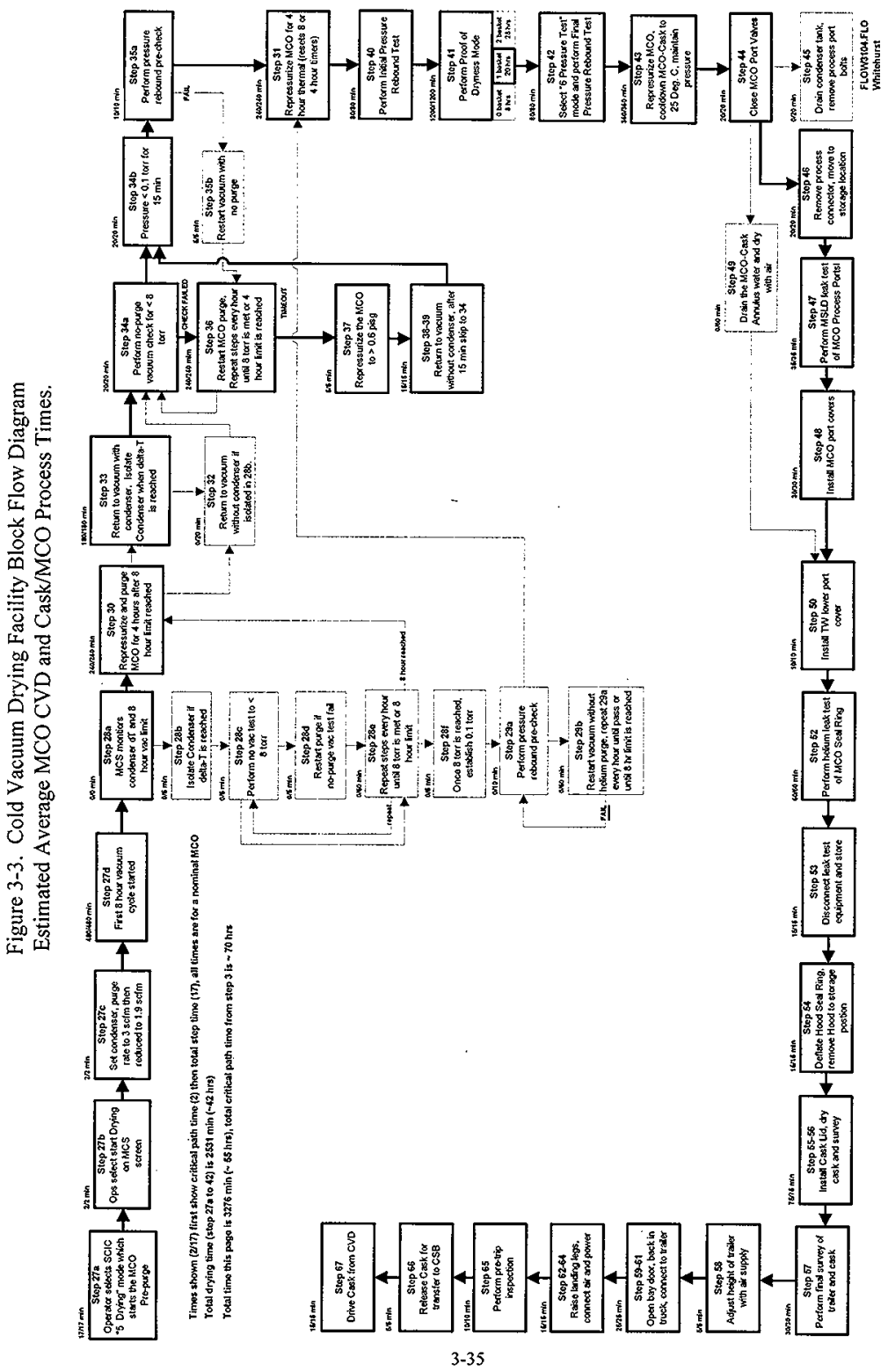




\subsubsection{Cold Vacuum Drying Facility Prerequisites for the Cask-Multi-Canister Overpack Transporter Receipt Operation and Normal Cold Vacuum Drying Process Operation}

The following activities must be completed prior to receipt of a cask-MCO from the $\mathrm{K}$ Basins and before initiation of normal cold vacuum drying operation.

- Prepare cask transporter receiving area at the CVDF for cask and trailer receipt. Remove any obstacles and lay fire retardant plastic sheeting on floor surfaces (if required) to minimize spread of contamination.

- Verify that the electrical systems are operational.

- Verify that the process bay crane and telescoping door are operational.

- Verify that the instrument air system is operational.

- Verify that the general service helium system (with two tube trailers) is operational.

- Verify that the deionized water system is operational.

- Verify that the HVAC, reference air, and stack monitoring systems are operational.

- Verify that the chilled water, tempered water cooling, and VPS chilled water systems are operational.

- Verify that the MCS is operational.

- Verify that the radiation monitoring and room air quality systems are operational.

- Verify that the fire protection system is operational.

- Verify that the communications system is operational.

- Verify that the security system is operational.

- Verify that the tempered water (annulus) system is leak tight and operationally ready.

- Verify that the SCHe system is operationally ready.

- Verify that the SCIC system is operationally ready with the mode switch in the BYPASS position.

- Verify that the PWC and contaminated water sampling and analysis system are operationally ready.

- Verify that the process hood/seal ring, and VPS connectors are operationally ready.

- Verify that the VPS is operationally ready. 
SNF-2356 Rev. 1

- Verify that the helium MSLD and auxiliary vacuum system is operationaily ready.

Time to complete operation: $0 / 180$ minutes.

\subsubsection{Cask-Multi-Canister Overpack Transporter Receipt Operation}

\subsubsection{Bay Equipment Pre-check(SCIC in 1 BYPASS mode)}

1. Perform the following prerequisites prior to authorizing the shipping of a $\mathrm{MCO} / \mathrm{Cask}$ from K Basins.

a. Verify that both the process connectors are bolted to the hood seal ring storage location. This allows bypass flow to test the VPS and Hood components.

b. Verify the SCIC Mode switch for this bay is in the "1 BYPASS" position in the control room.

c. At the MCS start the "BAY PRE-TEST" which will:

- Evacuate and pressurize all VPS lines to remove air from the lines

- Re-pressurize the VPS process lines to the helium source pressures of 20 and 4 psig.

- Perform vacuum pump down performance test .

- Verify remotely operated bay valves cycle properly by opening then closing one valve at a time (NOTE: PWC-GOV- $1 * 30,-1 * 03$ and VPS$2 * 16$ are interlocked closed if any other bay is using the PWC through MCS controls. The MCS will indicate this status on all other bay screens.)

- Verify proper RGM operation and corresponding display on the MCS screen

- Perform full vacuum (base pressure $<0.1$ torr), pressure rise test to detect in leakage. Run system without condenser, close VPS-GOV $2 * 07$ when at full vacuum and monitor pressure rise. Note: This is a gross check for leakage.

- Verify proper flow control verifying proper flow indication on FI $1 * 20$ and $1 * 21$ for both $1.9 \mathrm{scfm}$ and $10 \mathrm{scfm}$ on FIC $1 * 20$. Route flow through PCV $2 * 37$ and verify pressure control at $1 \geq 0.2$ psig on PI $2 * 08$. (He-GOV-1*02, He-GOV- $1 * 06$, VPS-GOV- $1 * 09$, VPS-GOV-1*05, VPS-GOV-2*03 and VPS-GOV-2*04 open)

- Verify $4 \pm 0.2$ psig pressure control when TBD-PCV $1 * 27$ is in-line and VPS-PCV $2 * 37$ is isolated.

- Verify condenser cooling is operational (FI 7078 and TI $2 * 35 / 2 * 36$ )

- Perform facility system checks including DI, IA, He, TWC, HVAC, Security, CHW, etc. (NOTE: Only some of the indications necessary to confirm operational status are available to the MCS, the MCS will verify these are within limit. For all others, a walk down is required. 
- Remove the helium line (if connected) from VPS-GOV $1 * 11$ and install the DI line from DI-GOV $1 * 01$

Time to complete operation: $0 / 60$ minutes.

VPS VALVE LINEUP: All process GOVs closed.

\subsubsection{Cask Transporter Operations. (SCIC in 1 BYPASS mode)}

2. Verify that the cask is placed on the transporter at the $\mathrm{K}$ Basins loadout area, pressurized with helium cover gas, and ready for transport. The MCO will contain SNF covered with water; there will be a helium cover gas over the water. The MCO process vent port will have been opened at the $\mathrm{K}$ Basins to vent the MCO to the cask headspace. The cask annulus will contain water (derived from the $\mathrm{K}$ Basins integrated water treatment system discharge into the basin load out pit). Verify that the CVDF is ready to receive a cask. Perform health physics surveys at K Basins of cask, transporter, and related equipment for the as low as reasonably achievable (ALARA) program and to verify that the external surfaces of the cask and transporter do not exceed contamination limits. Verify the quality assurance package is complete and a copy is given to the truck driver. Drive the cask transporter to the CVDF staging area at east side of the CVDF and back the transporter into position in front of the required process bay (determined by the CVDF shift operations manager).

Time to complete operation: 0 CVDF minutes.

\subsubsection{Positioning and Preparing the Trailer for the Cold Vacuum Drying Process. (SCIC in 1 BYPASS mode)}

3. Perform the followings steps for the trailer:

a) Retrieve exhaust trunks from the CVDF storage locker then install the trunks onto the tractor exhaust

b) Open the process bay door

c) Back loaded cask trailer into facility until it rests against trailer stops at the back of the bay. The trailer is to be located within \pm 4 in. of the longitudinal centerline and $0.5 \mathrm{in}$. of the lateral centerline (restrained by the trailer stops).

d) Verify that center of cask is centrally located with respect to the CVDF floor markings.

Time to complete operation: $30 / 30$ minutes.

4. Set the tractor brakes only. Shut off the tractor engine.

Time to complete operation: 2 minutes. 
5. Lower the trailer hydraulic jacks until the weight of the trailer is lifted off the tractor. Release the fifth wheel

Time to complete operation: $5 / 5$ minutes.

6. Disconnect the tractor air lines and electrical cable from the trailer and disengage trailer.

Time to complete operation: $5 / 5$ minutes.

7. Connect the building air supply to the landing leg air supply glad hand using the CVDF instrument air flexline and mating glad hand.

Time to complete operation: $5 / 5$ minutes.

8. Start the tractor engine. Release the tractor brakes and drive tractor forward then close the door and remove the exhaust trunks.

Time to complete operation: $10 / 10$ minutes.

9. Verify that the process bay ventilation system achieves the required negative pressure.

Time to complete operation: $5 / 5$ minutes.

10. Retract trailer jacks to level trailer from front to back.

Time to complete operation: $5 / 5$ minutes.

11. Disconnect the glad hand from landing leg.

Time to complete operation: $5 / 5$ minutes.

12. a) Utilizing the CVDF portable radiation meters, perform radiation surveys

b) Post the exposure rates

c) Verify accountability

d) Verify that the security system is in place

e) Verify quality assurance package acceptability.

Time to complete operation: $60 / 100$ minutes.

13. a) Install the mezzanine bridge

b) Configure work platform hand rails (removable sections)

c) Prepare the trailer work platform and cask lid laydown area for work (lay down contamination control covers).

Time to complete operation: $30 / 60$ minutes. 


\subsubsection{Cask Preparations for Cold Vacuum Drying - Cask Venting (SCIC in 1 BYPASS mode)}

During this operation the MCO will contain SNF covered with water, the nominal temperature of the MCO-SNF will be $13^{\circ} \mathrm{C}$.

14. a) Remove cask lid vent port cover using CVDF-provided wrenches. Store cover plate in storage box to protect it from loss and damage.

b) Install vent equipment including special tool (containing flow orifice), isolation valve, local pressure gauge, sample cartridge, process purge line (He-*02-ST-1/4"), process vent line (PV-*04-ST-1/4), and auxiliary vacuum source to the cask lid vent port equipment.

Time to complete operation steps $14 a, 14 b: 30 / 30$ minutes.

c) Evacuate the vent line and sample cartridge, isolate the vacuum source

NOTE: The next step opens the Cask vent port to the vent tool. The cask pressure is an indication of thermal changes from the basin but may also be an indication of highly reactive fuel in the $\mathrm{MCO}$. Caution should be taken when opening the connection to the cask. Trends will be made for the Cask pressure upon receipt in the MCS for comparison.

d) Open vent port connection and record cask pressure from PI-1*32 into the MCS.

e) Verify PI- $1 * 32$ is less than 45 psig, if not, stop work until this condition is reviewed. Take a gas sample using the sample cartridge (open and then isolate the sample cartridge using PV-V-*109). Send the sample cartridge to lab for later analysis and trending. The sample results are not required to continue with PWC transfers.

Note: Gas samples may only be required for the first group of MCOs processed during the validation program.

Time to complete operation steps $14 \mathrm{c}-14 \mathrm{e}: 18 / 18$ minutes.

f) Open PV-V-*068 to vent the Cask to $\sim 0.5 \mathrm{psig}$, verify reading on local pressure gauge, $\mathrm{PI}-1 * 32$.

g) Open system isolation valves He-V-*016 and He-V-*066 to supply helium to the cask, nominally 20 psig

h) Close and reopen PV-V-*068 an additional six times then close PV-V-*068.

Time to complete operation steps $14 \mathrm{f}-14 \mathrm{~h}$ : $20 / 20$ minutes. 
15. Retrieve cask lid lifting fixture (CVDF-provided design) from the CVDF process bay storage location and attach to the CVDF crane. Translate lift fixture to the cask lid and attach to lid lifting trunnions installed on the cask lid.

Time to complete operation: $15 / 15$ minutes.

\subsubsection{Cask Preparations for Cold Vacuum Drying - Cask Lid Removal (SCIC in 1 BYPASS mode)}

Note: There can be no delay between the removal of potential $\mathrm{H}$ within the cask-MCO and the removal of the lid other than physical limitations to this operation. If this operation is not completed within four hours, the hydrogen purging steps must be repeated. All cask lid removal preparations steps shall be done in parallel with the hydrogen purge steps.

16. a) Following cask purging and final vent to 0.5 psig utilizing the CVDF-provided pneumatic wrenches (lift by the overhead crane), de-torque and verify the retraction of cask lid bolts (bolting is self captured) in the sequence indicated on the cask lid.

b) Remove vent and purge connections and remove venting equipment from the cask lid port to equalize pressure to atmosphere (leave vent port open, close following lid removal). Decon (as required) the cask vent tools and store in process bay storage locker.

Time to complete operation: $60 / 60$ minutes.

17. a.) Remove the cask lid and place the lid in the storage location in the process bay. Take care to protect the cask and lid sealing surfaces. Remove crane hook from the lid lifting fixture. Close the lid vent plug and then replace cask lid port covers and bolting (lubricate threads with Neolube), torque bolting to the specified value of $15 \pm 3 \mathrm{ft} / \mathrm{lb}$. Survey bottom of cask lid and decontaminate as required to meet contamination limits.

b) Verify and record the MCO serial number into the MCS .

Time to complete operation: $15 / 45$ minutes.

\subsubsection{Cask/MCO Hood/Seal Ring Installation (SCIC in 1 BYPASS mode)}

The process connections are made after moving the process hood into place and removing the flange covers from the MCO using torque wrenches. The MCO has two process ports, one for the long process tube port (port \#3) that communicates with the bottom of the $\mathrm{MCO}$ and the other for the process vent port (port $\mathrm{H} 2$ ) that communicates with the headspace of the MCO. As received from the K Basins, the long process tube port process port plug is in the closed position while the process vent port plug is received in the open position but closed in step $18 \mathrm{~b}$.

Note: There can be no significant delay between the removal of the cask lid and closing of the $\mathrm{MCO}$ process vent port plug (or installation and purging with the MCO 
process connector). Air entry into the open $\mathrm{MCO}$ port could allow flammable concentrations to exist inside the MCO after 9 hours.

18. a) Remove the port cover from the MCO process vent port

b) Close the MCO process vent port plug VPS-V-*010 torque to a specified value of $100 \pm 5 \mathrm{ft}-\mathrm{lb}$.

c) Remove port covers from the long process tube port. Store covers and bolting in the process bay storage locker

Time to complete operation steps $18 \mathrm{a}-18 \mathrm{c}: 15 / 15$ minutes.

d) Install the crane lifting fixture onto the cask-MCO process hood/seal ring and hook to the crane

e) Move hood/seal ring onto top of cask.

Time to complete operation steps $18 \mathrm{~d}-18 \mathrm{e}: 30 / 30$ minutes.

19. a) Install hood/ring bolts (lubricate threads with Neolube) and tighten until snug (hand tight).

b) Verify ventilation flow through the process hood (flow is on continuously)

c) Remove lifting fixture from the seal ring/process hood and translate crane to parking position.

Time to complete operation: $22 / 32$ minutes.

\subsubsection{MCO Vacuum Purge System Hookup (SCIC in 1 BYPASS mode)}

20. a) Install the two MCO process connectors and new gaskets that are stored in the process hood/seal ring. Torque bolting to 35 ft/lbs.

b) Install the rupture disc check valve ventilation connection to both the 30 psig (port 2 process connector) and 150 psig rupture disc (port 4).

Time to complete operation: $20 / 20$ minutes.

21. a) At the MCS start the PROCESS PORT LEAK TEST. This provides helium at 20 psig to the long process tube port and 4 psig helium to the process vent port. The MCS will verify $20 \pm 0.5$ psig on PI $1 * 34$ and $4 \pm 0.5$ psig on PI $1 * 36$ and $1 * 37$.

b) Verify connectors are leak tight utilizing the helium MSLD, and the RGA, as required. 
VPS VALVE LINEUP: VPS-GOV- $2 * 03$, VPS-GOV- $1 * 05$, VPS-GOV $-1 * 09$, He-GOV- $1 * 12$ open $(4$ psig on vent side piping). He-GOV $1 * 06$, He-GOV- $1 * 02$ open with FIC $1 * 20$ set at 1 scfm (supplies $20 \mathrm{psig}$ helium on long tube port).

Time to complete operation: $32 / 32$ minutes.

22. Following successful completion of the leak test, purge the VPS suction line (with the process port plug closed) with helium to reduce residual air in the line.

a. Evacuate and purge the VPS suction line by drawing a vacuum $(\sim 0.1$ torr $)$ on the process vent port connector with the VPS vacuum pump. Re-pressurize this line with helium to 4 psig from $\mathrm{He}-\mathrm{PCV} 1 * 27$.

b) Select " 2 HEATUP" at the SCIC Mode Control Panel in the control room. The MCS will open VPS-GOV-2*04 to line up the 1 psig pressure control vent.

Time to complete operation steps $22 \mathrm{a}-22 \mathrm{~b}: 12 / 12$ minutes.

c) Open the process vent port plug VPS-V-*010. This will immediately open the MCO to the 1 psig vent path.

d) At the MCS start the MCO PRESSURE/VENT CYCLE to reduce the hydrogen concentration in the MCO. This will cycle He-GOV $1 * 12$ and VPS-GOV $2 * 04$ to alternate pressure between $4 \mathrm{psig}$ and $1 \mathrm{psig}$. This sequence will continue 10 times prior to starting the drain cycle (step 25 ). The MCS will verify pressure cycles from $1 \pm 0.3$ psig to $4 \pm 0.5$ psig on PI $1 * 36$ and $1 * 37$, an alarm will be generated if these cycles do not occur.

Note: The MCS shall have a means to allow Operations to select an automatic pressure/vent cycle ( 4 psig helium to 1 psig vent on the MCO vent plug) during the "2 HEATUP" and "3 DRAIN" modes.

Time to complete operation steps $22 \mathrm{c}-22 \mathrm{~d}: 5 / 55$ minutes.

\subsubsection{Cask Tempered Water System Hookup and Heatup (SCIC in 2 HEATUP mode)}

Caution: If water is present after removing the lower port cask port cover, this could indicate a leaking quick disconnect or piping connection. This "leak" must be assessed for the need for repair prior to proceeding.

23. a) Utilizing special remote handling tool, remove cask process port (at lower end of cask) cover plate (de-torque and verify retraction of cover plate bolts; bolting is self captured with tool). Store cover plate and tool in storage box to protect from loss and damage. 
b) Connect the tempered water system supply line (TW-*01-SS-1-1/2) to the lower cask process port TW-QD-*018 (utilize second special remote handling tool) and quick disconnect.

Time to complete operation steps $23 \mathrm{a}-23 \mathrm{~b}$ : 5/25 minutes.

c) Inflate cask-MCO seal ring inflatable seals to 45 psig by manually actuating IAV-*022 and observe PIT 1*04.

d) At the MCS initiate the TW STARTUP sequence. Immediately verify no leakage at the skid or cask.

e) Verify tempered water flow (FI $3 * 16>30 \mathrm{cfm}$ ) and correct water level in the tempered water system surge tank (LI $3 * 04$ between 20 and $80 \%$ ) with the system running.

Time to complete operation steps $23 \mathrm{c}-23 \mathrm{e}: 7 / 7$ minutes.

f) At the MCS, begin the MCO HEAT-UP process using a setting of $46^{\circ} \mathrm{C}$ tempered water as monitored on TIC- $3 * 05$ (TWS Heater outlet).

g) The $\mathrm{MCO}$ will be allowed to heat to a temperature of $46{ }^{\circ} \mathrm{C}$ for a period of 330 minutes. The nominal MCO/SNF temperature at this point is predicted to be $15^{\circ} \mathrm{C}$.

Time to complete operation steps $23 \mathrm{f}-23 \mathrm{~g}$ : $332 / 332$ minutes.

h) Connect the auxiliary vacuum pump (from the $\mathrm{MCO}$ helium leak test equipment) to the seal ring vacuum port. (May be performed in parallel with $23 \mathrm{~g}$ )

i) Initiate and verify vacuum service to this port (vacuum of less than 60 torr shall be achieved within 10 minutes). (May be performed in parallel with 23g) Continue vacuum pump out of the seal ring until step 47 .

Time to complete operation steps $23 \mathrm{~h}-23 \mathrm{i}: 0 / 35$ minutes.

24. a) Verify that a mandatory operation duration of $51 / 2$ hours at the $46^{\circ} \mathrm{C}$ setpoint is accomplished prior to step 25 to equalize the MCO contents at the required temperature.

Time to complete operation: $2 / 15$ minutes 


\subsubsection{MCO Bulk Water Drain Operation (SCIC in 2 HWATUP mode)}

Drain Prerequisites

- All support systems (e.g., MCS, instrument air, electrical, radiation monitoring, security) are operational

- The PWC system is ready and the receiving tanks are below $10 \%$ level

- The PWC suction pressure is $<400$ torr.

- No other process bay requires the use of the PWC system

- The MCO is pressurized at between 4 psig and 1 psig of helium from PCV-1*27 and supplied to the MCO process vent port PCV $2 * 37$

- The long process tube port plug is closed

- The tempered water system is running at approximately $46^{\circ} \mathrm{C}$ with a 6 -hour mandatory heatup

- The line to VPS-GOV-1*11 for DI or helium is connected to the DI source

VPS VALVE LINEUP: VPS-GOV- $2 * 03$, VPS-GOV- $1 * 05$, VPS-GOV- $1 * 09$ open. He-GOV $1 * 12$ to apply 4.psig on the MCO vent port.

25. This following sequence will drain the free-flowing water from the MCO.

Note: The PWC system cannot be used to perform any other processes while draining an $\mathrm{MCO}$ in any other bay.

a. Place the SCIC system switch is in the DRAIN" position. The MCS will automatically start a PWC pre-purge by opening He-GOV $1 * 06, \mathrm{He}-\mathrm{GOV}-1 * 02$, PWC-GOV- $1 * 30$ and PWC-GOV- $1 * 03$ with FIC $1 * 20$ set at $\sim 10 \mathrm{scfm}$ helium flow. The purge will last for a total of 21 minutes ( 2 minutes to allow for flow meter response, 19 minutes of purge rate $>8.4 \mathrm{scfm}$,). The SCIC will monitor for proper purge flow of $>8.4 \mathrm{scfm}$ during the 19 minute pre-purge time. FI $1 * 20$ or $1 * 21$ (which ever is lower) will be used for this measurement. A means to bypass the PWC Pre-purge shall be provided on the MCS to allow for manual PWC purge, supervisory password required.

Time to complete operation steps $25 \mathrm{a}: 21 / 21$ minutes.

VPS VALVE LINEUP: VPS VALVE LINEUP: VPS-GOV- $2 * 03$,VPS-GOV- $1 * 05$, VPS-GOV- $1 * 09$ open. He-GOV $1 * 12$ to apply 4 psig on the MCO vent port.

He-GOV-1*06, He-GOV-1*02, PWC-GOV- $1 * 30$, PWC-GOV- $1 * 03$ open with FIC $1 * 20$ set at 10 scfm helium for the PWC pre-purge.

b. Once the PWC pre-purge is completed or by operator direction, FIC $1 * 20$ is set to $0 \mathrm{scfm}$ and PWC-GOV $1 * 30$, PWC-GOV-1*03, He-GOV-1*02 and He-GOV$1 * 06$ are closed. The Operator then opens the MCO long process tube port plug (VPS-V-*019). 
Note: The operators should then leave the general vicinity of the drain line to minimize exposure.

Time to complete operation steps $25 \mathrm{~b}: 5 / 10$ minutes.

c. At the MCS start the MCO PRESSURE/VENT CYCLE to reduce the hydrogen concentration in the MCO just prior to the start of MCO DRAINING. This will cycle He-GOV $1 * 12$ and VPS-GOV $2 * 04$ to alternate pressure between 4 psig and 1 psig. This sequence will continue 10 times prior to starting the drain cycle (step 25). The MCS will verify pressure cycles from $1 \pm 0.3$ psig to $4 \pm 0.5$ psig on PI $1 * 36$ and $1 * 37$, an alarm will be generated if these cycles do not occur.

Time to complete operation steps $25 \mathrm{c}: 15 / 15$ minutes.

d. At the MCS, start the MCO DRAIN sequence which will open PWC-GOV $1 * 30$ and PWC-GOV-1*03 initiating the drain to the PWC tanks. VPS-GOV $2 * 04$ is closed to stop the pressure/vent cycle.

NOTE: At a $5 \mathrm{gal} / \mathrm{min}$ design rate, approximately 30 minutes will be needed to drain the $150 \mathrm{gal}$ of water from the MCO. Upon detection of water suction breakthrough (large increase of PWC inlet pressure on PI 4031) the drain lineup will stay unchanged for an additional five minutes to remove residual water. This signifies the $\mathrm{MCO}$ is drained.

VPS VALVE LINEUP: VPS-GOV- $2 * 03$, VPS-GOV- $1 * 05$, VPS-GOV- $1 * 09$, He-GOV- $1 * 12$ open with 4 psig on the MCO vent port. PWC-GOV $-1 * 30$ and PWC-GOV-1*03 are open (drain starts as soon as these two valves are open).

Time to complete operation steps $25 \mathrm{~d}: 32 / 32$ minutes.

\subsubsection{SCHe Purge, PWC Line Rinse and PWC Tank Post-Purge After Drain (SCIC in 3 DRAIN mode)}

26. The following steps outline the automatic sequences started after the 4 PURGETLUSH mode is started.

a. Place the SCIC mode switch is in the 4 PURGEALUSH" position. This will automatically initiate a SCHe purge to the long dip tube for 2 mimutes to clear any collected water in these lines. (SCHe-GOV-5*12 and SCHe-GOV-5*31 cycle open)

Time to complete operation steps 26a: $4 / 4$ minutes.

b. After 2 minutes from the start of the PURGEnLUSH mode, the MCS will automatically start a PWC line flush by lining up the DI water (DI-GOV $1 * 01$, VPS-GOV-1*11 and VPS-GOV-1*17 open) to the MCO long process tube port. The PWC suction will pull the water from the port to the receiving tanks through 
PWC-GOV-1*30 and PWC-GOV-1*03. The MCO pressure is maintained by the 4 psig helium on the vacuum port side. The rinse will run for 15 minutes to rinse $\sim 80$ gallons of DI water to the receiving tanks. NOTE: The MCS timer runs solely based on the time from the mode switch change. Interruptions in flow will not stop the timer.

Time to complete operation steps $26 \mathrm{~b}: 15 / 15$ minutes.

VPS VALVE LINEUP: VPS-GOV-2*03, VPS-GOV- $1 * 05$, VPS-GOV-1*09, He-GOV- $1 * 12$ open with 4 psig on the MCO vent port. PWC-GOV-1*30 and PWC-GOV-1*03 are open to the PWC. DIGOV-1*01, VPS-GOV-1*11 and VPS-GOV-1*17 open to supply DI water rinse.

c. After 17 minutes from the start of the 4 PURGESLUSH mode, the MCS shuts the DI lineup, turns both (only one operating normally) PWC Recirc pumps and starts the PWC Post-Purge. At this time the SCIC interlocks VPS-GOV $1 * 09$ and VPS-GOV $-1 * 05$ to assure helium purge flow is going only to the PWC Receiver Tanks. FIC $1 * 20$ is set to $10 \mathrm{scfm}$ and He-GOV $1 * 06$ and He-GOV-1*02 are open to supply 20 psig helium to the MCO. The 4 psig supply on the MCO vent port is still applied.

Note: The MCS will automatically commence the PWC Post-Purge to remove collected hydrogen from the drain sequence. This takes 19 minutes @ $>8.4$ scfm helium from FV $1 * 20$ and an additional 2 minutes to allow the flowmeter indication to reach steady state. .

Time to complete operation steps 26c: $19 / 19$ minutes.

VPS VALVE LINEUP: He-GOV $1 * 06$, He-GOV $-1 * 02$ open with FIC $1 * 20$ set at $10 \mathrm{scfm}(20$ psig) supply. PWC-GOV $1 * 30$ and PWC-GOV $1 * 03$ are open to the PWC suction. PWC Recirc Pumps shutdown (PWC-P-4035 and 4036). VPS-GOV $1 * 09$ and VPS-GOV-1*05 are closed and interlocked closed by the SCIC

d. At the conclusion of the PWC Post-Purge, 38 minutes from selecting 4 PURGLALUSH mode the SCIC will remove the interlock for VPS-GOV $1 * 09$ and $\mathrm{He}-\mathrm{GOV}-\mathrm{I}^{*} 02$. The MCS based on this same time or as directed by operator, will set FIC $1 * 20$ to $0 \mathrm{scfm}$ and close $\mathrm{He}$-GOV $1 * 06$ and He-GOV $1 * 02$. The 4 psig helium pressure is reestablished and the PWC pump is restarted.

Time to complete operation steps $26 \mathrm{~d}: 2 / 2$ minutes.

VPS VALVE LINEUP: VPS-GOV- $2 * 03$, VPS-GOV- $1 * 05$, VPS-GOV- $1 * 09$, He-GOV- $1 * 12$ open with 4 psig on the MCO vent port. PWC-GOV- $1 * 30$ and PWC-GOV- $1 * 03$ are open to the PWC suction. PWC recirc pump running. 
e. Operations then swaps from DI to helium at the quick disconnect to VPS-GOV $1 * 11$. At the MCS select, DI Blowdown which opens VPS-GOV $1 * 11$ and VPSGOV $1^{*} 17$. This immediately starts a helium blowdown of the lines from the quick disconnect which has some water remaining in it. The operator will verify blowdown by monitoring FI-TBD for greater than $10 \mathrm{scfm}$ for 2 minutes. Operations will then disconnect and cap the helium line from VPS-GOV-1*11 and verify no lines connected.

Time to complete operation steps $26 \mathrm{e}: 14 / 15$ minutes.

VPS VALVE LINEUP: VPS-GOV-2*03, PWC-GOV- $1 * 05$, VPS-GOV-1*09, He-GOV- $1 * 12$ open with 4 psig on the MCO vent port. PWC-GOV- $1 * 30$ and PWC-GOV-1*03 are open to the PWC. GOV VPS $1 * 11$ and VPS-GOV-1*17 open to supply helium to blowdown the rinse line.

f. At the MCS select "DI Blowdown Complete", which will close PWC-GOV 1 *30, PWC-GOV- $1 * 03$, VPS-GOV-1*17 and VPS-GOV- $1 * 11$ and establish normal long tube to process vent helium flow. The MCS will open GOV $1 * 02$ and $1 * 06$, set FIC $1 * 20$ to $10 \mathrm{scfm}$, then close GOV $1 * 12$ and open GOV $2 * 04$ to control MCO pressure at $\sim 1$ psig. Wait at least 2 minutes before proceeding to the next step to give the flowmeters time to reach a stable reading.

Time to complete operation steps $26 \mathrm{f:} 6 / 6$ minutes.

VPS VALVE LINEUP: He-GOV- $1 * 06$, He-GOV- $1 * 02$, VPS-GOV- $1 * 05$, VPS-GOV- $1 * 09$, VPSGOV $-2 * 03$, VPS-GOV-2*04 open with FIC $1 * 20$ set at $10 \mathrm{scfm}$ helium through VPS-PCV $2 * 37,1$ psig pressure control vent.

\subsubsection{Eight Hour Vacuum/Purge Drying Operation (SCIC in 4 PURGETLUSH mode)}

\section{Starting Conditions Vacuum/Purge Drying Operation}

- All support systems (e.g., MCS, instrument air, electrical, radiation monitoring, security) are operational.

- The 4 PURGEIFUUSH and blowdown operation is complete.

- The MCO is pressurized at $\sim 1$ psig with approximately $10 \mathrm{scfm}$ normal helium purge, from $\mathrm{He}-\mathrm{FV}-1 * 20$, supplied to MCO long process tube port and out the HEPA filter and process vent, and through pressure-regulating valve VPS$\mathrm{PCV}-2 * 37$.

- The VPS vacuum pump is operational. Operation of the vacuum pump is verified from PI- $2 * 08$ (the vacuum pump will be operated continuously except for maintenance downtime). Pump inlet pressure with isolation valve VPSGOV $-2 * 07$ closed will be less than 0.1 torr. 
- The SCIC system switch is in the "4 PURGEILUSH" position

- The VPS condenser chilled water is operational, FI7078 $>5-20 \mathrm{gpm}, \mathrm{TI} 2 * 35$ and $2 * 36<2{ }^{\circ} \mathrm{C}$.

- The condenser drain tank is ready to receive condensate (this is verified from the previous bay recovery $\log$ )

- Tempered water is running at approximately $46^{\circ} \mathrm{C}$

- The deionized water flex hose is disconnected from VPS-GOV- $1{ }^{*} 11$

- The condenser delta-T display is set to zero by the operator to remove any bias or off-set in the reading.

VPS VALVE LINEUP: He-GOV $1 * 06$, He-GOV- $1 * 02$, VPS-GOV- $1 * 09$, VPS-GOV- $1 * 05$, VPSGOV-2*03, VPS-GOV-2*04 open with FIC $1 * 20$ set at $10 \mathrm{scfm}$ helium through VPS-PCV $2 * 37,1$ psig pressure control vent.

27. a. The Operator selects 'S DRYING" on the SCIC mode panel. Based on this switch position, the SCIC will monitor for completion of the MCO Pre-Purge prior to going below atmospheric conditions. Failure to complete the purge would cause a SCIC trip. The MCO Pre-purge will take $\sim 15$ minutes at $>8.4$ scfm. A flow of less than 8.4 will reset the 15 minute timer. The timer must have reached 15 minutes in order to bypass the $\mathrm{MCO}$ low pressure trip.

Time to complete operation steps $27 \mathrm{a}: 17 / 17$ minutes.

b. At the MCS the operator starts the DRYING sequence.

Note: The "START" button will not appear until the MCO Pre-Purge is meet, helium flow is above the low (1.9 scfm) purge flow trip and the SCIC 5

DRYING mode is selected.

Time to complete operation steps $27 \mathrm{~b}: 2 / 2$ minutes.

c. The MCS sets helium flow to $3.0 \mathrm{sefm}$ on $\mathrm{FIC}-1 * 20$ to control the MCO internal HEPA flow. VPS-GOV $2 * 21$ and VPS-GOV-2*22 are then opened and VPSGOV $2 * 03$ is closed to establish condenser flow. VPS-GOV $2 * 04$ is closed (isolates 1 psig PCV vent path) and VPS-GOV $2 * 07$ is opened (vacuum pump is lined up). The helium flow rate will remain at $3.0 \mathrm{sefm}$ for 30 minutes then automatically decrease to $1.9 \mathrm{scfm}$ over the next 15 minutes.

Time to complete operation steps $27 \mathrm{c}: 2 / 2$ minutes.

d. The above actions start the vacuum cycle with expected MCO pressures $<100$ torr after 10 minutes. [The 8 hour under vacuum timer is started and continues to 
count anytime MCO pressure is $<0.5$ psig. Reset occurs only when the $\mathrm{MCO}$ is above 0.5 psig for a minimum of 4 hours. ] During the first 8 hours under vacuum, if pressure in the MCO goes above $0.5 \mathrm{psig}$, a 4 hour thermal reset must be completed, going above 0.5 psig then back below 0.5 psig will result in a trip. This assures that the 8 hours under vacuum is continuous which assures known temperatures of the MCO fuel.

Note: Anytime MCO pressure has gone below $-11.7 \mathrm{psig}$ ( $\sim 155$ torr) then increases above $-11.1 \mathrm{psig}$ ( $\sim 185$ torr), the MCS automatically increases FIC $1 * 20$ to $10 \mathrm{scfm}$, closes VPS-GOV $2 * 07$ and opens $2 * 04$ to re-pressurize the $\mathrm{MCO}$ to $\sim 1.0 \mathrm{psig}$. Restarting a purge must satisfy the "minimum purge rate of $>1.9 \mathrm{scfm} "$ ". Failure to perform these steps will result in a SCIC MCO isolation and purge.

VPS VALVE LINEUP: He-GOV- $1 * 06$, He-GOV- $1 * 02$, VPS-GOV- $1 * 09$, VPS-GOV- $1 * 05$, VPSGOV-2*21, VPS-GOV-2*22, VPS-GOV-2*07 open with FIC $1 * 20$ set at $1.9 \mathrm{scfm}$ helium through the condenser and vacuum pump.

Time to complete operation steps $27 \mathrm{~d}: 480 / 480$ minutes.

28. a. The MCS monitors both condenser differential temperature $(\Delta \mathrm{T})$ and the total time the $\mathrm{MCO}$ is < 0.5 psig (i.e. under vacuum).

Note: If during the drying process the 8 hour vacuum timer limit is reached, the MCS will reestablish MCO pressure at 1 psig for 4 hours per step 30.

Time to complete operation steps $28 \mathrm{a}: 0 / 0$ minutes.

b. When condenser $\Delta \mathrm{T}$ is less than $0.2^{\circ} \mathrm{C}$ for at least 5 minutes the MCS isolates the condenser by first opening the condenser bypass valve VPS-GOV $2 * 03$ and then closing VPS-GOV $2 * 22$ and VPS-GOV $2 * 21$, the condenser isolation valves. As an option, the operator may choose to isolate and bypass the condenser at anytime during drying. This allows for drying should the condenser be unavailable or if the time to reach the $\Delta T$ criteria is excessive.

Time to complete operation steps $28 \mathrm{~b}: 0 / 5$ minutes.

VPS VALVE LINEUP: He-GOV- $1 * 06, \mathrm{He}-\mathrm{GOV}-1 * 02$, VPS-GOV-1*09, VPS-GOV- $1 * 05$, VPSGOV-2*03, VPS-GOV-2*07 open with FIC $1 * 20$ set at $1.9 \mathrm{scfm}$ helium through the condenser bypass and the vacuum pump.

c. The MCS will perform the No Purge Vacuum Check by setting FIC $1 * 20$ to 0 scfm then closing GOV $1 * 06$ and GOV $1 * 02$. This isolates the normal helium flow. If the $\mathrm{MCO}$ pressure decreases below 8 torr within 5 minutes the helium purge will not be restarted, skip to step $28 \mathrm{f}$, otherwise continue. The timer starts 
from a flow value $<1.9 \mathrm{scfm}$ and restarts above $1.95 \mathrm{scfm}$. Note that the flowmeter response time must be considered for restarting the purge, TBD.

Note: Anytime MCO pressure is $\geq 8.0$ torr for more than 280 seconds without a minimum helium purge, the MCS will automatically restart the helium purge, regardless of the process step. An SCIC trip will occur after 5 minutes without a purge above 9 torr ( 12 torr safety limit).

Time to complete operation steps $28 \mathrm{c}: 0 / 5$ minutes.

VPS VALVE LINEUP: VPS-GOV- $1 * 09$, VPS-GOV- $1 * 05$, VPS-GOV- $2 * 03$, VPS-GOV- $2 * 07$ open with FIC $1 * 20$ set at 0 scfm helium.

d. If 8 torr is not reached, the MCS re-opens He-GOV $1 * 06$ and He-GOV $1^{*} 02$ and sets FIC $1 * 20$ to $1.9 \mathrm{scfm}$ to restart helium purge.

Time to complete operation steps $28 \mathrm{c}: 0 / 5$ minutes.

VPS VALVE LINEUP: He-GOV $1 * 06$, He-GOV- $1 * 02$, VPS-GOV- $1 * 09$, VPS-GOV- ${ }^{*} 05$, VPSGOV $-2 * 03$, VPS-GOV-2*07 open with FIC $1 * 20$ set at $1.9 \mathrm{scfm}$ helium through the condenser bypass and the vacuum pump.

e. The MCS will automatically repeat steps $28 \mathrm{c}$ and $28 \mathrm{~d}$ every 60 minutes until the MCO pressure can be reduced below $<8$ torr with flow stopped. When $<8$ torr is achieved, proceed to step $28 \mathrm{f}$. If the 8 hours at vacuum is reached skip to step 30 .

Note: As an option, the operator may choose to re-pressurize and purge the $\mathrm{MCO}$ at anytime during drying with a control feature on the computer screens.

Time to complete operation steps $28 \mathrm{e}: 0 / 60$ minutes.

f. After the 8 torr is reached, the MCS will monitor MCO pressure for a value of $<$ 0.1 torr for at least 15 minutes. Once this pressure is reached proceed with step 29, Pre-Pressure Rebound Test.

Time to complete operation steps $28 \mathrm{f}: 0 / 5$ minutes.

VPS VALVE LINEUP: VPS-GOV- $1 * 09$, VPS-GOV-1*05, VPS-GOV-2*03, VPS-GOV- $2 * 07$ open with FIC $1 * 20$ set at 0 scfm helium.

29 a. The MCS automatically performs the Pre-Pressure Rebound Test by isolating the vacuum pump by closing VPS-GOV- $2 * 07$. The MCS monitors the MCO vacuum pressure, if pressure changes are less than 0.5 torr over the 10 -minute period skip to step 31 . 
Time to complete operation steps $29 \mathrm{a}: 0 / 10$ minutes.

b. If not, resume vacuum service by opening valve VPS-GOV-2*07 and continue vacuum pumping without helium purge, provided MCO pressure is $<8$ torr. Repeat the Pre-Pressure Rebound Test (29a) every hour until it passes then skip to step 31 or until the 8 hour vacuum timer timeout is reached then proceed to step 30. Excessive time to reach 8 torr may be an indication of a leak or vacuum pump degradation. As an option, the MCO may be re-pressurized at any point in the vacuum sequence to allow for determination of the excessive time. The steps outlined in step 30 shall be used for MCO re-pressurization.

Time to complete operation steps $29 \mathrm{a}: 0 / 10$ minutes.

30. At 8 hours under vacuum the MCS will open $\mathrm{He}-\mathrm{GOV}-1 * 06$ and $\mathrm{He}-\mathrm{GOV}-1 * 02$, set purge flow on FIC $1 * 20$ to $\sim 10$ scfm and isolate the vacuum pump by closing VPS-GOV $2 * 07$ and opening VPS-GOV $2 * 04$ ( 1 psig vent path). This will cause a rapid re-pressurization of the $\mathrm{MCO}$. After $\mathrm{MCO}$ pressure is above 0.5 psig on PI $1^{*} 36$ and $1 * 37$, and purge flow above $8.4 \mathrm{scfm}$ is maintained for at least 15 minutes (MCO PrePurge is satisfied), flow is then reduced to $1.9 \mathrm{scfm}$. This pressurized condition is maintained for a minimum of 4 hours. Skip to step 32 if the condenser was previously isolated or step 33 if not isolated.

Note: The increased purge flow of $\sim 10 \mathrm{scfm}$ is necessary to prevent a SCHe initiation on the $-\mathbf{1 1 . 1}$ psig ( 185 torr) to $>0.5$ psig safety class trip. This trip is set if $>0.5 \mathrm{psig}$ MCO pressure is not reached within 5 minutes once pressure increases above -11.1 psig ( 185 torr) from a vacuum state below $\mathbf{- 1 1 . 7} \mathbf{~ p s i g ~ ( ~} 155 \mathrm{torr}$ ). This safety class function provides indication of a leak that would result in oxygen inleakage into the $\mathrm{MCO}$.

VPS VALVE LINEUP: He-GOV $1 * 06$, He-GOV- $1 * 02$, VPS-GOV- $1 * 09$, VPS-GOV- $1 * 05$, VPSGOV-2*03, VPS-GOV-2*07 open with FIC $1 * 20$ set at $\sim 10 \mathrm{scfm}$ to $1.9 \mathrm{scfm}$ helium through the condenser bypass and PCV2*37 ( 1 psig vent).

Time to complete operation: $240 / 240$ minutes.

\subsubsection{Four Hour MCO Pressure Operations (Thermal Reset) (SCIC in 5 DRYING mode)}

31. Perform a 4 hour "Thermal Reset" as a pre-requisite for the Pressure Rebound Test and a reset for either the 8 or 4 hour under vacuum limit. The MCS opens He-GOV $1 * 06$ and He-GOV-1*02, increases the purge flow setting on FIC $1 * 20$ to $10 \mathrm{scfm}$ then isolates the vacuum pump by closing VPS-GOV $2 * 07$ and opening VPS-GOV $2 * 04$. This will cause a rapid re-pressurization of the MCO. After MCO pressure is above 0.5 psig on PI $1 * 36$ and $1 * 37$, and purge flow above $8.4 \mathrm{scfm}$ is maintained for at least 15 minutes (MCO PrePurge is satisfied), flow is then reduced to $1.9 \mathrm{scfm}$. In addition, the purge must satisfy the "minimum purge rate of $1.9 \mathrm{scfm}$ ". This pressurized condition is maintained for a minimum of 4 hours. Skip to step 40 .

Time to complete steps: $240 / 240$ minutes. 


\subsubsection{Four Hour Vacuum/Purge Drying Operation (SCIC in 5 DRYING mode)}

32. If the condenser was isolated in step $28 \mathrm{~b}$, restart the vacuum mode with process flow bypassing the condenser. After 15 minutes at vacuum, skip to step 34, no purge vacuum check.

VPS VALVE LINEUP: He-GOV $1 * 06$, He-GOV- $1 * 02$, VPS-GOV- $1 * 09$, VPS-GOV- $1 * 05$, VPSGOV-2*03, VPS-GOV-2*07 open with FIC $1 * 20$ set at $1.9 \mathrm{scfm}$ helium through the condenser bypass and the vacuum pump.

Time to complete operation: $0 / 20$ minutes

33. If the condenser was not isolated in step $28 \mathrm{~b}$, re-start the vacuum mode with process flow through the condenser.

VPS VALVE LINEUP CONDENSER IN LINE: He-GOV $1 * 06$, He-GOV- $1 * 02$, VPS-GOV- $1 * 09$, VPS-GOV- $1 * 05$, VPS-GOV- $2 * 21$, VPS-GOV-2*22, VPS-GOV- $2 * 07$ open with FIC $1 * 20$ set at 1.9 scfm helium through the condenser and vacuum pump.

When condenser $\Delta \mathrm{T}$ is less than $0.2^{\circ} \mathrm{C}$ for at least 5 minutes the MCS isolates the condenser by first opening the condenser bypass valve VPS-GOV $2 * 03$ and then closing VPS-GOV $2 * 22$ and VPS-GOV $2 * 21$, the condenser isolation valves. Verify helium flow at $>1.9 \mathrm{scfm}$. After 15 minutes at vacuum, skip to step 34 , no purge vacuum check.

Note: As an option, the operator may choose to isolate and bypass the condenser at anytime during drying. This allows for drying should the condenser be unavailable or if the time to reach the $\Delta \mathrm{T}$ criteria is excessive. Follow steps outlined in step 30 for $\mathrm{MCO}$ re-pressurization.

VPS VALVE LINEUP CONDENSER BYPASSED: He-GOV $1 * 06$, He-GOV-1*02, VPS-GOV$1 * 09$, VPS-GOV- $1 * 05$, VPS-GOV- $2 * 03$, VPS-GOV- $2 * 07$ open with FIC $1 * 20$ set at $1.9 \mathrm{scfm}$ helium through the condenser bypass and the vacuum pump.

Time to complete operation: $180 / 180$ minutes

\subsubsection{No Purge Vacuum Check (SCIC in 5 DRYING mode)}

34. The no purge vacuum check consists of the following steps:

a. The MCS will perform the No Purge Vacuum Check by setting FIC $1 * 20$ to 0 scfm then closing He-GOV-1*06 and He-GOV-1*02. This isolates the normal helium flow. If the $\mathrm{MCO}$ pressure decreases below 8 torr within 5 minutes the helium purge will not be restarted, skip to step $34 \mathrm{~b}$, otherwise skip to step 36 . The timer starts from a flow value $<1.9 \mathrm{scfm}$ and restarts above $1.95 \mathrm{scfm}$. Note 
that the flowmeter response time must be considered for restarting the purge, TBD.

Note: Anytime MCO pressure is $\geq 8.0$ torr for more than 280 seconds without a minimum helium purge, the MCS will automatically restart the helium purge, regardless of the process step. An SCIC trip will occur after 5 minutes without a purge above 9 torr ( 12 torr safety limit). If pressure limit is met continue with step $34 \mathrm{~b}$. If pressure limit is not met skip to step 36 .

Time to complete operation steps $34 \mathrm{a}: 20 / 20$ minutes.

b. . Once MCO pressure decreases to less than 0.1 torr for a minimum of 15 minutes, perform pressure rebound pre-test in step 35 unless returning from step 39 then skip to step 40 . If time under vacuum reaches 4 hours go to step 37.

Note: The series of steps from 34 through 39 are repeated as either the Pressure Rebound Pre-test fails or the time under vacuum limit is reached. The pre-test needs only to be passed once and not repeated, however the No Purge Vacuum Check is performed each time the MCO pressure exceeds 9.5 torr.

Time to complete operation steps $34 \mathrm{~b}: 20 / 20$ minutes.

35. a. Pressure rebound pre-test: If the pressure conditions from step $34 \mathrm{~b}$ are obtained, isolate the vacuum pump by closing VPS-GOV-2*07. Monitor MCO vacuum pressure over a 10-minute period. If pressure changes less than 0.5 torr over the 10-minute period proceed to step 31, Thermal Reset.

Time to complete operation steps $35 \mathrm{a}: 10 / 10$ minutes.

b. If the pressure rebound pre-test fails, resume vacuum service by opening valve VPS-GOV-2*07 and continue vacuum pumping without helium purge. Proceed to step 36. If the 4 hours under vacuum is reached skip to 37.

Time to complete operation steps $34 \mathrm{~b}: 0 / 5$ minutes.

36. Open He-GOV-1*02, He-GOV-1*06 and set FIC $1 * 20$ to $1.9 \mathrm{scfm}$, continue vacuum purge mode with helium flow. Each hour repeat the no purge vacuum check (go to step 34). Should the time to reach below 8 torr become excessive, this may be an indication of a leak or excess water. A decision for this off-normal condition will require some analysis and the RGA should be used to understand this condition.

Time to complete: $240 / 240$ minutes.

37. At 4 hours under vacuum the MCS will open He-GOV $1 * 06$ and He-GOV- $1 * 02$, set purge flow on FIC $1 * 20$ to $\sim 10 \mathrm{scfm}$ and isolate the vacuum pump by closing VPS-GOV $2 * 07$ and opening VPS-GOV $2 * 04$ ( 1 psig vent path). This will cause a rapid re-pressurization of the $\mathrm{MCO}$. After MCO pressure is above 0.5 psig on $\mathrm{PI}-1 * 36$ and PI$1 * 37$, and purge flow above $8.4 \mathrm{scfm}$ is maintained for at least 15 minutes (MCO Pre- 
Purge is satisfied), flow is then reduced to $1.9 \mathrm{scfm}$. This pressurized condition is maintained for a minimum of 4 hours. Skip to step 32 if the condenser was previously isolated or step 33 if not isolated.

Note: The increased purge flow of $\sim 10 \mathrm{scfm}$ is necessary to prevent a SCHe initiation on the $-\mathbf{1 1 . 1}$ psig ( 185 torr) to $>0.5$ psig safety class trip. This trip is set if $>0.5$ psig MCO pressure is not reached within 5 minutes once pressure increases above -11.1 psig ( 185 torr) from a vacuum state below $-11.7 \mathrm{psig}$ ( $155 \mathrm{torr}$ ). This safety class function provides indication of a leak that would result in oxygen inleakage into the MCO.

Time to complete operation: $5 / 5$ minutes.

38. After the 4 hours at above atmospheric pressure and after the thermal and minimum purge resets are met, proceed to next step.

Note: Minimum Purge reset is accomplished when a volume of 125 cubic feet of helium is replaced in the $\mathrm{MCO}$ as measured by FI- $1 * 20$ and $1 * 21$. Failure to purge this volume will result in a SCIC trip.

Time to complete operation: $0 / 0$ minutes.

39. Re-start the vacuum mode with process flow through the condenser bypass. After 15 minutes at vacuum, stop the purge and perform no purge vacuum check (go to step 34).

Note: Steps 34 through 39 may need to be repeated several times until the pressure rebound pretest (step 35 ) is successful. Failure of step 35 may require administrative action to determine if a system leak or other malfunction has occurred.

Time to complete operation: $15 / 15$ minutes.

\subsubsection{Initial Pressure Rebound Test (SCIC in 5 DRYING mode)}

Note: The Initial Pressure Rebound Test is MCS controlled but the test performance verifications are all done administratively.

40. Starting Conditions Initial Pressure Rebound Test

- The MCO has been pressurized above 0.5 psig for a minimum of 4 continuous hours, step 31 completed. Vacuum is < 0.1 torr for 15 minutes and

- Tempered Water inlet temperature must be maintained at $46 \cdot 2{ }^{\circ} \mathrm{C}$

- MCO pressure is $<0.1$ torr

a. As soon as the prerequisites are meet the Pressure Rebound Test Start button will become visible on the MCS control screens. The selecting of this start sequence will close all open MCO isolation valves (He-GOV- $1 * 02$, He-GOV- 
$1 * 06$, VPS-GOV- $1 * 09$, VPS-GOV- $1 * 05$ ) and start the one hour plot of MCO pressure and TW temperatures (inlet and outlet).

VPS VALVE LINEUP: VPS-GOV-2*03, VPS-GOV-2*07 are open with FIC $1 * 20$ set at 0 .

Note: If the pressure rises to above 3 torr within one hour, the test fails and more vacuum drying is necessary. In addition, if the plot shows an unfavorable result Operations may choose to abort the test and continue drying. In either case, the operator will direct the MCS whether the test passed or failed.

b. If the test fails, further helium purging and vacuum pumping is necessary. Wait for 1 hour then return to step 35. Note: The RGA can be used to determine if the test failed because of leaks or because of water.

c. If the test passes proceed to step 41, Proof Of Dryness Demonstration.

Time to complete operation: $80 / 80$ minutes.

\subsubsection{Proof of Dryness Demonstration (SCIC in 5 DRYING mode)}

41. Select "6 PROOF" mode on SCIC, this will eliminate the need for the $8 / 4 / 4$ hour cycles. The proof mode provides an additional vacuum sequence which is required to determine if the fuel in the MCO is off-gassing at $\sim 46^{\circ} \mathrm{C}$. The goal of this step is to maintain the $\mathrm{MCO}$ under vacuum less than 8 torr for a minimum cumulative period of 8,20 or 28 hours for no scrap basket, one scrap basket or two scrap baskets, respectively. Upon completion of the proof of dryness, proceed to step 42 .

Note: Should an unexpected pressure increase above 8 torr occur the MCS will automatically start a helium purge by opening He-GOV-1*02, He-GOV-1*06 and setting FIC $1 * 20$ to $1.9 \mathrm{scfm}$. This increase of pressure may indicate an off-gassing of the hydrates, a leak of air or helium, additional free water in the MCO being released or potential off-gassing from other sources. The RGA may be used to determine the source of pressure.

The following conditions exist:

- The tempered water system circulation temperature is maintained at the $46 \pm 2$ ${ }^{\circ} \mathrm{C}$

- The time at vacuum timer is started

- The condenser is bypassed and isolated

- The vacuum pump is running and open to the MCO

Note: If the MCO pressure is greater than 8 torr and duration is less than 2 hours after passing the 1-hour pressure rise test then a fault condition (leak) must exist and recovery is required. 
VPS VALVE LINEUP: VPS-GOV- $1 * 09$, VPS-GOV- $1 * 05$, VPS-GOV- $2 * 03$, VPS-GOV- $2 * 07$ open.

Time to complete operation: $1,200 / 1,200$ minutes.

\subsubsection{Final Pressure Rebound Test (SCIC in 6 PROOF mode)}

42. This step confirms that bulk water was not re-introduced during the vacuum drying cycle. The MCO is isolated from potential water sources and the pressure rebound test is repeated the final time. This data is important for long term storage of spent nuclear fuel and is designated as OCRWM data. All records will be kept for the life of the MCO.

Note: The Final Pressure Rebound Test is MCS controlled but the test performance verifications are all done administratively.

Starting Conditions Final Pressure Rebound Test

- The Proof of Dryness Demonstration step 41 is completed

- Tempered Water inlet temperature must be maintained at $46 \bumpeq 2{ }^{\circ} \mathrm{C}$

- MCO pressure is $<0.1$ torr

a. As soon as the prerequisites are met, the Final Pressure Rebound Test Start button will become visible on the MCS control screens. The selecting of this start sequence will close all $\mathrm{MCO}$ isolation valves and start the one hour plot of $\mathrm{MCO}$ pressure and TW temperatures (inlet and outlet).

b. The Operator will place the SCIC mode switch in the "7 PRESSURE TEST" position. The MCS will close VPS-GOV-1*09, VPS-GOV-1*05, VPS-GOV$1 * 06$ and VPS-GOV-1*02. The SCIC also interlocks closed VPS-GOV-1*09 and VPS-GOV- $1 * 05$ to prevent water addition sources.

VPS VALVE LINEUP: VPS-GOV-2*03, VPS-GOV-2*07 open all MCO isolation valves closed.

Note: If the pressure rises to above 3 torr within one hour, the test fails and a recover procedure will be necessary as this indicates a failure in the system. In addition, if the plot shows an unfavorable result, Operations may choose to abort the test. In either case, the operator will direct the MCS whether the test passed or failed.

c. If 3 torr per hour pressure rise is exceeded from a base pressure of 0.1 torr or less, determine if system leak, water ingress, or hydrate decomposition is the likely cause. If hydrate decomposition is suspected, re-pressurized with helium for four hours then repeat final pressure rebound test as necessary. 
d. After passing 3 torr per hour pressure rise test, re-pressurize the MCO with helium by opening He-GOV- $1 * 02, \mathrm{He}-\mathrm{GOV}-1 * 06$ and setting FIC- $1 * 20$ to $10 \mathrm{scfm}$. Control the pressure in the MCO by cycling $\mathrm{He}-\mathrm{GOV}-1 * 06$ and $\mathrm{He}-$ GOV $-1 * 02$ to maintain $\sim 3.0$ to $5.0 \mathrm{psig}$.

Time to complete operation: $80 / 80$ minutes.

\subsubsection{Cooldown to $25^{\circ} \mathrm{C}$ Operation (SCIC in 7 PRESSURE TEST mode)}

43. The $\mathrm{MCO}$ requires cooling to $<25^{\circ} \mathrm{C}$ before final preparation for shipping. This is done by turning the heaters off and by starting cooling water flow through the tempered water system cooler (open TWC-GOV-3*01). This cooling water is derived from the HVAC chiller system. During cooldown, maintain MCO pressure to $11 \pm 0.5$ psig by setting FIC- $1 * 20$ to $20 \%$ open, and cycling He-GOV-1*06 and He-GOV-1*02.

Note: There is no method to reduce MCO pressure so the MCS must not exceed 11.5 psig during this pressure control mode using $\mathrm{He}-\mathrm{GOV} 1 * 06$ and $\mathrm{He}-\mathrm{GOV}-1 * 02$.

A mandatory hold of 6 hours is required to allow the contents of the MCO to come to temperature equilibrium with the tempered water system. Following the 6 hour hold, the MCO pressure is manually verified at $11 \pm 0.5$ psig on PI $1 * 40$ and $1 * 41$.

Time to complete operation: $360 / 360$ minutes.

44. Close both MCO port plugs, VPS-V-*010 and VPS-V-*019. Torque to a specified value of $100 \pm 5 \mathrm{ft}-\mathrm{lb}$. Record the time and date that the port plugs were closed into the MCS data log. Close He-GOV-1*06, He-GOV-1*02 with FIC $1 * 20$ at $0 \mathrm{scfm}$. Position the SCIC system switches to "I BYPASS" for this bay.

Time to complete operation: $20 / 20$ minutes.

\subsubsection{MCO Helium Leak Test (SCIC in 1 BYPASS mode)}

Process connections require disengagement after cool-down has completed.

45. a. Drain the condenser drain tank (VPS-TK-2*15) per section 3.5.3 Process Water Conditioning Vacuum Pumping and Receiving - VPS Condenser Tank Draining.

Remove the rupture disc check valve ventilation connection to both the $30 \mathrm{psig}$ (port 2 process connector) and 150.psig rupture disc (port 4).

c. Equalize pressure to atmosphere in the long dip tube to permit removal of the valve operators and prevent a pressurized condition by de-energizing the $\mathrm{PWC}$ pumps PWC-P-4035 and 4036 (removes ejector vacuum) and opening PWCGOV $1 * 03$ and PWC- $1 * 30$ for 5 minutes. For the short dip tube side, open the following valves to depressurize the lines, VPS-GOV- $1 * 09$, VPS-GOV- $1 * 05$, VPS-GOV-2*03, VPS-GOV-2*05. 
Time to complete operation: $0 / 20$ minutes.

46. Remove all MCO valve operator securing bolts then remove the MCO valve operators. Place the MCO valve operators in their storage sockets in the process hood (this connects the process jumper). Once complete, instruct the MCS to close all open process valves and restart the PWC recirc pumps, PWC-P-4035 or 4036.

Time to complete operation: $20 / 20$ minutes.

47. Isolate auxiliary vacuum system from the seal ring and then perform a MSLD leak check of the MCO process ports. Decontaminate the MCO plugs and valve flange surfaces for contamination and water residue. Decontaminate the MCO shield plug top surfaces. Hand dry areas around connector ports to minimize potential for spread of contamination.

Time to complete operation: $35 / 35$ minutes.

48. Replace and secure the MCO port cover blind flanges (install blind flanges on the long process port, process vent, and rupture disk ports). Reinstall the port cover bolting. Torque bolting to specified value $(17 \pm 2 \mathrm{ft}-\mathrm{lb})$ using torque wrenches.

Time to complete operation: $30 / 30$ minutes.

49. The cask-MCO annular space is isolated from the tempered water system and then the annular space between the MCO and the cask is drained to the PWC system. Water is drained by turning of the tempered water system circulation pump TW-P-3*14, closing TW-GOV-1*14 and TW-GOV-3*14. With RPT ready to collect up to 2 ounces of water, disconnect the tempered water supply line from the cask lower port (TW-QD-*018) and connect the PWC system drain line to the cask lower port (PWC-QD-*020). Purged instrument air will drain the annular area to the PWC system receiver tank by opening CA-GOV- $1 * 15$ and then PWC-V-*048. Purge annulus with instrument air for one hour.

Note: This will cause a "BAY * ANNULUS LOW LEVEL" alarm on the SCIC Annunciator panel in the control room. Once this alarm is confirmed the "BAY * $\mathrm{LVL}^{\prime}$ alarm bypass switch is placed in "ON".

Time to complete operation: $0 / 60$ minutes (done in parallel with steps 45 through 48 ).

50. Disconnect the cask drain to the PWC line. Install the cask lower port cover and boit the cover with CVDF special tooling. Torque bolting (lubricate threads with Neolube) to specified values $15 \pm 3 \mathrm{ft}-\mathrm{lb}$.

Time to complete operation: $10 / 10$ minutes.

51. Step Deleted 
52. Achieve operating vacuum pressure 0.5 torr or less in seal ring vacuum volume and conduct helium leak test.

Time to complete operation: $60 / 60$ minutes.

53. Disconnect helium leak test equipment and transfer the test equipment to its storage location in the process bay.

Time to complete operation: $15 / 15$ minutes.

54. Deflate hood/seal ring by manually turning IA-V-*022 to vent, verify PIT $1 * 04$ is $<0 \pm .2$ psig. Remove its bolting. Install the crane lifting fixture onto cask hood/ring. Move hood/ring onto its storage location on the process bay mezzanine.

Time to complete operation: $15 / 15$ minutes.

\subsubsection{Preparation of Cask for Departure (SCIC in 1 BYPASS mode)}

55. Engage the crane to the cask lid lifting fixture and install the cask lid. Install and torque twelve cask lid bolts in appropriate sequence, as indicated on the cask lid. Torque bolting (lubricate threads with Neolube) to specified value $300 \pm 10 \mathrm{ft}-\mathrm{lb}$ using pneumatic torque wrenches.

Time to complete operation: $45 / 45$ minutes.

56. Dry cask surfaces and take smears of cask to verify contamination cleanliness of cask surfaces.

Time to complete operation: $30 / 30$ minutes.

57. Perform cask and trailer final radiation and contamination surveys. Decontaminate as required. The cask-MCO is ready for shipment to the CSB.

Time to complete operation: $30 / 30$ minutes.

\subsubsection{Preparation of Trailer for Transport (SCIC in 1 BXPASS mode)}

58. Connect building air supply to the landing leg air supply glad hand. Raise the front of the trailer to match the tractor fifth wheel height. Re-inflate the air ride system.

Time to complete operation: $5 / 5$ minutes.

59. Install the exhaust trunk, secure security system for the process bay, open the telescoping process bay door, and back the tractor under the cask trailer. Engage trailer kingpin to the tractor fifth wheel and lock in place.

Time to complete operation: $15 / 15$ minutes. 
60. Check to make sure the fifth wheel is latched (visual or tugging).

Time to complete operation: $5 / 5$ minutes.

61. Set the tractor brakes. Shut off tractor.

Time to complete operation: $5 / 5$ minutes.

62. Raise the landing legs. Change the building air supply from the landing leg air supply glad hand to the trailer supply glad hand.

Time to complete operation: $5 / 5$ minutes.

63. Change the override valve to automatic. Disconnect the building air supply.

Time to complete operation: $5 / 5$ minutes.

64. Connect tractor air lines and electrical cable.

Time to complete operation: $5 / 5$ minutes.

65: Perform standard pre-trip inspection per pre-trip inspection requirements.

Time to complete operation: $10 / 10$ minutes.

\subsubsection{Transport Cask-MCO Out of the Cold Vacuum Drying Facility (SCIC in 1 BYPASS mode)}

66. Give a copy of the MCO quality assurance package to the truck driver. Release cask for transfer to CSB.

Time to complete operation: $5 / 5$ minutes.

67. Start tractor engine. Release tractor and trailer brakes. Drive out of the process bay. Close the process bay door, remove exhaust trunk from tractor, and transport the cask-MCO to the CSB. Store the exhaust trunk in the storage locker.

Time to complete operation: $15 / 15$ minutes. 


\subsection{PROCESS WATER CONDITIONING SYSTEM OPERATION}

The normal PWC system operations process system is shown in the block flow diagrams, Figure $3-4$, and the process flow diagram (H-1-82166). The following describes the operating sequences that will activate the functions embodied in the PWC P\&ID ( $H-1-83766$ ). Note, indicated process step duration times are "Average Basis" engineering estimates, definitive estimates will be provided during Preoperational testing and the Process Validation operation.

\subsubsection{Process Water Conditioning Vacuum Pumping and Receiving - Prerequisites}

Operation of the PWC system vacuum pumping and receiving include controlling and monitoring PWC pump operation, flow loop performance, receiver tank conditions, and suction line performance.

The PWC receiving system is online continuously to support the CVD process systems. Either of the two receiving system pumps are run continuously except for those periods when none of the four process bays are processing a $\mathrm{MCO}$ or recovering from processing a MCO. Maintenance activities, including a shutdown to change out an IXM, will require the placement of any MCO, prior to bulk water drain, in cold standby. The system will allow completion of MCO drying operations for MCOs that have completed bulk water draining. The PWC Operations Block Flow Diagram is depicted in Figure 3-4.

1. The PWC system is powered by two (one running and one spare) canned pumps (PWC-P-4035 and PWC-P-4036) capable of pumping $45 \mathrm{gal} / \mathrm{min}$ at a discharge pressure of 60 psig. The receiver tank must have a minimum heel of 50 gallons, $0.0 \%$ reading from LI-4033, in order to prevent cavitation of the PWC Pump. The receiving tanks are initially filled with de-ionized water from the DI system by directing DI valve DI-GOV4057 to open and filling the tank until a $0.0 \%$ reading is indicated from PWC-LI- 4033. The pumps are then either manually started or remotely started using a hand operated actuator from the MCS. The pump discharges into receiver tanks PWC-TK-4032, with underflow balance line connection to PWC-TK-4033, through water jet-ejector PWC-EJR-4031.

Time to complete operation: 10 minutes.

2. Monitoring the pump operation is done by tracking the pump and valve status on the MCS. Pump PWC-P-4035 is the primary pump with three way flow control valves PWC-GOV-4045 and PWC-GOV-4046 ported to primary pump in the fail port position (no instrument air needed). If a trip is detected, the PWC system is considered not ready for continued operation. Operator intervention will be required to utilize the redundant pump by remote changeover from the operator control station in the CVDF control room.

Time to complete operation: 1 minute. 
SNF-2356 Rev, 1
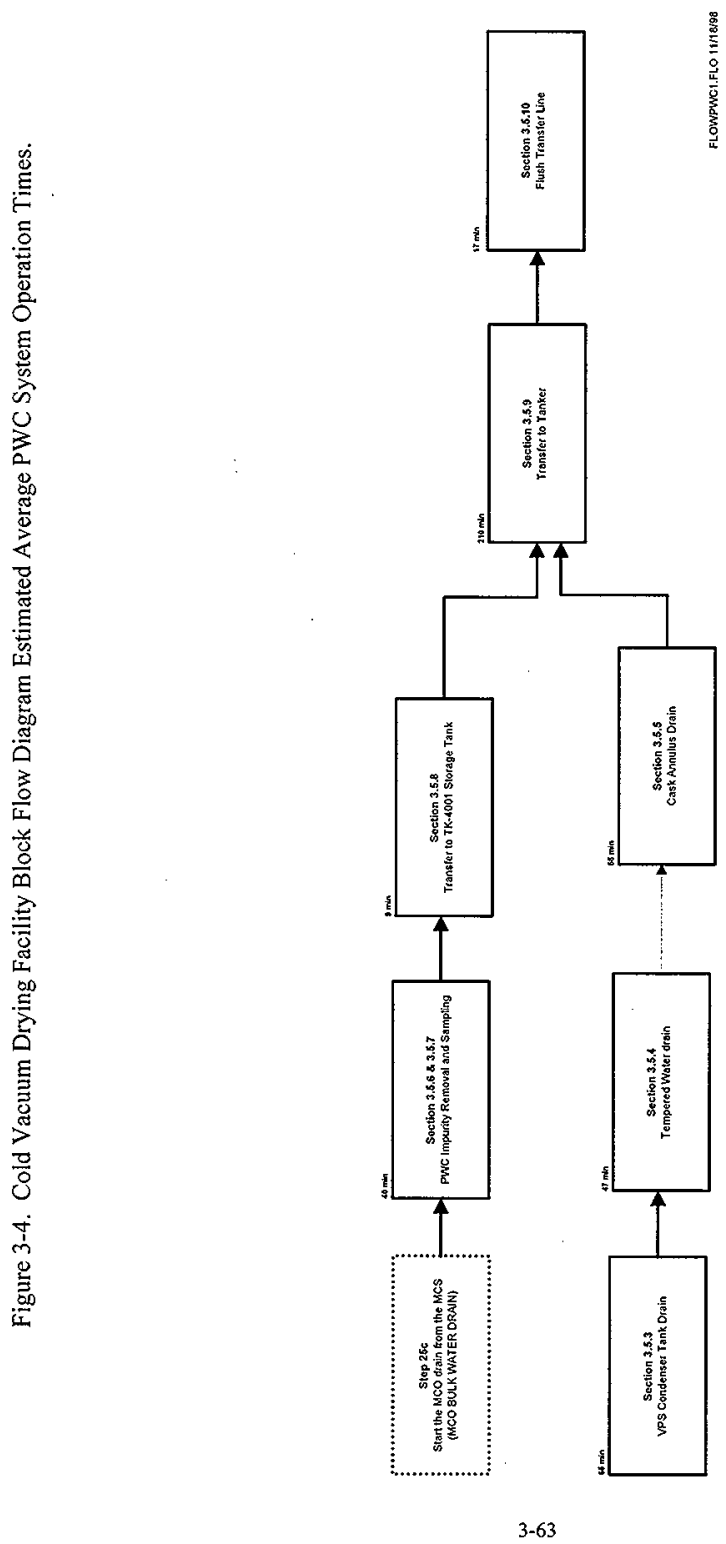
SNF-2356 Rev. 1

3. Flow loop performance is a less direct way of monitoring pump operation. FIT-4037 and PIT -4038 are used to determine if adequate flow and pump discharge pressure are being maintained. If less than $25 \mathrm{gal} / \mathrm{min}$. or $40 \mathrm{psig}$ are being achieved, the PWC system is considered incapable of continued operation.

Time to complete operation: 1 minute.

4. Receiver tank conditions measurements are used to determine if the PWC system is ready to receive additional water from the CVDF process systems. If a new $\mathrm{MCO}$, or other process system, is ready to discharge water, the $\mathrm{PWC}$ receiver tanks must be at the lower level as measured by LAL-4034 (no alarm) and $0.0 \%$ reading from LI-4033 (calibration set point). Both of these meters must be active in order for the system to be considered operational. If LAL- 4034 alarms on low-level outside the $0.0 \% \pm 0.7 \%$ range of LI- 4033 , the PWC system requires operator attention. The receiver tanks have a combined total capacity of 236 gallons between level probes LAL-4034 and LAH-4032 and the range of LI-4033. If during operations either LAH-4032 or $100 \%$ LI- 4033 occur, the PWC system is considered not ready and the MCS directs the pump(s) to stop.

Time to complete operation: 1 minute.

5. Suction line performance is used to determine initial startup conditions and to monitor line operation. The ejector is capable of pulling at least $5 \mathrm{gal} / \mathrm{min}$. of liquid at a vacuum of 12.5 psig) of water. For initial startup before any MCO bulk water draining, tempered water expansion tank level adjustment, VPS condenser tank emptying, cask-MCO annulus draining, or various line flushing, the process water suction line should be demonstrating adequate vacuum (PI-4031 less than - $5 \mathrm{psig}$ ). Once the PWC system ready permissive is received and flow has started, the MCS monitors for breakthrough, (defined as the transition from liquid flow to gas flow) by looking for a sudden pressure rise in PIT-4031 from less than -5 psig to approximately -2 psig. The MCS is programmed to sense this change and proceed with the next processing step (with nominal holds of 1 to 2 minutes) as defined in the CVD operational sequences. Utilization of the PWC for CVDF draining operations is described in steps 3.5 .2 through 3.5 .5 below.

Time to complete operation: 1 minute.

\subsubsection{Process Water Conditioning Vacuum Pumping and Receiving - MCO Bulk Water Draining}

MCO bulk water draining can commence if the PWC system is ready to accept water, ie. receiver tank level indication $0.0 \%$ level at LIT-4033, transfer pump PWC-P-4035/-4036 operational with flow at $25 \mathrm{gal} / \mathrm{min}$. at FIT-4037 and discharge pressure at $40 \mathrm{psig}$ or more at PIT-4038, ejector suction pressure at less than - 5 psig. During MCO bulk water draining, the full flow of water from the transfer pumps is directed through the PWC ejector and no flow is directed through the IXM or filter loop (three way valve, 
PWC-GOV-4039, directed to ejector). The PWC can only process one MCO during a 8 hour period, therefore scheduling of multiple MCO bulk water drain operations is required.

6. MCO bulk water draining and subsequent transfer line flush and receiver tank helium gas purging is performed in accordance with SNF-2356, section 3.4.2 steps 25 a through $25 \mathrm{~g}$ (Vacuum Purge System Operation - Drain Operation). The MCO bulk water drain shall nominally transfer 230 gallons of water ( 150 gallons of MCO bulk water and 80 gallons of flush water) to the PWC receiver tanks.

7. The transferred water must be processed through the PWC IXMs and filter and transferred to the storage tank, PWC-TK-4001, prior to another PWC water receiving operation.

8. At the end of the MCO bulk water drain, nominally 280 gallons of contaminated water is in the receiver tanks. The receiver tanks have been purged of any potential hydrogen by a helium gas purge. The PWC is operating with full flow through the ejector loop.

Time to complete operation: 80 minutes (steps 6,7 and 8).

\subsubsection{Process Water Conditioning Vacuum Pumping and Receiving - VPS Condenser Tank Draining}

VPS condenser tank draining can commence if the PWC system is ready to accept water, ie. receiver tank level indication $0.0 \%$ level, transfer pump PWC-P-4035/-4036 operational with flow at a minimum of $25 \mathrm{gal} / \mathrm{min}$ and discharge pressure at 40 psig or more, ejector suction pressure at less than -5 psig. During VPS condenser tank draining, the full flow of water from the transfer pumps is directed through the PWC ejector and no flow is directed through the IXM or filter loop (flow is set to to ejector port at PWC-GOV-4039).

9. VPS condenser tank draining can be performed after CVD operations are performed on a MCO. Condenser tank draining can be done only after SNF-2356, section 3.4.2.10 (Four Hour MCO Pressure Operations (Thermal Reset) ) is completed and preferably after SNF-2356, section 3.4.2.17 (MCO Helium Leak Test) is completed. VPS condenser tank draining shall nominally take 5 to 10 minutes. The VPS condenser tank draining shall nominally transfer 3.2 gallons ( 12 liters) of water to the PWC receiver tanks. The VPS condenser tank has a maximum working volume of 8.5 gallons ( 32 liters). Tank level alarm high, VPS-LAH- ${ }^{*} 25$, alarms when the tank level reaches this max. working level. The response to this alarm requires that the CVD process to isolate the VPS condenser and condenser tank.

10. Condenser tank draining is accomplished by verifying that the tank is isolated by closure of VPS valves VPS-GOV-2*21, VPS-GOV 2-*22 and VPS-GOV-2*16. There are two options for condenser tank draining; 1) drain with $\mathrm{PWC}$ ejector operation assisted with a 


\section{SNF-2356 Rev. 1}

helium pressurization at the top of the condenser tank and 2) drain with PWC ejector operation without assistance of a helium pressurization at the top of the condenser tank.

11. Drain with PWC ejector operation assisted with a helium pressurization at the top of the condenser tank is accomplished by verifying that the CVD operation is complete through CVD operation sequence SNF-2356, section 3.4.2.17 (MCO Helium Leak Test). The following VPS valves are verified closed, VPS-GOV-1*12, VPS-GOV-2*03, VPS-GOV$2 * 04$, VPS-GOV- $2 * 05$, VPS-GOV- $2 * 07$, VPS-GOV- $2 * 16$, VPS-GOV $-2 * 21$ and VPSGOV $-2 * 22$. The PWC receiver tank is verified ready to receive additional water and the PWC ejector is verified operational. A helium pressurization of the condenser tank to 4 psig is accomplished through operator action from the MCS by opening He-GOV-1*12, pressure is verified at VPS-PIT- $2 * 09$. Then VPS-GOV- $2 * 03$, VPS-GOV-2*22 and VPSGOV $-2 * 16$ are then opened by MCS command, this initiates water flow to the PWC receiver tank. The tank is empty when breakthrough is determined at the PWC ejector inlet pressure from PIT-4031. The drain tank is allowed to be purged with helium for 10 minutes after breakthrough, then the condenser tank drain valve, VPS-GOV-2*16, is closed, the helium purge valve, He-GOV-1*12, and condenser isolation tank valves,VPSGOV $-2 * 03$, VPS-GOV $-2 * 22$, are closed. With a water drain rate of $5 \mathrm{gal} / \mathrm{min}$, the nominal transfer of 3.2 gallons (12 liters) of water to the PWC receiver tanks is accomplished in less than 1 minute. The maximum condenser tank working volume of 8.5 gallons ( 32 liters) would require a transfer time of less than 2 minutes. At the end of this step, the condenser tank is empty of water but has a 4 psig helium cover gas.

12. Drain with PWC ejector operation without assistance of a helium pressurization at the top of the condenser tank is accomplished by verifying that the CVD operation is complete through CVD operation sequence SNF-2356, section 3.4.2.10 step 31 (Four Hour Nominal Helium Purge - Thermal Reset). The following VPS valves are verified closed, VPS-GOV-2*16, VPS-GOV-2*21 and VPS-GOV- $2 * 22$. The PWC receiver tank is verified ready to receive additional water and the PWC ejector is verified operational. A helium pressurization of the condenser tank to nominally 1 psig (part of the normal CVD process prior to condenser and condenser tank isolation) was previously verified at VPS-PI- $2 * 09$, but the pressure gauge is isolated from the tank by closure of VPS-GOV$2 * 21$. VPS-GOV $-2 * 16$ is then opened by MCS command, this initiates water flow to the PWC receiver tank. The condenser tank is empty when breakthrough is determined at the PWC ejector inlet pressure from -PI-4031. The condenser tank is allowed to be drained for an additional 5 minutes after breakthrough, then the condenser tank drain valve, VPSGOV- $2 * 16$, is closed and the helium purge valve, He-GOV-1*12, is closed. With a water drain rate of $5 \mathrm{gal} / \mathrm{min}$., the nominal transfer of 3.2 gallons ( 12 liters) of water to the PWC receiver tanks is accomplished in less than 1 minute. The maximum condenser tank working volume of 8.5 gallons ( 32 liters) would require a transfer time of less than 2 minutes. At the end of this step, the condenser tank is empty of water and replaced a 400 to 500 torr helium cover gas. The vacuum in the tank will be refilled with helium after the CVD process is completed. 


\section{SNF-2356 Rev. 1}

Time to complete operation: 15 minutes (steps 9 through 12).

\subsubsection{Process Water Conditioning Vacuum Pumping and Receiving - Tempered Water System Draining}

Tempered Water system draining can commence if the PWC system is ready to accept water, ie. receiver tank level indication of $0.0 \%$ level, transfer pump PWC-P.4035/-4036 operational with flow at 25 $\mathrm{gal} / \mathrm{min}$ and discharge pressure at $40 \mathrm{psig}$ or more, ejector suction pressure at less than $-5 \mathrm{psig}$. During Tempered Water system draining, the full flow of water from the transfer pumps is directed to ejector port at PWC-GOV-4039).

13. Tempered Water system level adjustment can commence only after the CVD process for a $\mathrm{MCO}$ is completed and the Tempered Water system is disconnected from the Cask-MCO annulus through CVD operation sequence SNF-2356, section 3.4.2.17 (MCO Helium Leak Test). Inadvertent draining of the Tempered Water system during the CVD process is a Safety Class event .

14. The Tempered Water system is verified in shutdown mode; the circulation pump, TW-P. $3 * 14$, is inactive, flow is not circulating (FIT-3*16 at zero), electric heater, TW-HTR$3 * 11$, and cooler, TW-CLR- $3 * 10$, are inactive and isolation valves, TW-GOV-1*14, TWGOV-3*14 and IA-GOV-1*15 are closed. For Tempered Water system draining to be necessary, the expansion tank, TW-TK-3*12, level must be at or near the high level alarm point, LAH-3*06, or near $100 \%$ at LIT- $3 * 04$, or water contamination is suspected or maintenance activities are required on the TW system.

15. The draining of the TW expansion tank with PWC ejector operation is accomplished by opening PWC valve PWC-V-*051 (manual valve located on the PES in the Process Bay). For a full expansion tank, there will be approximately 50 gallons of water in the system that will be drained to the PWC. At $5 \mathrm{gal} / \mathrm{min}$. drain rate, this will take approximately 10 minutes. Once breakthrough (indicated at PIT-4031) is achieved, continue drain operation for an additional 5 minutes and then direct the operator to close valve PWC-V*051.

16. At the end of the drain sequence the affected TW system is empty of water and 1 atmosphere of air is in the system. The TW system can be refilled with DI water from the DI flush line located at the top of the TW expansion tank by opening DI-V-*049 and monitoring the level on TW-LI- $3 * 04$.

Time to complete operation: 47 minutes (steps 13 through 16). 
SNF-2356 Rev. 1

\subsubsection{Process Water Conditioning Vacuum Pumping and Receiving - Cask-MCO Annulus Draining}

Cask-MCO annulus draining can commence if the PWC system is ready to accept water, ie. receiver tank level indication $0.0 \%$ level, transfer pump PWC-P-4035/-4036 operational with flow at 25 $\mathrm{gal} / \mathrm{min}$ and discharge pressure at $40 \mathrm{psig}$ or more, ejector suction pressure at less than $-5 \mathrm{psig}$. During Cask-MCO annulus draining, the full flow of water from the transfer pumps is directed through the PWC ejector and no flow is directed through the IXM or filter loop (flow is set to ejector port at PWC-GOV4039).

17. Cask-MCO annulus draining can commence only after the CVD process for a MCO is completed and the Tempered Water system is disconnected from the Cask-MCO annulus through CVD operation sequence SNF-2356, section 3.4.2.17 (Multi-Canister Overpack Helium Leak Test). The drain line PWC-*03-SS-1" is connected to the Cask lower port using PWC-QD *020. Inadvertent draining of the Tempered Water system during the CVD process is a Safety Class event and cannot be tolerated.

18. The Tempered Water system is verified in shutdown mode; the circulation pump, TW-P$3 * 14$, is inactive, flow is not circulating (FIT- $3 * 16$ at zero), electric heater, TW-HTR$3 * 11$, and cooler, TW-CLR- $3 * 10$, are inactive and isolation valves, TW-GOV-1*14, TWGOV $-3 * 14$ and IA-GOV $-1 * 15$ are closed.

19. The draining of the Cask-MCO annulus with PWC ejector operation is accomplished by opening IA-GOV-1*15, PWC valve PWC-V-*048 (manual valve located on the PES in the Process Bay) per CVD operation sequence SNF-2356, section 3.4.2.17. For a full Cask-MCO annulus, there will be approximately 28 gallons of water (Ref. HNF-SD-TPSARP-017, Table BB-1) in the system that will be drained to the PWC. At $5 \mathrm{gal} / \mathrm{min}$. drain rate, this will take approximately 6 minutes. Once breakthrough (indicated at PIT4031 ) is achieved, continue drain operation for an additional 60 minutes and then direct the operators to close valves IA-GOV- $1 * 15$ and then PWC-V-*048. The additional 60 minutes of Instrument Air flowing through the annulus will dry the annulus of residual water.

20. At the end of the drain sequence the affected Cask-MCO annulus is empty of water and 1 atmosphere of air is in the system. The PWC receiver tanks have accepted an additional 28 gallons of water that potentially has low levels of contamination.

Time to complete operation: $65-80$ minutes (steps 17 through 20 ).

\subsubsection{Process Water Conditioning Impurity Removal}

The PWC impurity removal consists of a flow branch for feeding $40 \mathrm{gal} / \mathrm{min}$. of process water through IXMs PWC-IXM-4037 or PWC-IXM-4038 and a separate particulate filter PWC-F-4042 (flow at 


\section{SNF-2356 Rev. 1}

$10 \mathrm{gpm}$ ), for final transfer to PWC-TK-4001. Automatic sampling is done utilizing PWC-SMP-4039, PWC-SMP-4040 and PWC-SMP-4041. Process water can be directed to the storage tank or returned to the receiver tanks.

21. Control of process water to the IXMs is through PWC-GOV-4039 at a maximum rate of $45 \mathrm{gal} / \mathrm{min}$. Whenever flow is registered through FI-4037, the three samplers must take appropriate samples suitable to the mode of operation. The modes of operations are a) PWC ejector recycle mode per section 3.5.2, 3.5.3, 3.5.4 or 3.5.5, b) Process Water Conditioning Impurity Removal per section 3.5 .6 or c) Process Water Conditioning Transfer to PWC Holding Tank, PWC-TK-4001, per section 3.5.8.

22. After the process water has passed through the IXMs, the treated water can be returned to the receiver tanks for recirculation through the PWC process again. Recirculating improves the impurity removal. PWC-GOV-4047 must be positioned, by MCS action, to the PWC-008-SS-11/2" branch for recycle. For purifying the bulk water from the MCO, the water is circulated through the IXMs for a sufficient time to achieve six water volume exchanges in the PWC receiver tanks. For a 280 gallon total volume in the receiver tanks and an IXM flowrate of $10 \mathrm{gal} / \mathrm{min}$, this would require a minimum processing time of 168 minutes. For an IXM flowrate of $40 \mathrm{gal} / \mathrm{min}$., a minimum processing time of 42 minutes is required.

Time to complete operation: 45 minutes (steps 21 and 22).

Certain manual operations, such as cleaning -up spills utilizing the PWC suction wand through isolation valve PWC-V-036, and extra sample bottle volume, need to be performed periodically. Coordination between the control room and the field operator is necessary.

\subsubsection{Process Water Conditioning IXM Water Sampling}

Water sampling is necessary to calculate the radionuclide loading on the IXM ion exchange media, TRU and cesium limits are specified in the CVDF DRD.

23. The MCS sends a momentary sample initiation signal to samplers PWC-SMP-4039, PWC-SMP-4040, and PWC-SMP-4041. High differential pressure alarm PDAH-4040 alarm when the IXMs are beginning to plug (operating experience will determine what differential pressure to set).

24. Sampler PWC-SMP-4039 takes samples from the inlet of PWC-IXM-4037 or -4038. Sampler PWC-SMP-4040 takes samples from the outlet of PWC-IXM-4037 or -4038, , and sampler PWC-SMP-4041 takes samples from the outlet of PWC-F-4042.

25. Whenever flow is registered through FIT-4037, the three samplers must be functional (but the MCS, by Operator action, may not direct a sample be taken). The MCS controls 


\section{SNF-2356 Rev. 1}

the sampling at each sampler to one $10 \mathrm{cc}$ sample for every 100 gallons of flow. Each $10-$ cc sample is held in a 500-ml shielded bottle. After each sampling, the operator replaces the filled sample bottle with a fresh bottle. The sample is sent to the $100 \mathrm{~K}$ area laboratory or $222 \mathrm{~S}$ laboratory for analysis.

26. A sampling program shall be developed by the CVDF project and implemented by the Operations staff. Elements of this program will provide direction on how and when to sample water at the IXM's and how to sample for multiple pass processing of the water through the IXM's.

Time to complete operation: 45 minutes (steps 23 through 26 ).

\subsubsection{Process Water Conditioning Transfer to PWC Holding Tank, PWC-TK-4001}

Following impurity removal as described above, water contained in the $\mathrm{PWC}$ receiver tanks can be transferred to the PWC holding tank, PWC-TK-4001.

27. When there is a demand for a receiver tank level decrease, PWC-GOV-4047 must be positioned to the PWC-009-SS-11/2" branch (filter PWC-F-4042 inlet) to force the treated process water stream into storage tank PWC-TK-4001. This operation is accomplished by operator command prior to draining a new MCO. PWC manual valves, PWC-V-013 and PWC-V-015 are verified closed and valves PWC-V-002 and PWC-V-019 (located in PWC Tank room) are to be verified open prior to water transfers to PWC-TK-4001. The receiver tanks are emptied by routing water with a final pass (with sampling) through the IXMs (described above), through the filter and ultimately to storage tank PWC-TK-4001. Initial draining of the receiver tanks is completed when a $0.0 \%$ reading is indicated on LIT-4033. A water flush of the receiver tank and transfer lines is then accomplished by opening PWC-GOV-4057 and allowing 100 gallons of DI water to flow into receiver tank, PWC-TK-4033. DI flush water has a nominal flow rate of $5 \mathrm{gal} / \mathrm{min}$, therefore a 20 minute period of water flush is required.

28. Following draining and transfer of water to the holding tank, PWC-GOV-4047 is instructed to close the transfer line to the filter and to open to the IXM recycle position. Valves PWC-V-002 and PWC-V-019 (located in PWC Tank room) are verified closed.

Time to complete operation: 9 minutes (steps 27 and 28).

\subsubsection{Process Water Conditioning Transfer from PWC-TK-4001 to KW Basin Tractor Trailer}

The Conditioned Water Shipping system consists of (1) a tractor trailer with a ventilating highefficiency particulate air (HEPA) filter; a quick disconnect flexible transfer line; valves, instruments, and controllers to receive conditioned water and transport it to $\mathrm{K}$ West Basin. The tractor trailer will be positioned in CVDF process bay \# 1 for transfer of the water from PWC-TK-4001. Just prior to and during 


\section{SNF-2356 Rev. 1}

transfer, no PWC receiving or impurity removal operations may be conducted as personnel entries into the PWC Tank room are required for this operation.

29. To transfer water to the tractor trailer, the HEPA filter shall be installed on the trailer vent port and the transfer hose connected to the fill port.

30. The holding tank shall have a minimum of 4000 gallons ready for transfer as indicated on LI-4014. The transfer line shall have isolation valves, PWC-V-003 (Tank room), PWCV-004 (Tank room), PWC-V-006 (Process Bay \#1), PWC-V-008 (Tank room), recirculation line isolation valve, PWC-V-009 (Tank room), and sample valve, PWC-V007 (Tank room), previously verified in the closed position.

31. The trailer flexible transfer line shall be connected to the transfer line quick disconnect (Process Bay \#1) and valve PWC-V-006 (Process Bay \#1) opened. The operator shall then enter the tank room and open valves PWC-V-003, PWC-V-004 and PWC-V-008 and exit the room.

32. The MCS shall be directed to start pump PWC-P-001 to start the transfer of the water to the tractor trailer. The water will be transferred by the pump until a holding tank low level alarm is received from LSL- 4014 which is interlocked to the pump. At a flow of 45 $\mathrm{gal} / \mathrm{min}$ the transfer of 5000 gallons will take approximately 2 hours.

33. After the pump shuts down, operators close valves PWC-V-003, PWC-V-004 and PWC$\mathrm{V}-008$. Valve PWC-V-006 is then closed in Process bay \#1, the flexible line is disconnected, the trailer fill port closed, and the HEPA filter port is closed. The tractor trailer is ready to transport the water to the $\mathrm{KW}$ basin.

Time to complete operation: 3 hr 30 minutes (steps 29 through 33 .

\subsubsection{Process Water Conditioning Line Flush}

TBD

\subsection{AUXILIARY SYSTEMS OPERATIONS}

The process vent is part of an integrated, multi-zone HVAC venting system described in detail in SNF-3081. The process vent system removes offgas from the process module and provides a sweep function for the process vent hood located on the top of the MCO. The MCS controls all HVAC functions according to the detailed HVAC operational control description located in SNF-3081. 


\section{SNF-2356 Rev. 1}

The chilled water supply for the tempered water cooler is supplied by an intermediate cooling loop interfaced with the facility chilled water system through a process heat exchanger. The intermediate loop consists of a circulation loop with spare pumps. The system is designed to remove $73 \mathrm{~kW}$ $(250,000 \mathrm{Btu} / \mathrm{h})$. The cooling circuit can provide cooling to the MCOs in each of the four process bays at any given time.

The chilled water supply for the VPS condenser is supplied by a dedicated low-temperature chiller. This chiller is capable of supplying $13.2 \mathrm{~kW}(45,000 \mathrm{Btu} / \mathrm{h})$ of $1.5^{\circ} \mathrm{C}\left(35^{\circ} \mathrm{F}\right)$ water to all condensers. A total of $4 \mathrm{gal} / \mathrm{min}$ is available to each process bay.

The instrument air system supplies dry, filtered oil-free instrument air at approximately $100 \mathrm{psig}$ to the process equipment skid. This air is used to operate the spring return automatic valves and to inflate the $\mathrm{MCO}$ hood/seal ring bladder.

The instrument air system supplies dry filtered instrument air for pneumatic tools. Instrument air is required for pneumatic wrenches for removal/installation of the cask lid, , and for the cask transporter air ride suspension.

The PWC system is used to receive all process liquid generated from the process equipment skids. This system receives drain water from the MCOs, condensate from the VPS system, MCO-cask annular space drain water, and any flush water. Water is collected in two receiver tanks with a combined working volume of $236 \mathrm{gal}$, metered through up to two shielded filter/LXMs, and collected in a 5,000 gal shipping tank.

Deionized water is made up from potable water in a leased system. This water is used to flush lines, make up tempered water deficits, and flush the PWC system.

Helium is supplied from a leased high pressure tube trailer. High pressure helium is pressurecontrolled to approximately 10.0 psig, safety relieved at 15 psig, and monitored for performance. Helium is used on the process equipment skids for purging and pressurizing liquids for removal to the PWC system. The helium is used for purging, heat-transfer fluid, and back-filling.

\subsubsection{Operation of the Safety Class Instrument and Control System}

The SCIC system is designed to actuate the SCHe system, to disable the MCO heating system, or to indicate loss of heat-transfer fluid in the cask-MCO annulus.

The SCHe system actuation portion of the SCIC system will activate if any of the following occur.

- A seismic event of sufficient magnitude.

- A loss of power event. This includes power supply to the CVDF and control power failure. 
- An operator or MCS emergency actuation (e.g., bad valve line-up detection, system failures that impact safety).

- The MCO reaches an incorrect pressure state without adequate, verified purge volume.

- The MCO must be maintained above a positive pressure setting 0.5 psig to prevent oxygen intrusion (a prior administratively controlled procedure verified purge of any MCO oxygen content).

- Once purge has been verified for a preset duration, the MCO is allowed to decrease to below the positive pressure setpoint without actuating the SCHe. During this time period the system must provide continued purge to keep the timer reset, increase the pressure to above the positive pressure setpoint, or decrease the pressure to the vacuum to less than 12.0 psig (140) torr.

- The MCO pressure rises above the vacuum setpoint after the purge timer has timed-out. 


\section{SNF-2356 Rev. 1}

\subsection{REFERENCES}

ANSI C2, 1993, National Electrical Safety Code, American National Standards Institute, New York, New York.

ASTM D 1557, 1991, Test Method for Moisture Density Relations of Soils and Soil Aggregate Mixtures Using 10-lb Rammer and 18-in Drop, American Society for Testing and Materials, Wast Conshohocken, Pennsylvania.

CMAA 74, 1994, Specifications for Top Running and Under Running Single Girder Electric Overhead Traveling Cranes Utilizing Under Running Trolley Hoist, Crane Manufacturing Association of American, Charlotte, North Carolina.

DOE/RL-92-36, 1993, Hanford Site Hoisting and Rigging Manual, U.S. Department of Energy, Richland, Washington.

DOE Order 6430.1A, 1989, General Design Criteria, U.S. Department of Energy, Washington, D.C.

Fire Resistance Directory, 1997, Underwriters Laboratories, Incorporated, Northbrook, Illinois.

H-1-82092, Cold Vacuum Drying Facility Site Plan, Fluor Daniel Hanford, Richland, Washington.

H-1-82094, Cold Vacuum Drying Facility Site Utility Details, Fluor Daniel Hanford, Richland, Washington.

H-1-82095, Cold Vacuum Drying Facility Overhead Service Plan \& Profile, Fluor Daniel Hanford, Richland, Washington.

H-1-82101, Cold Vacuum Drying Facility First Floor Plan, Fluor Daniel Hanford, Richland, Washington.

H-1-82102, Cold Vacuum Drying Facility Second Floor Plan, Fluor Daniel Hanford, Richland, Washington.

H-1-82103, Cold Vacuum Drying Facility Detail Plans, Fluor Daniel Hanford, Richland, Washington.

H-1-82104, Cold Vacuum Drying Facility Architectural Sections, Fluor Daniel Hanford, Richland, Washington.

H-1-82132, Cold Vacuum Drying Facility Crane Plan, Section, Details, Fluor Daniel Hanford, Richland, Washington. 
SNF-2356 Rev. 1

H-1-82160, Cold Vacuum Drying Facility P\&ID Legend, Notes and Definitions, Fluor Daniel Hanford, Richland, Washington.

H-1-82166, Cold Vacuum Drying Facility Process Equipment Skid P\&ID Flow Diagram, Fluor Daniel Hanford, Incorporated, Richland, Washington.

H-1-82195, Cold Vacuum Drying Facility HVAC Air Flow Diagram Administration Area, Fluor Daniel Hanford, Richland, Washington.

H-1-82201, Cold Vacuum Drying Facility Piping Diagram Chilled Water, Fluor Daniel Hanford, Richland, Washington.

H-1-82202, Cold Vacuum Drying Facility HVAC Sections, Fluor Daniel Hanford, Richland, Washington.

H-1-82203, Cold Vacuum Drying Facility HVAC Sections, Fluor Daniel Hanford, Richland, Washington.

H-1-82204, Cold Vacuum Drying Facility HVAC P\&ID Process Bay Supply, Fluor Daniel Hanford, Incorporated, Richland, Washington.

H-1-82205, Cold Vacuum Drying Facility HVAC P\&ID General Supply, Fluor Daniel Hanford, Incorporated, Richland, Washington.

H-1-82206, Cold Vacuum Drying Facility HVAC P\&ID Exhaust System, Fluor Daniel Hanford, Incorporated, Richland, Washington.

H-1-82207, Cold Vacuum Drying Facility HVAC P\&ID Facility Instrumentation, Fluor Daniel Hanford, Incorporated, Richland, Washington.

H-1-82208, Cold Vacuum Drying Facility FVAC P\&ID Chilled Water System, Fluor Daniel Hanford, Incorporated, Richland, Washington.

H-1-82209, Cold Vacuum Drying Facility P\&ID Stack Monitoring System, Fluor Daniel Hanford, Richland, Washington.

H-1-82222, Cold Vacuum Drying Facility Mechanical Utilities Instrument Air P\&ID, Fluor Daniel Hanford, Incorporated, Richland, Washington.

H-1-82223, Cold Vacuum Drying Facility Mechanical Utilities Drainage System P\&ID, Fluor Daniel Hanford, Incorporated, Richland, Washington.

H-1-82224, Cold Vacuum Drying Facility Mechanical Utilities Process Chilled Water P\&ID, Fluor Daniel Hanford, Incorporated, Richland, Washington. 


\section{SNF-2356 Rev. 1}

H-1-82237, Cold Vacuum Drying Facility Fire Protection First Floor Plan, Fluor Daniel Hanford, Richland, Washington.

H-1-82238, Cold Vacuum Drying Facility Fire Protection Second Floor Plan, Fluor Daniel Hanford, Richland, Washington.

H-1-82239, Cold Vacuum Drying Facility Fire Protection Sections, Fluor Daniel Hanford, Richland, Washington.

H-1-82240, Cold Vacuum Drying Facility Fire Protection Details, Fluor Daniel Hanford, Richland, Washington.

H-1-82241, Cold Vacuum Drying Facility Electrical Office Area Power Plan, Fluor Daniel Hanford, Richland, Washington.

H-1-82242; Cold Vacuum Drying Facility Electrical Lighting Plan, Fluor Daniel Hanford, Richland, Washington.

H-1-82243, Cold Vacuum Drying Facility Electrical Communications \& Alarm Plan, Fluor Daniel Hanford, Richland, Washington.

H-1-82244, Cold Vacuum Drying Facility Electrical First Floor Fire Alarm Plan, Fluor Daniel Hanford, Richland, Washington.

H-1-82245, Cold Vacuum Drying Facility Electrical Security \& CCTV Plan, Details, Fluor Daniel Hanford, Richland, Washington.

H-1-82246, Cold Vacuum Drying Facility Electrical Service Area One-Line Diagram, Fluor Daniel Hanford, Richland, Washington.

H-1-82247, Cold Vacuum Drying Facility Electrical Process Bay Panel Schedules, Fluor Daniel Hanford, Richland, Washington.

H-1-82248, Cold Vacuum Drying Facility Electrical Elementary Wiring Diagram, Fluor Daniel Hanford, Richland, Washington.

H-1-82291, Cold Vacuum Drying Facility Instrumentation Control System Block/Cable Diagram, Fluor Daniel Hanford, Richland, Washington.

H-1-82292, Cold Vacuum Drying Facility Instrumentation PLC Remote I/O Enclosure, Fluor Daniel Hanford, Richland, Washington. 
SNF-2356 Rev. 1

H-1-82293, Cold Vacuum Drying Facility Instrumentation Control Room PLC Enclosure, Fluor Daniel Hanford, Richland, Washington.

H-1-82294, Cold Vacuum Drying Facility Instrumentation Bay I/O Enclosure, Fluor Daniel Hanford, Richland, Washington.

H-1-82295, Cold Vacuum Drying Facility Instrumentation Mechanical Room Remote I/O Enclosure, Fluor Daniel Hanford, Richland, Washington.

H-1-82296, Cold Vacuum Drying Facility Instrumentation Mechanical Room I/O Connection Diagram, Fluor Daniel Hanford, Richland, Washington.

H-1-82297, Cold Vacuum Drying Facility Control System Conduit Plan, Fluor Daniel Hanford, Richland, Washington.

H-1-82301, Cold Vacuum Drying Facility SCIC System Instrument Assembly, Fluor Daniel Hanford, Richland, Washington.

H-1-82364, Cold Vacuum Drying Facility MCO Process Hood, Fluor Daniel Hanford, Incorporated, Richland, Washington.

H-1-82366, Cold Vacuum Drying Facility MCO Single Connection Valve Operator Details, Fluor Daniel Hanford, Incorporated, Richland, Washington.

H-1-82368, Cold Vacuum Drying Facility MCO Double Connection Valve Operator Details, Fluor Daniel Hanford, Incorporated, Richland, Washington.

H-1-83275, Cold Vacuum Drying Facility Seal Ring Assembly, Fluor Daniel Hanford, Incorporated, Richland, Washington.

H-1-83766, Cold Vacuum Drying Facility Process System P\&ID, Fluor Daniel Hanford, Incorporated, Richland, Washington.

H-1-83767, CVDF Vacuum Purge Chilled Water System P\&ID, Fluor Daniel Hanford, Incorporated, Richland, Washington.

H-1-83768, CVDF Chilled \& Tempered Cooling Water System P\&ID, Fluor Daniel Hanford, Incorporated, Richland, Washington.

H-1-83769, Cold Vacuum Drying Facility HVAC System P\&ID, Fluor Daniel Hanford, Incorporated, Richland, Washington. 
HNF-1851, 1998, Cold Vacuum Drying Residual Free Water Test Description, Rev. 1, Fluor Daniel Hanford, Incorporated, Richland, Washington.

HNF-3228, CVD Safety Class Instrument and Control System Performance Specification, Rev. 0, Fluor Daniel Hanford, Incorporated, Richland, Washington.

HNF-S-0403, 1997, Standard Specification for Hanford Site Telecommunications Systems and Facilities, Rev. 3, Fluor Daniel Hanford, Incorporated, Richland, Washington.

HNF-SD-SNF-DRD-002, 1998, Cold Vacuum Drying Facility Design Requirements, Rev. 4, Fluor Daniel Hanford, Incorporated, Richland, Washington.

HNF-SD-SNF-SEL-002, 1998, Safety Equipment List for the CVDF, Rev. 4, Fluor Daniel Hanford, Richland, Washington.

HNF-SD-SNF-SAR-002, 1998, Safety Analysis Report for the Cold Vacuum Drying Facility, Phase 1, Supporting Installation of Processing Equipment, Rev. 4, Fluor Daniel Hanford, Incorporated, Richland, Washington.

HSRCM-1, 1994, Hanford Site Radiological Control Manual, Rev. 2, Westinghouse Hanford Company, Richland, Washington.

Lighting Handbook, 1993, Illuminating Engineering Society of North America, New York, New York.

NEMA 12, Industrial Control and Systems Enclosures, National Electrical Manufactures Association, Rosslyn, Virginia.

NEMA ICS Standards Type II-C, Industrial Control and Systems Series, National Electrical Manufacturers Association, Rosslyn, Virginia.

NFPA 70, 1993, National Electrical Code, National Fire Protection Association, Quincy, Massachusetts.

NFPA 101, 1991, Safety to Life from Fire in Buildings and Structures, National Fire Protection Association, Quincy, Massachusetts.

NFPA 780, 1995, Lightning Protection Systems, National Fire Protection Association, Quincy, Massachusetts.

Uniform Building Code, 1994, International Conference of Building Officials, Whittier, California.

SNF-3060, 1998, Cold Vacuum Drying Facility Personnel Monitoring/Radiation Monitoring/Room Air Quality System Design Description, Rev. 0, Fluor Daniel Hanford, Incorporated, Richland, Washington. 


\section{SNF-2356 Rev. 1}

SNF-3061, 1998, Cold Vacuum Drying Facility Civil/Structural/Architectural System Design Description, Rev. 0, Fluor Daniel Hanford, Incorporated, Richland, Washington.

SNF-3062, 1998, Cold Vacuum Drying Facility Vacuum Purge System Design Description, Rev. 0, Fluor Daniel Hanford, Incorporated, Richland, Washington.

SNF-3063, 1998, Cold Vacuum Drying Facility Residual Gas Monitoring System Design Description, Rev. 0, Fluor Daniel Hanford, Incorporated, Richland, Washington.

SNF-3064, 1998, Cold Vacuum Drying Facility Helium Mass Spectrometer Leak Detection and Auxiliary Vacuum System Design Description, Rev. 0, Fluor Daniel Hanford, Incorporated, Richland, Washington.

SNF-3065, 1998, Cold Vacuum Drying Facility Communications System Design Description, Rev. 0, Fluor Daniel Hanford, Incorporated, Richland, Washington.

SNF-3066, 1998, Cold Vacuum Drying Facility Instrument Air System Design Description, Rev, 0, Fluor Dariel Hanford, Incorporated, Richland, Washington.

SNF-3067, 1998, Cold Vacuum Drying Facility General Service Helium System Design Description, Rev. 0, Fluor Daniel Hanford, Incorporated, Richland, Washington.

SNF-3068, 1998, Cold Vacuum Drying Facility Safety Class Helium System Design Description, Rev. 0, Fluor Daniel Hanford, Incorporated, Richland, Washington.

SNF-3072, 1998, Cold Vacuum Drying Facility Cranes and Hoists System Design Description, Rev. 0, Fluor Daniel Hanford, Incorporated, Richland, Washington.

SNF-3073, 1998, Cold Vacuum Drying Effluent Drains System Design Description, Rev. 0, Fluor Daniel Hanford, Incorporated, Richland, Washington.

SNF-3074, 1998, Cold Vacuum Drying Facility Condensate Collection System Design Description, Rev. 0, Fluor Daniel Hanford, Incorporated, Richland, Washington.

SNF-3075, 1998, Cold Vacuum Drying Facility Electrical System Design Description, Rev. 0, Fluor Daniel Hanford, Incorporated, Richland, Washington.

SNF-3077, 1998, Cold Vacuum Drying Facility Fire Protection System Design Description, Rev. 0, Fluor Daniel Hanford, Incorporated, Richland, Washington.

SNF-3078, 1998, Cold Vacuum Drying Facility De-Ionized Water System Design Description, Rev. 0, Fluor Daniel Hanford, Incorporated, Richland, Washington. 


\section{SNF-2356 Rev. 1}

SNF-3079, 1998, Cold Vacuum Drying Facility Potable Water System Design Description, Rev. 0, Fluor Daniel Hanford, Incorporated, Richland, Washington.

SNF-3080, 1998, Cold Vacuum Drying Facility Sanitary Sewage Collection System Design Description, Rev. 0, Fluor Daniel Hanford, Incorporated, Richland, Washington.

SNF-3081, 1998, Cold Vacuum Drying Facility Heating, Ventilating, and Air Conditioning System Design Description, Rev. 0, Fluor Daniel Hanford, Incorporated, Richland, Washington.

SNF-3082, 1998, Cold Vacuum Drying Facility Process Water Conditioning System Design Description, Rev. 0, Fluor Daniel Hanford, Incorporated, Richland, Washington.

SNF-3083, 1998, Cold Vacuum Drying Facility Conditioned Water Shipping System Design Description, Rev. 0, Fluor Daniel Hanford, Incorporated, Richland, Washington.

SNF-3084, 1998, Cold Vacuum Drying Facility Contaminated Water Sampling and Analysis System Design Description, Rev. 0, Fluor Daniel Hanford, Incorporated, Richland, Washington.

SNF-3085, 1998, Cold Vacuum Drying Facility Cooling Water System Design Description, Rev. 0, Fluor Daniel Hanford, Incorporated, Richland, Washington.

SNF-3086, 1998, Cold Vacuum Drying Facility Chilled Water System Design Description, Rev. 0, Fluor Daniel Hanford, Incorporated, Richland, Washington.

SNF-3087, 1998, Cold Vacuum Drying Facility Vacuum Purge System Chilled Water System Design Description, Rev. 0, Fluor Daniel Hanford, Incorporated, Richland, Washington.

SNF-3088, 1998, Cold Vacuum Drying Facility Stack Monitoring System Design Description, Rev. 0, Fluor Daniel Hanford, Incorporated, Richland, Washington.

SNF-3089, 1998, Cold Vacuum Drying Facility Security System Design Description, Rev. 0, Fluor Daniel Hanford, Incorporated, Richland, Washington.

SNF-3090, 1998, Cold Vacuum Drying Facility Monitoring and Control System Design Description, Rev. 0, Fluor Daniel Hanford, Incorporated, Richland, Washington.

SNF-3091, 1998, Cold Vacuum Drying Facility Safety Class Instrumentation and Control System Design Description, Rev. 0, Fluor Daniel Hanford, Incorporated, Richland, Washington.

W-441-P1, 1997, Procurement Specification For the Fabrication, Acceptance Testing, and Shipment of the Cold Vacuum Drying System Equipment Process Skid, Rev. 1, Fluor Daniel Hanford, Incorporated, Richland, Washington. 


\section{SNF-2356 Rev. 1}

W-441-P2, 1997, Procurement Specification For the Fabrication, Acceptance Testing, and Shipment of the Cold Vacuum Drying System Equipment Process Water Conditioning Skid, Rev. 0, Fluor Daniel Hanford, Incorporated, Richland, Washington.

W-441-P3, 1997, Procurement Specification For the Fabrication, Acceptance Testing, and Shipment of the Monitoring and Control System of the Cold Vacuum Drying Facility Equipment, Rev. 0, Fluor Daniel Hanford, Incorporated, Richland, Washington.

W-441-P4, 1997, Procurement Specification For the Fabrication, Acceptance Testing, and Shipment of the Cold Vacuum Drying System Process Hood/Seal Ring, Rev. 0, Fluor Daniel Hanford, Incorporated, Richland, Washington.

W-441-P5, 1998, Procurement Specification For the Fabrication, Acceptance Testing, and Shipment of the Cold Vacuum Drying Facility Safety Class Helium Equipment, Rev. 0, Fluor Daniel Hanford, Incorporated, Richland, Washington.

WHC-SD-GN-DGS-30006, 1993, Seismic Design Guide for Safety Class 3 and 4 Equipment at the Hanford Site, Rev. 1, Westinghouse Hanford Company, Richland, Washington.

WHC-SD-SNF-FRD-020, 1998, K Basin Spent Nuclear Fuel Cold Vacuum Drying Facility Functions and Requirements, Rev. 1, Westinghouse Hanford Company; Richland, Washington.

WHC-SD-SNF-TI-016, 1996, Development of Design Basis Capacity for SNF Project Systems, Rev. 0, Westinghouse Hanford Company, Richland, Washington. 